\title{
Bridging the Communication Gap
}

What do primary healthcare practitioners in New Zealand know about health literacy? What are their attitudes towards it, and do they implement any internationally developed health literacy tools?

by

Jane Thomsen

Submitted to the School of Information Management, Victoria University of Wellington in partial fulfilment of the requirements for the degree of Master of Information Studies

\section{June 2014}




\section{Acknowledgments}

This research project has been a long and complicated process for so many reasons. I would like to firstly thank my Supervisor, Rowena Cullen, for her ongoing patience, support and good counsel. I would also like to thank my husband, Mark Stirling, who gave me constant encouragement, made sure I had some precious "quiet time" in my hectic life, and also lent his statistical and editorial skills whenever needed. Thanks too to my children, Lewis and Toby, who missed out on focused weekend Mum-time, put up with general grumpiness, and tried their best to be good while I was so busy - I promise I will be a lot more interactive from now on! Thank you too to my former work colleagues, the former Health Education Team at Learning Media Ltd - you were vital in the shaping of this research topic at the very beginning. Finally I would like to thank the 143 busy health professionals who contributed their thoughts - I greatly appreciate the time you spent assisting me with this project. 


\section{Contents}

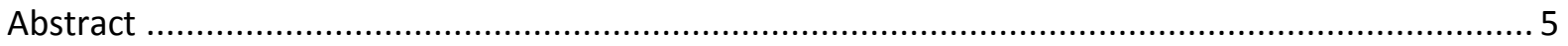

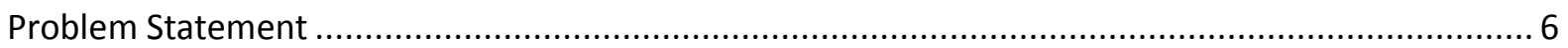

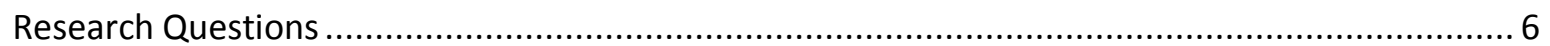

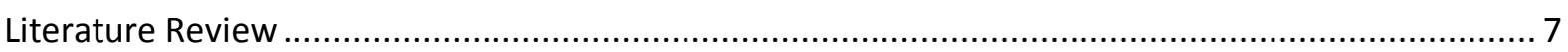

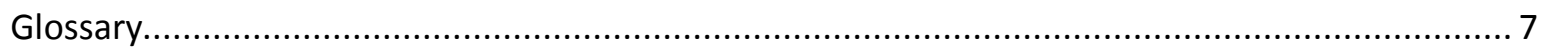

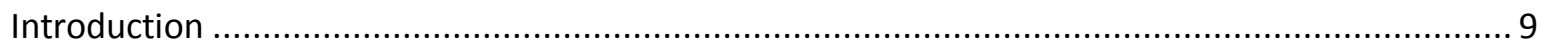

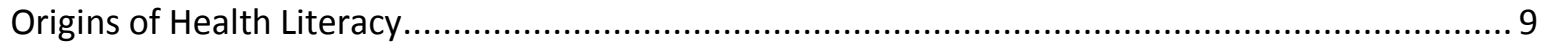

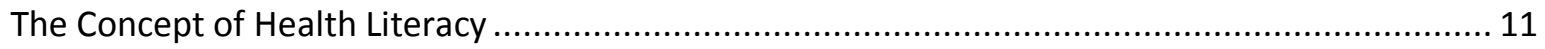

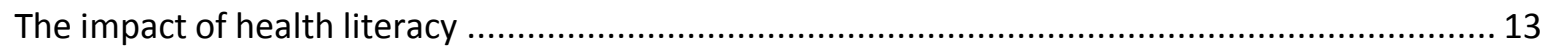

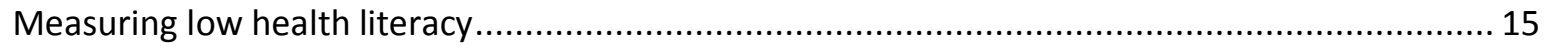

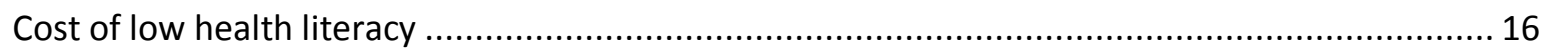

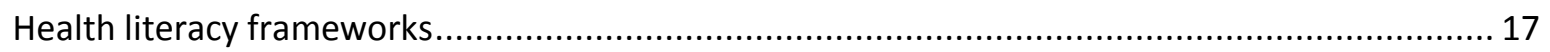

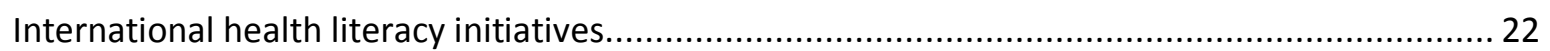

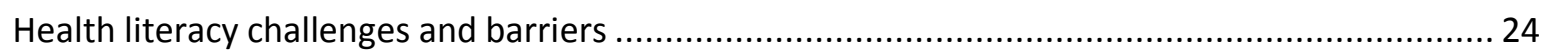

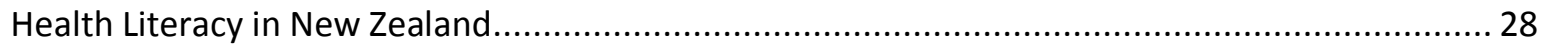

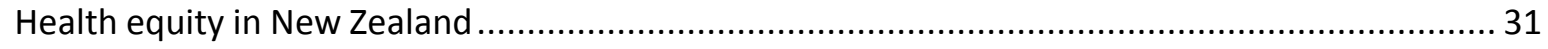

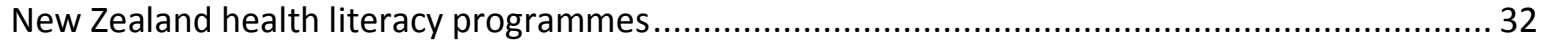

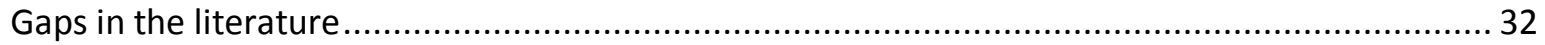

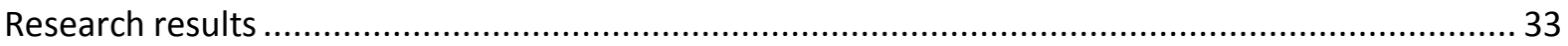

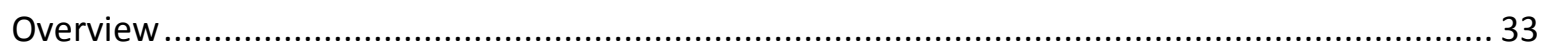

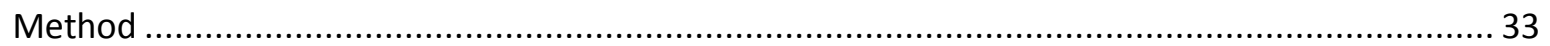

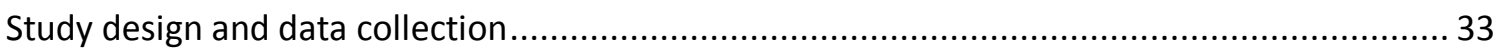

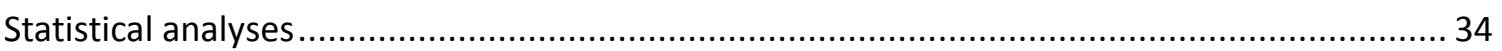

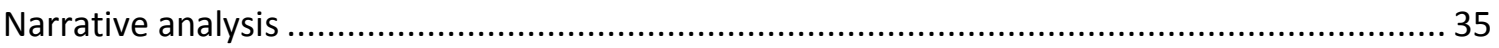

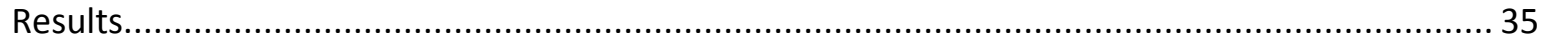

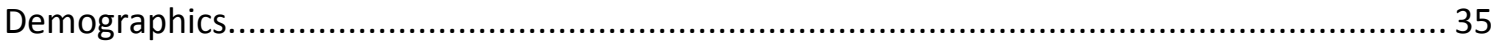

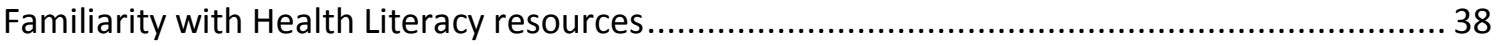

Communicating health information in GP practices............................................................. 40

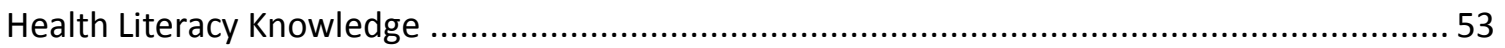

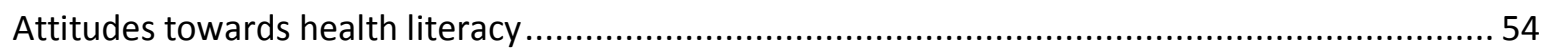

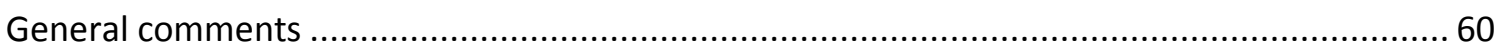

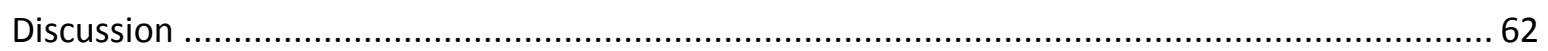

Relationship among health literacy knowledge, practice and demographic factors ...................62 62 


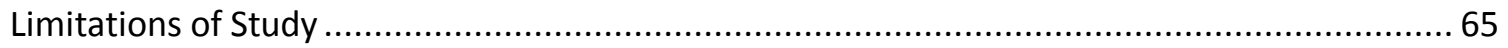

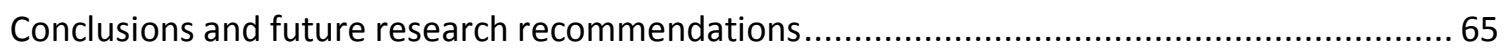

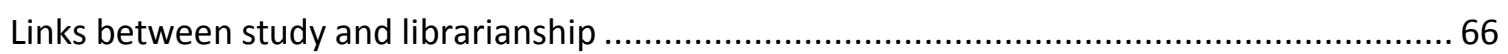

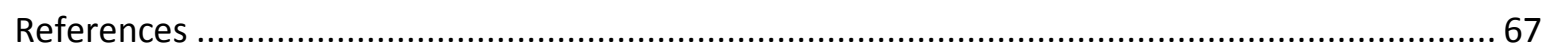

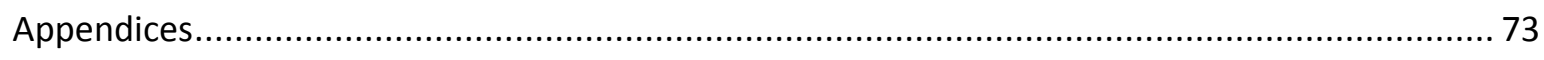

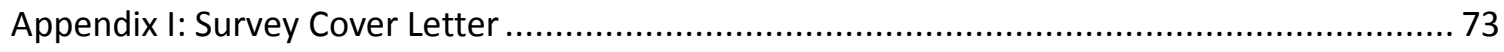

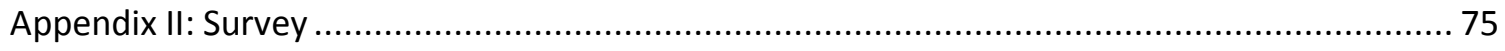




\section{Abstract}

Health Literacy has been identified internationally as an important component of health equity. As a health consumer, being health literate includes having the ability to make an informed choice about health. As a healthcare provider or health educator, being health literate is having the ability to enable the consumer to become fully informed, even if there are barriers that complicate or hamper this ability. Many health literacy tools have been developed to support clinicians, including those in primary care, in communicating effectively with their patients. When properly utilised, these tools have the potential to improve the health outcomes of their patients and also to reduce health system costs. The literature produced about health literacy has seen exponential growth, especially over the last eight years, due to increased recognition of its contribution to better healthcare outcomes. This research examined whether General Practitioners (GPs) in New Zealand were aware of health literacy concepts and the specific tools that have been developed, and whether they were utilising them. Although some health literacy tools and strategies are being implemented by GPs, they are not necessarily realising this, as their concept of health literacy seems to be focused on the general literacy level of their patients. Health literacy tools identified tended to be in the form of print and online health education materials.

\section{Keywords:}

Health Literacy; Health Communication; General Practice; Health Outcomes 


\section{Problem Statement}

Lack of effective communication between health providers and patients has been identified as one of the major drivers of health inequalities.

The first point of contact people have with the health system is often the primary care practitioner. Effective treatment at this point, whether medication or life-style change, can reduce the need for secondary care and rehabilitation, therefore reducing the costs to the healthcare system. The major reason for treatment failure has been labelled as patient non-compliance. This can be due to not taking medications correctly, not amending lifestyle as directed (for example following a specific diet), or not attending follow-up appointments. Research indicates that low levels of health literacy drive this, not a lack of desire for wellness.

Recognition of this has led to the development of many tools and resources to support clinicians communicate effectively with patients, especially within the primary care sector. There is however, uncertainty as to whether these tools are utilised, or whether primary care (and other) healthcare practitioners are even aware of them.

\section{Research Questions}

This research aims to explore this topic in a New Zealand primary care context. Specifically it asks:

- What primary healthcare practitioners in New Zealand know about health literacy;

- What their attitudes are towards health literacy;

- Whether they implement any internationally developed health literacy tools.

The research also looks at whether there is a gender or geographic bias in this knowledge, attitude and implementation of health literacy resources. 


\section{Literature Review}

Glossary

Adherence/Compliance

"In healthcare, the most commonly used definition of compliance is "patient's behaviors (in terms of taking medication, following diets, or executing life style changes) coincide with healthcare providers' recommendations for health and medical advice". Thus, therapeutic non-compliance occurs when an individual's health-seeking or maintenance behavior lacks congruence with the recommendations as prescribed by a healthcare provider. Other similar terms have been used instead of compliance, and the meaning is more or less identical. For example, the term adherence is often used interchangeably with compliance. Adherence is defined as the ability and willingness to abide by a prescribed therapeutic regimen." (Jin, Sklar, Min Sen Oh, \& Chuen Li, 2008).

\section{Consumer health}

Robert Gann defines Consumer health information as:

"Encompassing information about health and illness at a lay level; information about health care services available from the statutory and voluntary sectors; and information about choices in treatment and care" (Robert Gann, 1991).

\section{Health communication}

Health communication is defined by the Centers for Disease Control (CDC) as:

"The crafting and delivery of messages and strategies, based on consumer research, to promote the health of individuals and communities" (Roper, 1993).

\section{Health education}

Health education is defined as:

"Any combination of learning experiences designed to facilitate voluntary actions conducive to health" (Green \& Kreuter, 2005).

\section{Health literacy}

Health literacy is defined in the Institute of Medicine's (IOM) Healthy People 2010 as: 
"The degree to which individuals have the capacity to obtain, process, and understand basic health information and services needed to make appropriate health decisions" (United States Department of Health \& Human Services, 2000).

This is the definition that most commonly appears in the health literacy literature.

\section{Health promotion}

Health promotion is defined by the World Health Organization's 2005 "Bangkok Charter for Health Promotion in a Globalized World" as:

"Health promotion is the process of enabling people to increase control over their health and its determinants, and thereby improve their health." (World Health Organization, 2005)

\section{Informed consent}

Informed consent is defined by the American Medical Association as:

"The process of communication between a patient and physician that results in the patient's authorization or agreement to undergo a specific medical intervention".

\section{Patient-centred care}

The Ontario Medical Association defines Patient-centred care as:

"A system where patients can move freely along a care pathway without regard to which physician, other health-care provider, institution or community resource they need at that moment in time. The system is one that considers the individual needs of patients and treats them with respect and dignity." (Ontario Medical Association, 2010)

\section{Primary care}

"Primary (health) care relates to the professional health care received in the community, usually from a general practitioner (GP) or practice nurse." (Ministry of Health, 2013) 


\section{Introduction}

The term "health literacy" was first used in 1974 in a paper discussing the effect of health education on the health care system (Simonds, 1974). The literature produced on health literacy since then has seen exponential growth, especially over the last five years due to its contribution to healthcare outcomes being recognised. In 1998 the National Library of Medicine's PubMed database indexed three articles with the term "health literacy" in the title, whereas in 2008 there were 90 (Shipman, Kurtz-Rossi, \& Funk, 2009). The same search strategy limited to 2013 delivered 283 hits.

The term "health literacy" was introduced by the National Library of Medicine as a Medical Subject Heading (MeSH) in 2010, and a further search using this subject heading and limiting to the range 2010-2013 resulted in 1337 references. Publication in the health literacy field is cross-disciplinary, including the medical, nursing, pharmacy, public health, library science, social science, adult education, economics and communication fields. Relevant papers were identified by searching the CINAHL, PubMed and Communication \& Mass Media Complete databases, and by monitoring webbased news sites and online forums with an interest in health literacy. Search terms included health literacy, health communication, health education, consumer health information, professional patient relations and information dissemination. Papers were selected if they reflected the themes of health literacy or consumer health information outcomes and value, use of health literacy tools and concepts by clinicians, barriers to effective health communication, system support for patientcentred care, health literacy in primary care and the need for self-management of chronic disease, especially within a New Zealand context. Literature discussing methods of improving literacy in the community as a way of improving health literacy was not included, as it is not directly relevant to the topic. Similarly, literature discussing health literacy in the management of a specific disease was not included, unless any themes listed above were highlighted. Although there was potentially relevant information discussed within this subset of literature, it mainly served to illustrate points made by the more general literature, rather than adding new concepts. No literature was identified that discussed gender disparities in health practitioner knowledge of or attitudes to health literacy. Health literacy has a key role in health promotion, health education, consumer health, and patientcentred care.

\section{Origins of Health Literacy}

Interest in health information for the public, referred to within the library community as consumer health information, has been documented almost since written records began, which Breslow illustrates with this nutrition advice from a Chinese physician practising in 2000BC: 
"Cereals for energy, fruits for accessory, animals for benefit, vegetables for supplement." (Breslow, 1985).

Gann defines the "health care consumer" as including all members of the public who use, or consume, health services. This term expands the term "patient", as most of this health information is not sought or read by people actively receiving health care (R. Gann, 1992). There has been some criticism of the term "consumer" from healthcare professionals, but Gann sees the term as a reflection of the increasing consumerism in society, with people no longer content just to be told what to do. Instead, they prefer to have the information available in order to make informed choices between health care options. He sees this as a sharp contrast to the attitude of health practitioners towards patient access to health information as recently as the 1970 s, summed up by the phrase "a little knowledge is a dangerous thing" (Robert Gann, 1991). This argument does suggest that "consumer health information" is a more encompassing term than "patient education resources" or even "health education resources", although it is not widely used outside the library and information community.

There have been many initiatives to provide current, evidence-based consumer health information. Before the advent of the internet, consumer health collections were built up by public libraries and health organisations, including hospitals and support groups, in response to the information needs of the public. Health encyclopaedias and other publications aimed at the general public proliferated, and in 1981 Alan Rees released the first edition of his book "The Consumer health information source book", which reviewed and recommended consumer health materials to assist collection development (Rees \& Young, 1981). New editions of this resource continued to be published, with the most recent seventh edition published in 2003.

The increasing access to the internet in the 1990s was another opportunity for producers of consumer health information. The quality of this information was, and still is, highly variable. In 1997 the US National Library of Medicine (NLM) made their biomedical literature index MEDLINE freely available online via the PubMed interface. One third of the users of PubMed were found to be health consumers rather than the health professionals it was primarily aimed at, prompting the NLM to create MedlinePlus (www.nlm.nih.gov/medlineplus), a website of links to unbiased and qualityfiltered full-text health information (Hogan Smith \& Mayer, 2009). This continues to be one of the premier consumer health information websites and is under constant development, incorporating interactive tutorials, videos, calculators and quizzes, as well as more traditional text materials. Other websites of note that were developed during the same time period include the Healthfinder health resource gateway from the US National Health Information Center (healthfinder.gov), NOAH - New 
York Online Access to Health (www.noah-health.org) which was one of the first to provide consumer health resources in Spanish as well as in English, and the British Medical Journal's Best Health (besthealth.bmj.com). New Zealand lacked a similar comprehensive resource until Health Navigator NZ (www.healthnavigator.org.nz) was introduced in 2008. This is overseen by a Trust Board and Advisory Group including a mix of funders and providers from primary care, secondary services, universities, non-governmental organisations and consumers, and is still in the early stage of development with a limited number of health topics offered.

In the United Kingdom, the Department of Health launched an Information Standard in 2009, with the dual aims of providing the public with a way to judge the quality of consumer health information and supporting the producers of consumer health information to raise the standard and reliability of their product (UK Department of Health, 2009). Smith and Duman discuss this in more detail in their paper written just prior to the launch of this standard (Smith \& Duman, 2009).

Although the quality of printed (or online) consumer health information is an important component of health literacy, it is only part of the equation. Christine Zarcadoolas states that "reading level alone...does not explain the complex human skills involved in becoming a health literate citizen". She sees the emergence of health literacy as a convergence of a number of patient compliance studies carried out by health professionals and studies about the mismatch of print materials and patient reading abilities by health education and adult literacy specialists (Zarcadoolas, Pleasant, \& Greer, 2005).

As well as print literacy and patient compliance, health literacy also has its origins in the health promotion and informed consent fields. Health promotion seeks to encourage people to live a healthier lifestyle, by better food choices, exercise, smoking cessation, immunisation and other illness prevention strategies. Its focus is on changing behaviours, rather than contributing to informed choice, but it shares the goal of achieving a reduction in health inequalities with the concept of health literacy.

\section{The Concept of Health Literacy}

Helen Osborne describes the practice of health literacy as:

"A shared responsibility between patients (or anyone on the receiving end of health communication) and providers (or anyone on the giving end of health communication). Both must communicate in ways the other can understand." (Osborne, 2012)

This description illustrates the partnership necessary for health literacy, with both patients and providers responsible for communicating information to the other, providers about technical 
information and patients about their personal circumstances and experiences. It also puts health literacy into a broader context, encompassing consumer health and patient education information, rather than just the patient-provider interaction, or the health literacy skills of an individual. Osborne believes that there are three central components of health literacy that need to be addressed by those creating interventions. These are the communication skills of the person expressing the message, the learning needs of the person receiving the message, and the complexity of the message itself (Osborne, 2012).

Don Nutbeam describes two schools of thought within health literacy, health literacy as a risk and health literacy as an asset. Proponents of health literacy as a risk factor see low health literacy as putting the patient at risk and therefore something to be managed in the process of providing clinical care. Nutbeam asserts that this concept of health literacy is the one mainly supported in the US reflected by the IOM “Healthy People 2010" definition (United States Department of Health \& Human Services, 2000). He describes this definition of health literacy as being limited it to a set of individual capabilities that need to be measured in order to be controlled. These are:

- Cultural and conceptual knowledge;

- Speaking and listening skills;

- Writing and reading skills;

- Numeracy.

Improving patient health literacy, can therefore lead to improved health behaviour and better compliance. (This assertion also reinforces the fact that the same information can be interpreted in different ways by individuals, even those with advanced education. Shohet and Renaud claim in their 2006 paper on best practices in health literacy that the IOM definition was in fact the first one to reinforce the broader definition of health literacy (Shohet \& Renaud, 2006)). Nutbeam instead argues that a better definition describes the concept of health literacy as an asset, which when developed, can enable people to exert greater control over their health. Nutbeam sees health literacy as an outcome of health promotion and has identified three different levels:

- Basic or functional health literacy, which means having the skills to understand health risks, follow medication or self-care directions, and be able to use the health system;

- Interactive health literacy, which means being able to act independently on previous knowledge, applying it to new situations;

- Critical health literacy, which means being able to take social and political action, benefiting the wider society. 
This viewpoint was initially more likely to be reflected in the literature coming out of Europe according to Nutbeam (2008). In a literature review looking at how health literacy is described in the scientific literature, Mårtensson and Hensing argue a similar dichotomy. They conclude that there are two distinct understandings of health literacy, the first focusing on the basic functional skills needed to understand health information, with an individual having either high or low health literacy; or alternatively, as a complex approach. This complex approach includes the ways that culture, society and experience can affect health literacy, therefore identifying it as something more dynamic, with an individual's health literacy level changing depending on current context (Mårtensson \& Hensing, 2012). Pleasant and Kuruvilla (2008) describe these viewpoints as either a clinical or a public health approach. The clinical approach was originally an attempt to increase medication or treatment compliance by helping physicians with communication and patients with understanding. Early interventions included attempts at measuring health literacy in order to identify those most likely to struggle. Health Literacy projects in the United States and Europe mainly follow this approach. The public health approach connects health literacy with empowerment of individuals and this in turn connects it with health promotion and public health interventions. This approach can be found in the literature discussing Health Literacy in developing nations (Hernandez, 2013).

The definition of health literacy by the World Health Organization illustrates this:

"Health literacy represents the cognitive and social skills which determine the motivation and ability of individuals to gain access to, understand and use information in ways which promote and maintain good health." (World Health Organization, 1998).

\section{The impact of health literacy}

However broadly it is defined, health literacy is being recognised as an important component of health equity. As a health consumer, being health literate includes having the ability to make an informed choice about health. An individual may make an informed decision to not take a particular action, but they will know what the consequences are. Health literacy experts emphasise that health literacy is about knowledge, not about behaviour change (Rudd, Rosenfeld, \& Simonds, 2012; Stewart, 2012). As a healthcare provider or health educator, being health literate is having the ability to enable the consumer to become fully informed, even if there are barriers that complicate or hamper this ability.

The new healthcare model of patient-centred care described in many publications depends on increased self-management, especially in chronic care. Multiple health literacy experts claim that if this is not managed in a way that allows patients to be equal partners in their care, it will lead to 
more disparity in care and outcomes for vulnerable populations (Brooking, 2009; Eckman et al., 2012; Schillinger, Bindman, Wang, Stewart, \& Piette, 2004; Schnitzer, Rosenzweig, \& Harris, 2011; Sheridan et al., 2011).

Health literacy therefore, has been identified by several agencies and researchers as a social determinant of health that offers a powerful opportunity to reduce inequities in health. In addition to health literacy, the South Australian Council of Social Service identifies the following as social determinants of health:

- Income and social status;

- Social participation and social support networks;

- Education;

- Healthy living conditions;

- Racism, discrimination and culture;

- Early life factors and genetics;

- Individual behaviours and lifestyle factors;

- Access to health care, (Cannon, 2008).

Poor health literacy is recognised as being closely linked to poor health status (Nutbeam, 2008; Nutbeam \& Kickbusch, 2000). It is also recognised that health literacy is not only about raising the capability of the individual, but of entire health systems. These systemic changes need to happen in order to begin to combat health inequalities. Multiple studies identify specific populations with low literacy and low socioeconomic status, over-represented by indigenous groups, immigrants from non-English speaking countries (often refugees) and the elderly, and if attention is not paid to better communicating with these groups, health inequalities will continue (C. Baur, 2010; Hasnain-Wynia \& Wolf, 2010; Onieal, 2010; Sheridan et al., 2011). Robert Truog (2012), in his paper about the evolution of the patient-doctor relationship, found that many providers still operate within the traditional paternalistic model with these patients as it is seen as too hard and too time-consuming to communicate effectively. In one study, $32 \%$ of monitored clinical encounters were found to be "narrowly biomedical" consisting of closed end questions and technical talk, and this tended to take place with sicker, older and lower income patients (Mayer \& Villaire, 2007, p. 134). In a recent study looking at barriers to shared decision-making in the San Francisco Bay area, most patients wanted to engage in shared decision-making, but felt the need to conform to a traditional role in the clinical consultation. Two recurring reasons were that they didn't perceive that they were given any opportunity to enter into a discussion, and that they felt the need to adopt the role of a "good patient" rather than a "difficult patient" who questioned the expertise of the physician. The 
participants in this study were highly educated and wealthy, but still felt they were unable to assert themselves in a clinical consultation (Frosch, May, Rendle, Tietbohl, \& Elwyn, 2012). This illustrates the concept of health literacy as a "sliding scale", where anyone can struggle with health literacy depending on individual circumstances at a particular time or within a particular circumstance.

In an interview transcript published by the Center for the Advancement of Health in 2001, Rima Rudd is quoted:

"In a study of physician conversations with white- and blue-collar patients in the HMO setting, where the researchers compared how the physicians spoke to each group, they found that the physicians tended to use more plain and simple language with their whitecollar patients. Language can be used as a cultural divide. When people are not like you, you tend to be more formal in your presentation". (Mayer \& Villaire, 2007, p. 153).

In a report focused on health equity in New Zealand, it was concluded that while many providers may understand the issues around health equity, actually putting equity principles into practice can prove to be a challenge. The researchers found that although the achievement of health equity was recognised at a strategic level, it was not addressed at an implementation level, resulting in the continued utilisation of habitual, inequitable practices by health service personnel (Sheridan et al., 2011).

\section{Measuring low health literacy}

Researchers agree that the measurement of health literacy is a complex science that has not yet been completely addressed. Health literacy screening instruments focus on functional health literacy and don't measure interactive or critical health literacy (Abel, 2008).

In the 1990s, the OECD carried out a cross-country assessment of adult literacy, the International Adult Literacy Survey (IALS). This looked only at prose, document and quantitative literacy. In 2002 a second survey was designed, the Adult Literacy and Life Skills Survey (ALL) and included health literacy as a specific domain, although the focus was only on functional skills including interpreting medicine and nutrition labels. It was administered in two waves, the first to Bermuda, Canada, Italy, Mexico, Norway, Switzerland and the United States. The second wave surveyed Australia, New Zealand, the Netherlands, Hungary and South Korea (Thorn, 2009). Health literacy is measured in these population surveys on a scale of 0 to 500 , and this is broken down into five skill levels. People are defined as having low health literacy if they score at level 1 or 2 (a score from 0 to 275). Level 1 indicates very poor literacy skills, with people at this level unable, for example, to work out the correct amount of medicine to give a child from the instruction label. Level 2 indicates a capacity to 
deal only with simple, clear material involving uncomplicated tasks, but makes learning new tasks difficult (Priston, Searle, \& New Zealand Ministry of Health, 2010). The first phase of this survey was repeated more recently (OECD, 2013), with the second phase (once again including New Zealand) currently being undertaken with published results expected in 2016. A key finding of this was that most of the variation in skill was within, and not between countries. Ten per cent of adults in most of the countries in this recent surveyed were operating at or below level 1.

\section{Cost of low health literacy}

Studies have shown that people with low health literacy cost the healthcare system more (Berkman, Sheridan, Donahue, Halpern, \& Crotty, 2011; Brooking, 2009; Eichler, Wieser, \& Brügger, 2009; Nutbeam, 2008). Contributing factors include:

- Medication and treatment errors;

- Lack of compliance with treatment;

- Less use of preventive services including screening and immunisation;

- Limited self-management skills for chronic conditions;

- More use of health services due to increased complications from acute and chronic conditions;

- More and longer hospitalisations (people with low literacy have been found on average to remain in hospital for two days longer than those with higher health literacy), (Schnitzer et al., 2011).

The same study reported that additional care resulting from low health literacy costs four times as much as for those with higher health literacy skills. Another report claims that the savings made by increasing health literacy would be enough to insure every one of the 47 million uninsured people in the US (Vernon, Trujillo, Rosenbaum, \& DeBuono, 2009). A systematic review carried out in Switzerland on the costs of limited health literacy (Eichler et al., 2009) found that it cost the health system an additional 3 to $5 \%$ of total health costs each year. This review included studies from New Zealand although most data was sourced from the US. Because only direct costs were measured, the authors indicated that the true costs of low health literacy may be underestimated.

A recent study looking at improved preoperative patient education for haemorrhoidectomy gives a compelling argument for the effectiveness of health literacy. Sixty patients from an initial audit group and a second group of sixty patients following the introduction of improved patient education were recruited. The education itself consisted of written information about the surgery, postoperative self-care, and normal symptoms patients might expect to have after surgery. This 
information was also explained to the patients by both the surgeons and nursing staff to ensure it was understood. In the first ten days following surgery $57 \%$ of the first group sought follow-up care from their GP or the emergency department with post-operative concerns about typical symptoms. No individuals in the second group sought follow-up (Younis et al., 2013).

\section{Health literacy frameworks}

Researchers have developed several frameworks to explain health literacy. Four theories that contribute to our understanding of the complexity of health literacy are described here:

Activity Theory is an adult education theory model illustrating that learning doesn't happen in a vacuum, but that everything is filtered through culture, experience, and other influences. It is based on Engeström's Activity Theory Model, (Figure 1).

Activity Theory focuses on the interaction, or activity between Artefacts (the message, resource or intervention), Subject (the information being communicated), Community (the group being communicated to with their individual culture, influences, expectations and experience), Rules (the rules and expectations operating within this community, whether spiritual, cultural or legal), and Division of Effort (the group or individual communicating the message with their own culture, influences, expectations and experience). The resulting activity leads to an outcome using all these factors as a filter (Robertson, 2008). This is an effective tool for helping to develop an understanding of the complexity of health literacy and adult education.

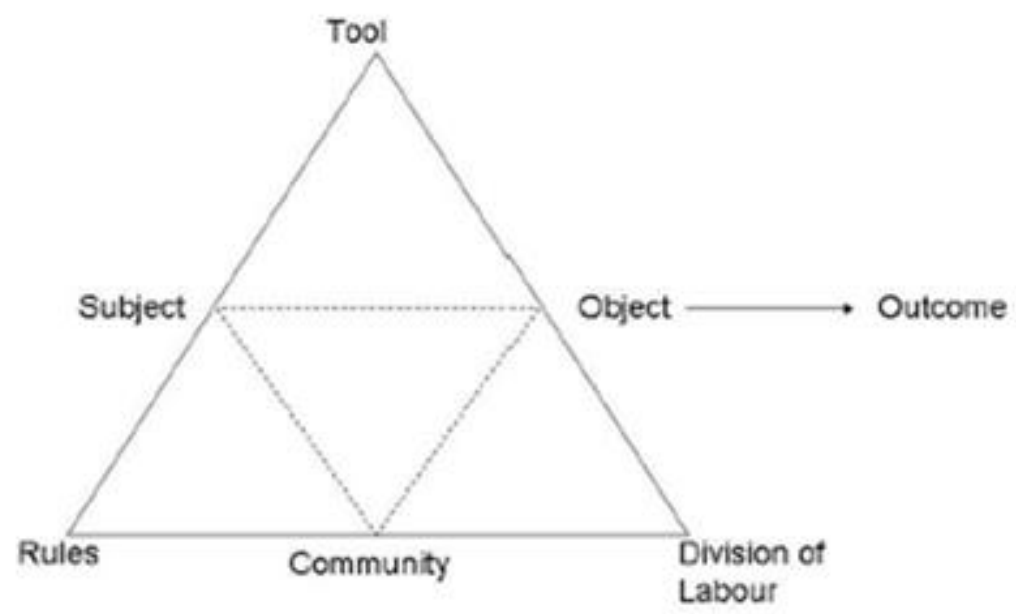

Figure 1: Engeström's Activity Theory Model 
The Shannon and Weaver model of communication has a focus on two areas of communication breakdown or "noise". It is based on electrical engineering concepts, and uses electrical metaphors to describe the process.

The first potential breakdown occurs during the transmission of the information between the provider of the information and the message, (Figure 2). The message is then not encoded in an accurate or accessible way.

A sender transmits a message over a channel to a receiver (sender challenge).

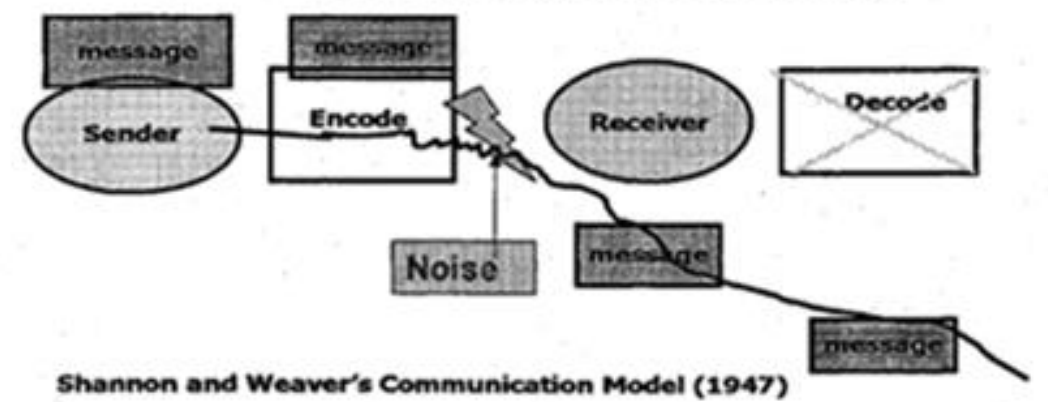

Figure 2: The Shannon and Weaver model of communication, part 1

The second potential breakdown occurs between the transmission of the message and the reception of the information (Figure 3), with the message not decoded accurately by the receiver (Shannon, 1948a, 1948b).

\section{A sender transmits a message over a channel to a receiver (receiver challenge)}

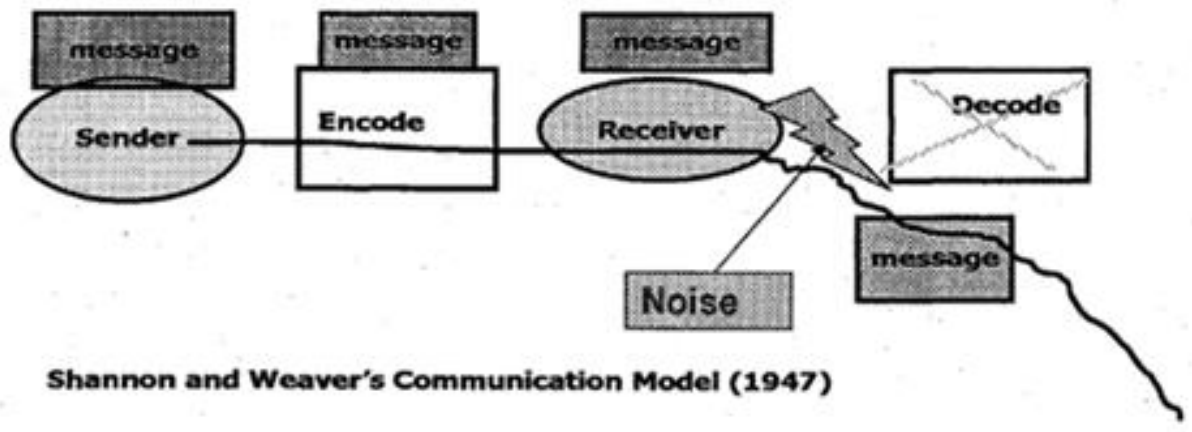


Susan Conaty-Buck used this as a model when examining the barriers to health literacy in her PhD thesis (Conaty-Buck, 2009). Although this theory looks at the message from both the provider and the receiver of the information, the flow of information is described as only going one way, and doesn't acknowledge the patient as expert on self.

Medagogy is a model created in the context of patient education that encompasses everything found within the other models (Figure 4), but emphasises the responsibility for health literacy by both the information provider and the information receiver (Stewart, 2012).

It begins with the equal partnership of two experts, the provider who is the technical expert, and the patient who is the expert on self. It then incorporates external influences and shows how this leads to action (which can be no action at all based on fully informed consent). Although this model was developed to illustrate the process of patient education rather than the development or evaluation of consumer health information resources, it best conceptualises the breadth of health literacy theory, and can certainly be applied to consumer health information.

A more recent "integrated conceptual model of health literacy" came out of Europe (Figure 5), and illustrates the both the clinical and public health approaches to health literacy (Sørensen et al., 2012). It draws together twelve dimensions of health literacy, the physical, cognitive and social factors that impact on them, and how they link to health outcomes. 


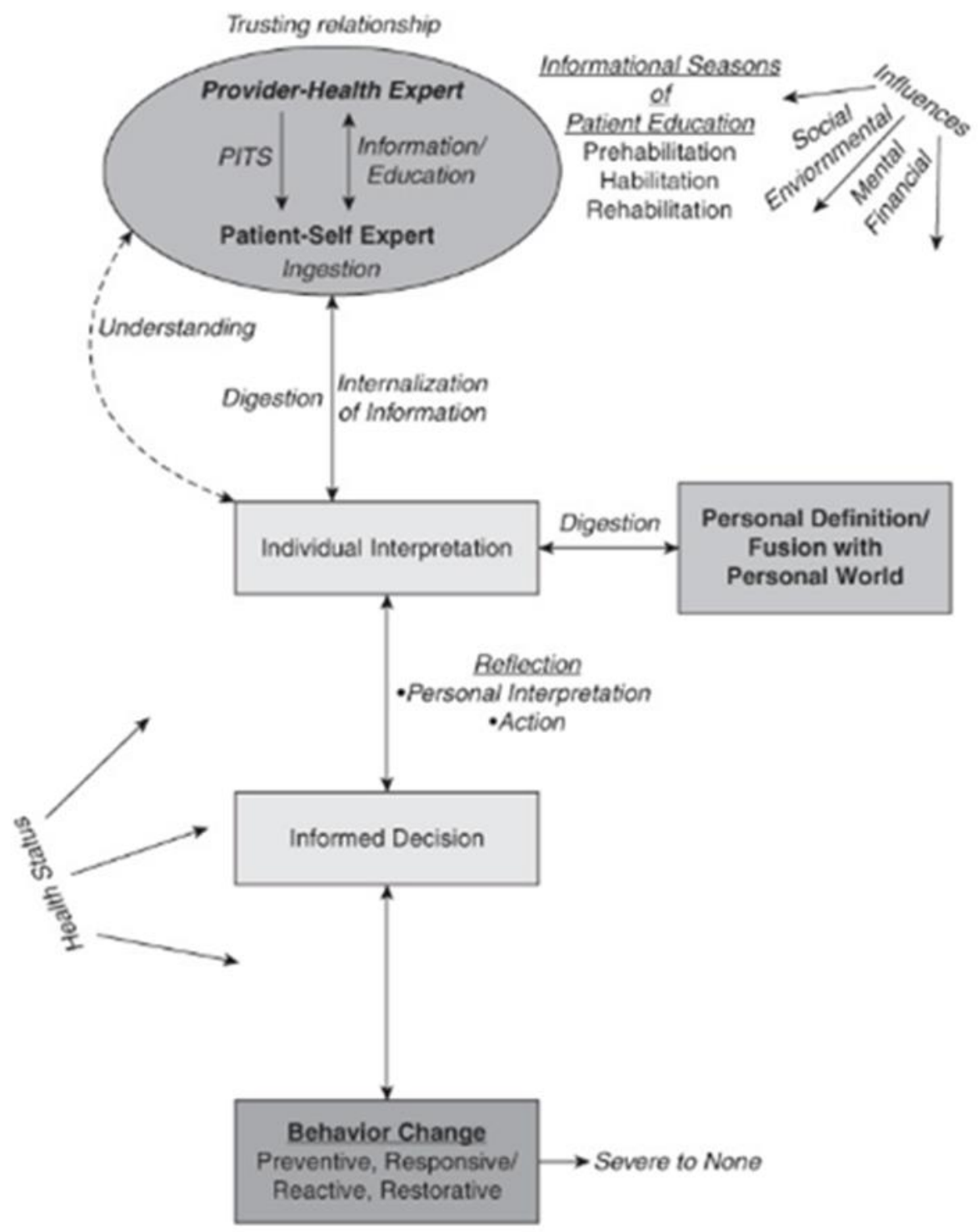

Figure 4: Medagogy Model 


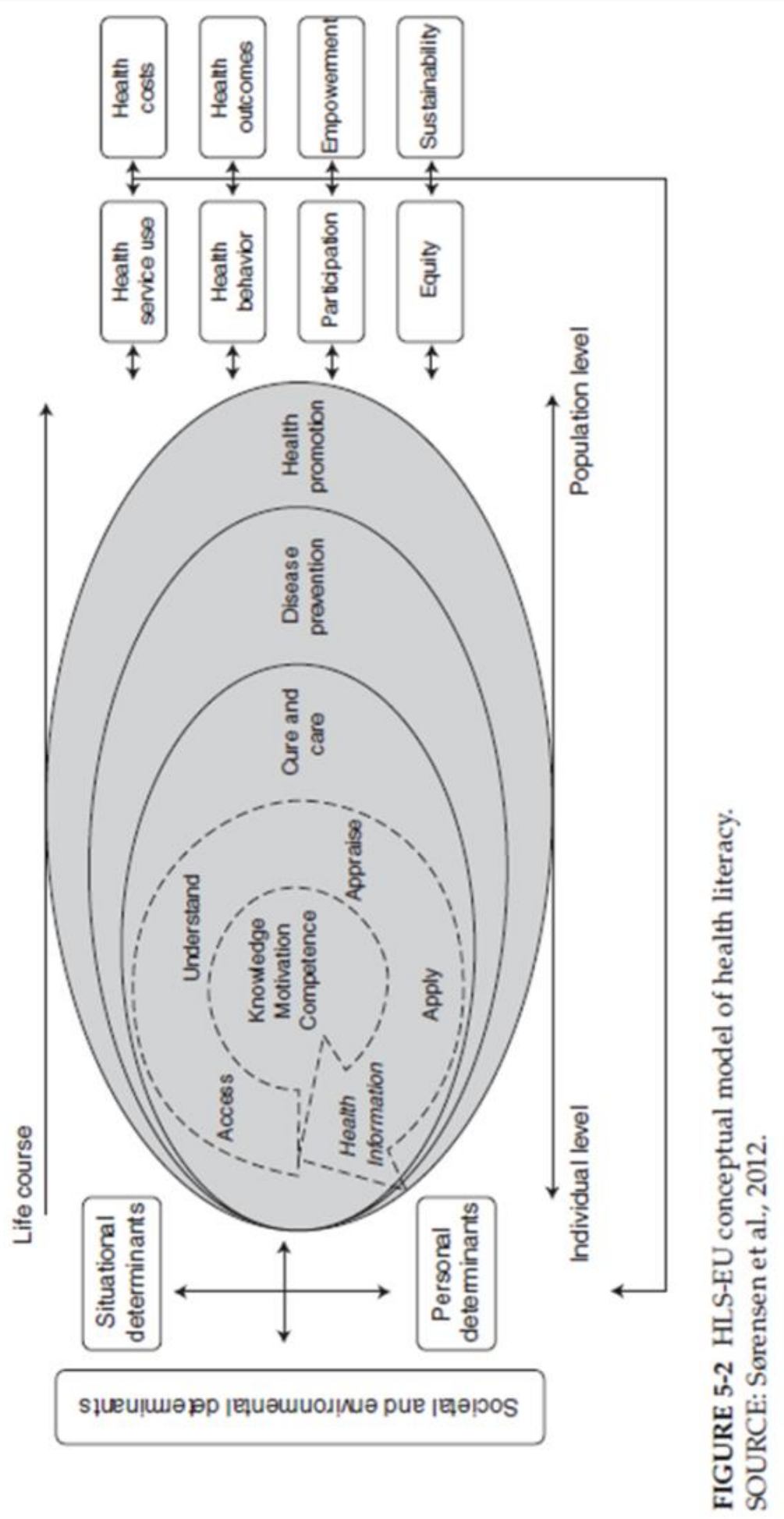

Figure 5: Integrated model of health literacy 


\section{International health literacy initiatives}

Interest in health literacy is exploding as it is recognised as a major contributor to health outcomes and equity. The first initiatives were from the United States where it is acknowledged as a priority by major government agencies including the Department of Health and Human Services (DHHS), the Agency for Healthcare Research and Quality (AHRQ) and the Centers for Disease Control (CDC). This interest was initiated by a report by the Institute of Medicine (Nielsen-Bohlman, Panzer, \& Kindig, 2004), which examined the body of knowledge that applies to the field of health literacy, and recommended actions to promote a health literate society. This report laid the foundation for the initiatives that were later developed. More recently, many European countries, Canada and Australia have also developed formal health literacy initiatives (Hernandez, 2013).

One significant initiative was the development of the Health Literacy Universal Precautions Toolkit by the AHRQ aimed at improving health literacy practice in primary care, (DeWalt et al., 2010). The term "universal precautions" was chosen because this refers to taking specific actions that minimise risk for everyone when it is unclear which patients may be affected. The toolkit contains a quick start guide, a six-step path to improvement, 20 tools which can be used by healthcare providers, and appendices with resources including sample forms and worksheets. These tools range from "Forming a team" and "Assessing your practice" guidelines, and modules to improve spoken and written communication, support improved self-management, and improve support systems. One of the best regarded tools included in the toolkit is "teach-back" (also known as "reflect back", "show me" or "closing the loop"), where the patient confirms understanding of an instruction by reflecting it back to the clinician in their own words (or demonstrating a required action). This toolkit was extensively tested for clarity and ease of use, both considered essential if the toolkit was to be utilised by its target audience (DeWalt et al., 2011).

The second major initiative later that year was the release of the National Action Plan to Improve Health Literacy (US Department of Health and Human Services, 2010). This describes seven goals to improve health literacy:

- Goal 1: Develop and disseminate health and safety information that is accurate, accessible, and actionable;

- Goal 2: Promote changes in the healthcare delivery system that improve information, communication, informed decision-making, and access to health services;

- Goal 3: Incorporate accurate and standards-based health and developmentally appropriate health and science information and curricula into child care and education through the university level; 
- Goal 4: Support and expand local efforts to provide adult education, English-language Instruction, and culturally and linguistically appropriate health information services in the community;

- Goal 5: Build partnerships, develop guidance, and change policies;

- Goal 6: Increase basic research and the development, implementation, and evaluation of practices and interventions to improve health literacy;

- Goal 7: Increase the dissemination and use of evidence-based health literacy practices and interventions.

The author of this document, Cynthia Baur, is now employed by the CDC and is one of the leading voices in the encouragement of these goals. In a 2011 article (Cynthia Baur), she "called the nation to act" and described the ways that individuals and organisations could use this plan.

In 2012 Canada released a discussion paper from the Public Health Association of British Columbia which calls for governments, the health sector, the education sector, workplaces and businesses and community organisations to:

1. Identify priorities and organize them into a comprehensive framework for improving health literacy in Canada;

2. Recommend a set of actions that could be taken at the national, provincial/territorial and local levels for the purpose of increasing health literacy among Canadians;

3. Facilitate conversations amongst practitioners, researchers and policy makers about health literacy and encourage cross-sectorial work around health literacy initiatives, (Public Health Association of BC, 2012).

The US Institute of Medicine has created a Roundtable on Health Literacy which brings health literacy researchers and experts together to identify ways that research can be translated into practical strategies to address health literacy issues. In a recent Roundtable workshop, Dean Schillinger discussed the value of health literacy interventions in improving the health of vulnerable populations. He has found that there are very few studies looking at the effects of interventions on vulnerable subgroups, but instead found most look at improvements across whole populations. He believes that for health literacy interventions to be successful in reducing health disparities, they need to target vulnerable populations, by using a two-tiered approach. Interventions can be developed to address the needs of the entire population, but also need to be focused on subgroups where the problem is seen to be most severe. Schillinger acknowledges that such focused and targeted intervention costs more and is aimed at fewer people, making it less attractive to policymakers than more general interventions that are shared across whole populations (Vancheri, 2011). 


\section{Health literacy challenges and barriers}

The biggest challenge in achieving health literacy is the requirement for change within the healthcare system itself. The move towards patient-centred care is a catalyst for change at systemic level, but in many practices health care is still not patient-centred, with the patient required to adapt to the existing system and navigate their way through it (Ontario Medical Association, 2010). Many researchers have called for health policy to support health literacy and make it a political priority and this has not been evident until the US initiatives outlined above (Nutbeam \& Kickbusch, 2000; Parker, Ratzan, \& Lurie, 2003; Vernon et al., 2009). In a follow-up editorial about the IOM report, Ruth Parker and David Kindig warn that the challenges posed by the report are daunting and will require sustained efforts over several decades, which will require significant time and resources (Parker \& Kindig, 2006).

There are however some positive indications that systemic change is slowly happening. As Ridpath et al note in their study, the Patient-centred Medical Home (PCMH) model of care is being accepted worldwide as an effective model with the potential to cut costs. A 2007 study by the Commonwealth Fund found that of seven countries surveyed, New Zealand had the highest prevalence of primary care practices that followed the principles of the Medical Home model: Good access to care, an on-going relationship between patient and provider, a whole-person orientation, team-based care and better coordination of care (Schoen et al., 2007). One of the categories of the PCMH model is "patient experience". The elements listed for this are clear communication, improved access, shared decision making, and self-management support. The PCMH and the most effective health literacy interventions share core features, especially around improved selfmanagement and treatment adherence. Ridpath et al suggest that health literacy could be embedded into the PCMH model and would therefore become part of something that health systems are already working towards, rather than a stand-alone priority. There are many education programmes being developed to support PCMH transformations so knowledge around how to integrate health literacy into practice could be a major component of this (Ridpath, Larson, \& Greene, 2012).

Another important challenge is the willingness of the health provider community to incorporate health literacy into their clinical encounters. Sherbino et al argue that continuing education still has a focus on the development of clinical skills, and "soft topics" like communication, conflict resolution and teamwork skills may not be allocated the same priority by clinicians (Sherbino, Upadhye, \& Worster, 2009). The outcome of this is a lack of knowledge around the importance and best methods of communicating with patients. 
In her 2009 PhD Thesis, Susan Conaty-Buck found that $80 \%$ of the health practitioners she surveyed reported that their education did not provide them with sufficient knowledge about how to deal with patients with low literacy, although most acknowledged health literacy among these patients was of concern. Her research sought to answer three questions:

1. What knowledge and perspectives do healthcare practitioners have about health literacy?

2. What strategies do practitioners in Harrisonburg City, Rockingham County currently employ to incorporate health literacy in practice activities?

3. What resources are required to help them strengthen application of health literacy practices?

The main barriers she identified included a lack of time in the clinical encounter, lack of staff resource and money for formal training, lack of knowledge about initiatives and tools, and low value placed on health literacy. Only one quarter of respondents were familiar with resources to help people with low health literacy, although three quarters indicated they would more likely to use them if effective tools were available at little or no cost. Time was a recurring concern, with less than half of primary care practitioners and only $10 \%$ of specialists reporting any scheduling flexibility. A lack of time was identified as a particular concern with patients from rural areas, as they tended to have fewer health provider visits and lower literacy. When these patients did visit a health provider, the visits tended to be significantly more focused on the illness management, rather than the implementation effective communication strategies which can be time-consuming. She makes specific reference to the 35 steps health providers can take to improve health literacy suggested by the Joint Commission:

"Time equals income in most healthcare practices leaving practitioners reluctant to add anything else to the clinical visit, let alone the Joint Commission's 35 "solutions" to improve communication between provider and patient" (The Joint Commission, 2007).

She also found that the current rapid development of tools like these actually can work as a barrier, confusing practitioners not sure which to use with which patients, and raising questions about which ones are evidence-based. Other findings from research:

- Seventy two per cent of the practitioners she surveyed reported a belief that reducing the complexity of health education materials would not change their patient's health literacy level, although research has found the opposite to be true; 
- Due to a lack of direct evidence of the economic impact of low health literacy, healthcare administrators ranked the need to address health literacy as a lower priority than the practitioners surveyed;

- More primary care practitioners reported recognising the impact of low health literacy and used health literacy strategies in their practice than specialty care providers.

There were however some limitations to her study. Data was only gathered from 40 health practitioners via a survey distributed during two formal 60 minute presentations on health literacy which were designed to be followed up by more informal discussion. No clinicians participated in the follow-up discussion sessions, so no qualitative data was available for evaluation (Conaty-Buck, 2009). It will be interesting to find out whether these themes are reflected by primary care practitioners practising in New Zealand. The theme of lack of evidence for the economic impact of health literacy was identified by the Institute of Medicine Roundtable on Health Literacy and has been recommended as a key area that should be systematically researched (Vancheri, 2011).

Even if there is a willingness to utilise health literacy practices within a healthcare practice, the culture of the organisation itself can hinder its use. Practices have traditionally been set up to maximise revenue rather than patient communication. Appointments are short, patients may see a different clinician each time they come, and the focus is on the physical rather than the emotional. Many of the tools that support health literacy have been found to add very little time to the appointment, but lack of time is one of the major barriers to their utilisation by clinicians and practices (DeWalt et al., 2011; Mayer \& Villaire, 2007).

In the DeWalt report on the development and testing of the Health Literacy Universal Precautions Toolkit, some of these challenges were also identified. Of particular interest was the testing phase of their study, where they trialled the toolkit with primary care practitioners to see how effective it was in practice. The Toolkit is divided into several sections:

- Tools to start on the path to improvement;

- Tools to improve spoken communication;

- Tools to improve written communication;

- Tools to improve self-management and empowerment;

- Tools to improve supportive systems.

Feedback provided some very useful information. Main findings were that teams needed to be formed in order for change to happen, and these teams needed to be diverse, representing as many different disciplines as possible within a practice. Practices tended to focus on one tool to improve 
spoken communication, for example, either AskMe ${ }^{\mathrm{TM}}$, or Teach Back, and respondents noted that Teach Back was actually quite hard and time consuming to learn, although they did acknowledge that once it was mastered it would take little time to utilise. Another major issue identified was the financial cost of providing interpreters for patients who didn't speak English. Most of the tools to improve written communication, including templates for new forms and strategies for creating more effective health education resources were rejected as being too time-consuming (DeWalt et al., 2011).

The cost of providing interpreters was also a significant finding in a 2012 Otago School of Medicine study led by Ben Gray, where health providers, especially in primary care, cited lack of funding as a major obstacle to interpreter use. They also found that when interpreters are used in New Zealand, they are more likely to be family members rather than trained medical interpreters, which is a recognised risk (Gray, Hilder, \& Stubbe, 2012).

Studies calling for system change have called for more focus on communication skills within all levels of clinician education. Communication skills are often included in the curriculum at medical schools, but postgraduate training in healthcare organisations has a focus on clinical skills, and attempts at patient communication can be discouraged by older clinicians who have not learned these skills. Wilson argues that this in turn socialises the doctor into a culture of looking at bodily processes rather than the patient as a person (Wilson, 2008). Felicity Goodyear-Smith has also pointed out that the concept of empowering the patient can also be perceived as a threat, especially to older clinicians (Goodyear-Smith \& Buetow, 2001).

In his study looking at attitudes towards health literacy by medical librarians and environmental health professionals, Logan focused on three aspects of health literacy:

1. What should be the primary intention of future health literacy initiatives?

2. What is health literacy?

3. What will be the primary health policy, cultural, patient outcomes, and impacts of health literacy initiatives?

The results of this study identified three distinct factors, or "perceptual prisms" among respondents when considering health literacy. He voices concerns that these differences could impede the momentum of health literacy. The first factor group was optimistic and supportive of the potential of the role of health literacy within clinical settings, especially primary care, and believed that health literacy initiatives should focus on helping patients and consumers better navigate the healthcare system and improve clinical interactions with providers. The second group was the most critical 
about the clinical role of health literacy and but saw it fitting well into K-12 classroom education settings with a focus on helping children to understand how the human body functions. The third factor group were supportive of health literacy but maintained that it should be a personal interaction with health information materials, and felt that it should be limited to improving a consumer's basic medical knowledge, rather than at a clinical level. He voices concerns whether these differences could impede the momentum of health literacy (Logan, 2007). Logan does not however discuss whether medical librarians or the environmental health experts were more likely to support specific factors which would have provided useful piece data.

In an effort to overcome the gap between health literacy knowledge and its implementation in practice, there is currently a focus on the development of health literacy curricula for health professionals. The first step was the identification of health literacy educational competencies, with a lack of these recognised as the main barrier to developing effective curricula. An expert panel was formed comprised of health education leaders with knowledge about health literacy or related concepts, including representatives from medicine, nursing, dental, pharmacy, veterinary medicine, optometry and allied health. The panel came to a consensus on 24 knowledge competencies, 27 skill competencies, and 11 attitude-based competencies which were written as measurable objectives. These are currently being used to develop a current pedagogy for health literacy for the health professions (Coleman, Hudson, \& Maine, 2013).

\section{Health Literacy in New Zealand}

The Minister of Health is responsible for developing policy for the health and disability sector supported by the Ministry of Health and its business units. Under the current National Government elected in 2011, policy is created around the "better, sooner, more convenient" health model (Ryall, 2008). Twenty District Health Boards (DHBs) are responsible for planning, managing, providing and purchasing health services for the population of their district. This includes funding for primary care, hospital services, public health services, aged care services, and services provided by other nongovernment health providers including Māori and Pacific providers.

Several objectives set out for the DHBs have direct relevance to health literacy, specifically:

- Promoting effective care or support of those in need of personal health services or disability support;

- Promoting the inclusion and participation in society and the independence of people with disabilities;

- Reducing health disparities by improving health outcomes for Māori and other population groups; 
- Reducing - with a view toward elimination - health outcome disparities between various population groups (Ministry of Health, 2013).

Patient-centred care is promoted by Ministry of Health policy, and this provides a framework for the promotion of health literacy in New Zealand. Patient-centred care is accepted as the main approach to medical care, especially in general practice, and practices are generally moving toward implementing it (Wilson, 2008).

As early as 1978 a New Zealand Library Association submission on hospital services discussed the need for patients to have information. The main issue identified by their work was the question of who should be responsible for providing this service (Oliver \& Bidwell, 2001).

In 1996, a "Focus Group on Consumer Health Information" was set up to discuss improving access to consumer health information in New Zealand. The recommendation from the group was for the provision of a "one-stop-shop" consumer health information service, purchased by the Regional Health Authorities (precursors of the current DHB system), providing health information from many sources and accessible by personal visit, mail, or 0800 number (Harris \& Hutt, 1996).

By 2001 however, it was obvious that this recommendation had never been actioned, although the creation of a health portal was one of the top 10 priorities of the WAVE project (WAVE Advisory Board, 2001), an initiative that was never followed up on.

In their research about the role of the hospital library in consumer health information, Oliver and Bidwell found that New Zealand information professionals believed that there was the need for an effective health information service for the general public, and that past initiatives have been fragmented at best. They also highlight three rights in the 1996 Health and Disability Commission's Code of Rights that relate to health information:

1. The right to effective communication;

2. The right to be fully informed;

3. The right to make an informed choice and give informed consent.

Internationally documents like this have resulted in better information services for consumers, but the Code of Rights has not been a catalyst for any national initiatives for the provision of consumer health information. Their survey of hospitals in New Zealand intended to find out which hospitals provided information services to consumers beyond the medical consultation found that healthcare workers had a lack of recognition of the need patients had for in-depth or complex information 
about their condition. If further information was given it tended to be at simple pamphlet level (Oliver \& Bidwell, 2001).

In 2001 the Ministry of Health published the WAVE (Working to Add Value through E-information) report, the "Health Information Management and Technology Plan". Although far broader in scope than consumer health information, it did highlight the failure of health information systems for Māori, and called for an integration of Māori models of health into the current system. The WAVE programme consisted of eight work streams, which looked at health information issues each from a different perspective. One of these, Knowledge, is of particular relevance to this study. For the purposes of the WAVE project knowledge management was defined as:

"The development and effective use of health information/decision support systems which provide timely access for all health professionals and the public to high quality, relevant information from global information sources and from data collected and analysed within the New Zealand health system."

Although mostly focused an improvement in health information systems including more accurate gathering and recording of population health data and better information sharing capabilities among health care providers, the report does claim that good quality, evidence-based electronic information would also benefit patients by ensuring they know about waiting times, the relative safety of procedures, about support groups and their rights and choices. One of the six success criteria listed is "Empowered communities: Designed information systems catering for different cultural needs and empowering individuals and communities to manage their own health care" (WAVE Advisory Board, 2001).

In a 2006 study looking at factors influencing medication compliance rates in New Zealand, Eagle et al found that medical practitioners are the primary and most important source of medical advice, followed closely by pharmacists. Another important source of information was the media, including news, documentaries, newspaper and magazine articles, and medical dramas. They suggest that the reason behind the popularity of these vehicles was that they were more user-friendly than health information provided by health practitioners. To verify this suggestion, they analysed a range of printed health education material using the SMOG (Simple Measure of Gobbledegook) Index, in order to measure the reading level. Resources included medication inserts and pamphlets from doctors and pharmacies as well as websites, magazine advertisements, newspaper editorials and medical dramas. Alarmingly they found that "the television medical dramas "Casualty", with a reading grade level of 7 and "ER", with 7.5 were the only potential information sources to operate at a level at which the average person could be expected to be able to fully comprehend the material". 
An interesting finding was that product brochures about complementary and alternative medicines were written at a higher level than brochures about mainstream pharmaceutical products, perhaps in an effort to give them more credibility (Eagle, Hawkins, Styles, \& Reid, 2006).

\section{Health equity in New Zealand}

New Zealand follows the international trend of increased cost of chronic disease to the healthcare system. This is due to increased life-expectancy, an aging population, an increasingly complex health system, and more expectation that patients will self-manage their illness (Brooking, 2009; Sheridan et al., 2011). New Zealand has also been found to have a higher incidence of infectious diseases leading to hospitalisation than any other Westernised country, especially within vulnerable populations (Baker et al., 2012).

Kōrero mārama, a report published in 2010 based on results from the 2006 Adult Literacy and Life Skills Survey described the health literacy skills of the adult Māori population compared to the adult non-Māori population. The report found that most New Zealanders did not have the health literacy skills "necessary to meet the complex demands of everyday life and work in the emerging knowledge-based economy" (Priston et al., 2010).

As Brooking points out in her thesis on health literacy and chronic illness in New Zealand, traditional ways of delivering health services are not able to meet the needs of patients in today's healthcare environment. She sees the need to identify key themes that cater to people with low literacy and incorporate these into models of long term condition management. This needs to be done at a macro or policy level, where policies are designed to create the environment at the meso or health provider level, in order to be able to design services to support the micro or patient level to become informed, motivated and skilled. She has identified an improvement of communication skills amongst health professionals as crucial to success. She recommends that "a comprehensive, coordinated, cooperative and integrated strategy on health literacy be developed, funded and implemented to improve the level of health literacy in New Zealand and the extent to which people with long term conditions receive the support they need to cope with the health literacy demands they encounter". She also found that a major barrier to solutions "is the attitudes of the health professionals responsible for enacting change within the patients and delivering service" (Brooking, 2009).

International studies show that increasing health literacy is one of the keys to reducing health inequality and there are signs that this is being recognised in the literature and by New Zealand healthcare organisations. 


\section{New Zealand health literacy programmes}

An interest in health literacy is growing in New Zealand, with organisations including Workbase and Health Navigator becoming involved in its support and promotion. In 2011 Workbase and Health Navigator released the "Waipuna Statement", which stated that "Health literacy is everyone's business" and called for signatories to support the concept (Health Navigator, 2011). In May 2012, Workbase organised a conference, "Health Literacy: from discussion to action", which gave individuals and organisations a chance to showcase specific health literacy initiatives. There are also significant health literacy projects by Pharmac and the New Zealand Health Quality and Safety Commission. Major consumer support societies, including the Cancer Society and the Heart Foundation, are also demonstrating and encouraging good health literacy practices.

\section{Gaps in the literature}

Health literacy literature has seen exponential growth over the last ten years. Much of it demonstrates the importance and potential of increasing health literacy, at personal, clinical and systemic level. There is also a lot of literature on the patient-centred care model, which is closely aligned to health literacy. There are many tools and interventions available, often without cost, from healthcare societies and international government organisations. Policy is starting to reflect health literacy as a priority, especially in the US, with recognition that has a major contribution to closing gaps in health.

There is some literature on the knowledge that GPs have about health literacy, what they think about it, whether they think it can work, whether they think there are barriers to implementing it, and whether they are prepared to actually do it. Conaty-Buck gathered research within a particular geographic population in the United States looking at these factors, but findings were limited by the study's methods (Conaty-Buck, 2009). There is very little discussion about these issues from a New Zealand perspective. Most New Zealand literature is in relation to the broader patient-centred care concept, or the delivery of consumer health material.

No literature was identified that discusses differences in the acceptance and use of health literacy practices by specific groups, for example rural versus urban health practitioners, or whether there is a gender influence on this. At a recent health literacy conference in Auckland "Health literacy: from discussion to action", at least $90 \%$ of the participants were women, indicating that female health professionals may prioritise "soft" skills like communication more highly than males. This was reinforced by a search of the Health Literacy Discussion list (http://listserv.ihahealthliteracy.org), which describes its purpose as: 
"To provide an on-going professional development forum where literacy practitioners, healthcare providers, health educators, researchers, policymakers, and others can discuss health literacy needs, goals and strategies. "

Between 25 April 2012 and 25 May 2012, 51 women posted to the forum. This is in contrast to six men.

This trend can also be seen in the literature reviewed in this document. Although many of the primary authors are men, those articles tend to be about chronic illness, patient-centred care and inequality. Papers with health literacy as a central topic are more likely to be authored by women

\section{Research results}

\section{Overview}

Many health literacy tools have been developed to support clinicians in communicating effectively with their patients. When properly utilised, these tools have the potential to improve the health outcomes of their patients and also to reduce health system costs. One of the earliest set of tools, the "Health Literacy Universal Precautions Toolkit" (DeWalt et al., 2010), was aimed specifically at General Practitioners (GPs), and was widely discussed in primary practice literature. Other GPrelated resources followed, as well as resources specifically aimed at other clinician groups, including Medical Specialists, Nurses, Nurse Practitioners, Allied Health Professionals and Pharmacists. This piece of research investigated whether New Zealand GPs were familiar with any of these tools, whether they considered them useful, and whether they were utilising them as part of their practice.

\section{Method}

\section{Study design and data collection}

Surveys were sent to $20 \%$ of all General Practitioners identified as practicing in New Zealand at the time the survey was developed in 2012. The survey was developed in part from questions used in the surveys created by Conaty-Buck (2009) and Logan (2007). These authors undertook similar research in the United States. Questions were edited to reflect the New Zealand healthcare system and terminology, or were removed if not pertinent. New questions were created to ensure the necessary information was gathered, including specific demographic questions. Questions were a mixture of closed and open format, and were intended to gather both quantitative and qualitative data. The first section of the survey was demographic and gathered data on geographic location, membership of a Primary Health Organisation (PHO), gender, age, experience and average number and length of patient visits. The next section examined health information communication within GP practices, and the last section investigated the knowledge and utilisation of health literacy tools 
within practices. Questions utilising the Likert scale deliberately excluded a "Neutral" option, in order to encourage participants to state their knowledge or beliefs. The large number and geographical distribution of potential respondents justified the use of mixed methodology, as recommended by Walliman in his research methods book (2011, p. 97). Results were analysed using simple statistics, cross tabulations and coding of open-ended questions.

Potential recipients were selected from the publicly accessible online directory "NZ Health Pages (Doctors - General Practitioners)" http://www.healthpages.co.nz/doctors-a-generalpractices/general-practitioners. Every fifth name was selected with the first name randomly selected by throwing a dice, resulting in a sample of $20 \%$ of practicing GPs. The administrators of this directory, Cervin Media Limited, capture and update the data on this website annually. This method of participant selection was used in order to gather a representative sample of responses from across New Zealand.

The GPs identified were sent a print copy of the survey with an addressed postage-paid return envelope. The cover letter included a link to an online survey option created using Qualtrics survey software. Responding GPs were therefore able to answer the survey in the method of their choice. A follow-up reminder email was sent to the practice email address of each recipient several weeks later which included the link to the online version of the survey.

Victoria University of Wellington required that an ethics approval be obtained for research involving human participants, and an approval was obtained for this research from the School of Information Management Human Ethics Committee in September 2012.

\section{Statistical analyses}

Quantitative data was analysed using Qualtrics software to run cross-tabulations of demographic data and the multiple choice or rating scale questions looking at current health information communication strategies, knowledge of health literacy and utilisation scores. This was done to investigate any statistical differences from a geographic context (including whether the practice was rural or urban and socioeconomic factors measured by the 2006 New Zealand Deprivation Index (Salmond, Crampton, \& Atkinson, 2007)), membership of a PHO, gender, age, experience as a GP and length of average consultation. Cross-tabulation tables were downloaded, along with associated Ttest results. All results with a T-test probability $(p)$-values of less than 0.15 indicated a statistically significant difference in answers, and these were subsequently analysed in more detail. 


\section{Narrative analysis}

Answers from each of the narrative questions were coded according to concepts expressed, allowing groups of related concepts to be created, as well as seeing if there were any significant trends or relationships. Two of the narrative questions were purely demographic - which Primary Health Organisation did the responder belong to (if they had answered yes to the question), and the approximate number of patient visits they dealt with in an average day. The other narrative questions dealt with the communication strategies utilised by GPs; ways in which they evaluated patient literacy; specific knowledge of health literacy strategies, tool and resources; whether they used any of these strategies; whether they found the strategies they implemented useful; where they found out about the particular strategies they employed; and a final "other comments" question.

Results

A total of 143 valid responses were gathered, 121 print surveys and 23 via the Qualtrics online survey software. A total of 34 print surveys were returned unopened due to the intended recipients no longer being at the listed address, two print surveys were returned blank, and one was only partially filled in. Results from the print surveys were entered into Qualtrics enabling the full dataset to be analysed in one place. Table 1 shows the demographic breakdown of the responses.

\section{Demographics}

Most completed surveys were from the main three regions and most identified their practices as urban. The most recent Urban-Rural profile developed by Statistics NZ (Statistics New Zealand, 2014 ) identified that $70 \%$ of New Zealanders lived in urban areas, so the $76 \%$ who identify their practices as urban is to be expected. GP practices serving all socioeconomic groups were represented in the survey responses, with most practices falling between 3 and 8 on the NZ Deprivation Index. More males than females responded to the survey, and this correlates to Statistics NZ data which indicates that $59 \%$ of the medical workforce is currently male (Medical Council of New Zealand, 2013).

The report the New Zealand Medical Workforce in 2010 (Medical Council of New Zealand, 2010) profiled the average age of GPs as 49. In 2012, when this survey was distributed, this GP group would have been two years older, which could partly explain the significantly higher number of responses in the 50-59 age range. The same report indicates that doctors tend to decrease their hours of work as they get older, perhaps leaving more time to participate in research. The largest percentage of participants had more than 20 years of practice as a GP, and the smallest had less than six. This is likely to reflect the age groups of the responding GPs. 
Overwhelmingly, the average length of consultation indicated in the responses was 15 minutes, with $76 \%$ of GPs reporting this to be the case.

Only five participants were not part of a PHO, and most did not know whether their PHO had a mandate for health literacy. Of those who knew whether there was a mandate, more answered to the affirmative than the negative.

The cross-correlations carried out within the survey data found statistically significant differences within all of the demographic groups:

- Geography

- Socioeconomic position of practice

- Urban vs rural

- Gender

- Age

- Experience

- Length of average consultation

PHO data was not taken into consideration, as very few participants did not identify as part of a PHO. 


\begin{tabular}{|l|l|r|r|}
\hline $\begin{array}{l}\text { Demographic } \\
\text { Groups }\end{array}$ & Total Sent & Responses \\
\hline $\begin{array}{l}\text { Geographic } \\
\text { Region }\end{array}$ & Northland & 25 & 3 \\
\cline { 2 - 4 } & Auckland & 196 & 39 \\
\cline { 2 - 4 } & Waikato & 49 & 12 \\
\cline { 2 - 4 } & Bay of Plenty & 40 & 12 \\
\cline { 2 - 4 } & Gisborne & 3 & 1 \\
\cline { 2 - 4 } & Hawkes Bay & 26 & 9 \\
\cline { 2 - 4 } & Taranaki & 17 & 4 \\
\cline { 2 - 4 } & Manawatu & 15 & 5 \\
\cline { 2 - 4 } & Whanganui & 9 & 2 \\
\cline { 2 - 4 } & Wellington & 65 & 18 \\
\cline { 2 - 4 } & Nelson & 13 & 2 \\
\cline { 2 - 4 } & Marlborough & 9 & 2 \\
\cline { 2 - 4 } & Canterbury & 100 & 20 \\
\cline { 2 - 4 } & Otago & 29 & 11 \\
\cline { 2 - 4 } & Southland & 16 & 3 \\
\hline
\end{tabular}

\begin{tabular}{|c|c|c|c|c|c|}
\hline $\begin{array}{l}\text { Demographic } \\
\text { Groups }\end{array}$ & & Responses & $\begin{array}{l}\text { Demographic } \\
\text { Groups }\end{array}$ & & Responses \\
\hline \multirow{12}{*}{$\begin{array}{l}\text { Deprivation } \\
\text { Index Score }\end{array}$} & \multirow{2}{*}{$\begin{array}{l}1 \text { - least } \\
\text { deprived }\end{array}$} & \multirow[t]{2}{*}{8} & \multirow{2}{*}{$\begin{array}{l}\text { Urban vs } \\
\text { Rural }\end{array}$} & Urban & 109 \\
\hline & & & & Rural & 34 \\
\hline & 2 & 11 & \multirow{6}{*}{ Age } & & \\
\hline & 3 & 21 & & $<30$ & 0 \\
\hline & 4 & 19 & & $30-39$ & 25 \\
\hline & 5 & 19 & & $40-49$ & 29 \\
\hline & 6 & 13 & & $50-59$ & 67 \\
\hline & 7 & 17 & & $>60$ & 22 \\
\hline & 8 & 17 & \multirow[t]{2}{*}{ Gender } & Male & 81 \\
\hline & 9 & 9 & & Female & 62 \\
\hline & $10-$ most & 9 & \multirow{4}{*}{$\begin{array}{l}\text { Average } \\
\text { Length of } \\
\text { Consultation }\end{array}$} & & \\
\hline & deprived & & & 10 minutes & $\frac{8}{96}$ \\
\hline \multirow{2}{*}{$\begin{array}{l}\text { Experience as } \\
\text { a GP }\end{array}$} & $0-5$ years & 25 & & 20 minutes & $\begin{array}{l}50 \\
15\end{array}$ \\
\hline & $6-10$ years & 13 & & $>20$ minutes & 8 \\
\hline
\end{tabular}


Familiarity with Health Literacy resources

Regionally, where there were more than five responses, Waikato had the highest percentage of participants who indicated they were familiar with resources that had been specifically created to address low health literacy with almost half of participants responding positively. One third of participants from Northland and Hawkes Bay also identified themselves as familiar with the concept. Wellington participants reported the lowest level of familiarity with only $12 \%$ responding positively (Figure 6).

Participants from rural practices were also more likely than those from urban practices to identify themselves as familiar with health literacy tools, as were participants with practices located in more highly deprived socioeconomic areas (Figure $7 \&$ 8). Gender was also a factor in familiarity with health literacy resources, with a higher percentage of male participants identifying themselves as familiar with the concept. Familiarity also increased significantly with age (although declined again in those over 60) (Figure 8).

There was not a significant difference in familiarity with health literacy resources and the number of years a GP had been practicing, although those with 6-10 years of experience and those with more than 20 years of experience were more likely to identify themselves as familiar with health literacy resources (Figure 8).

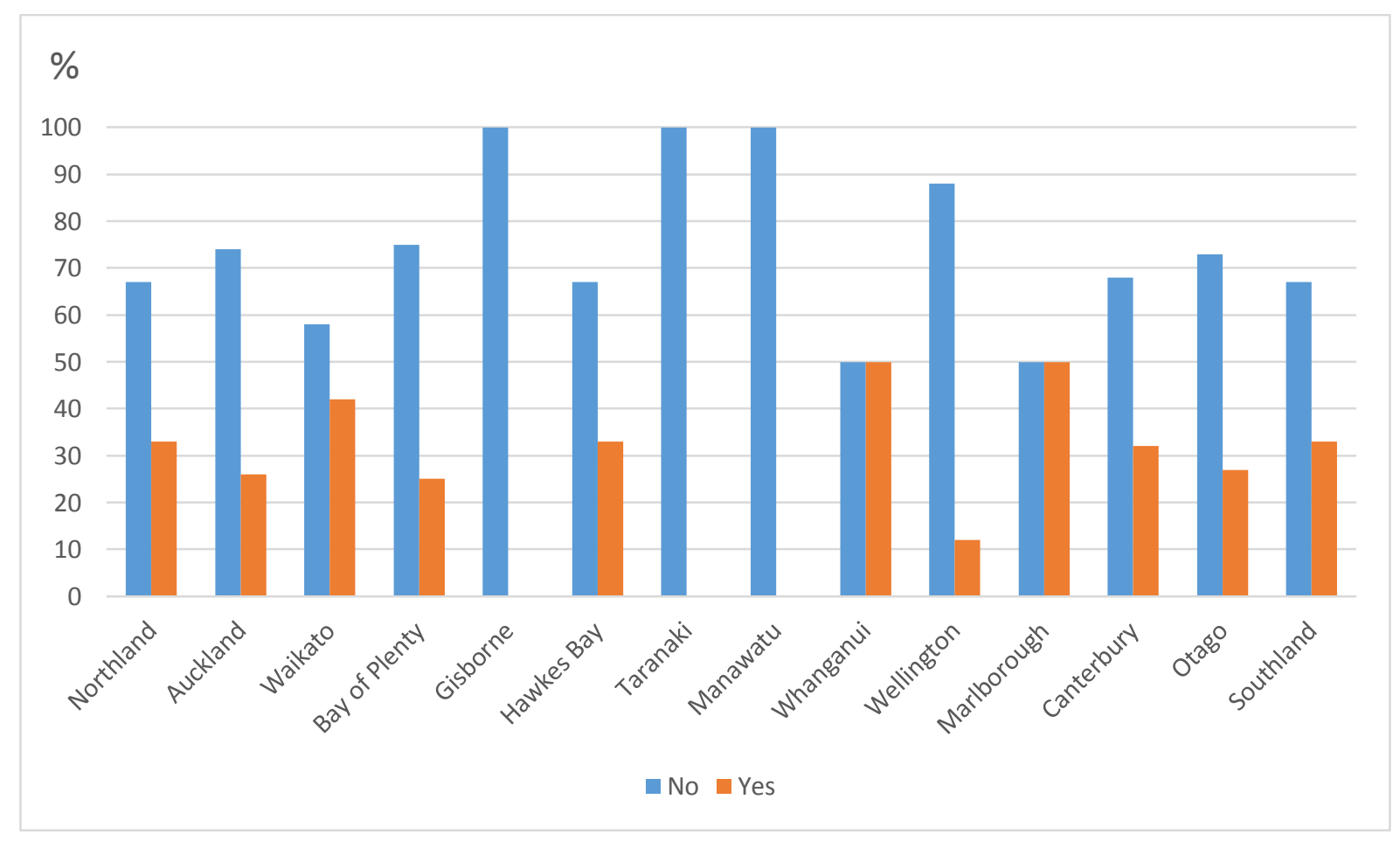

Figure 6: Health Literacy Resource Familiarity and Geography 


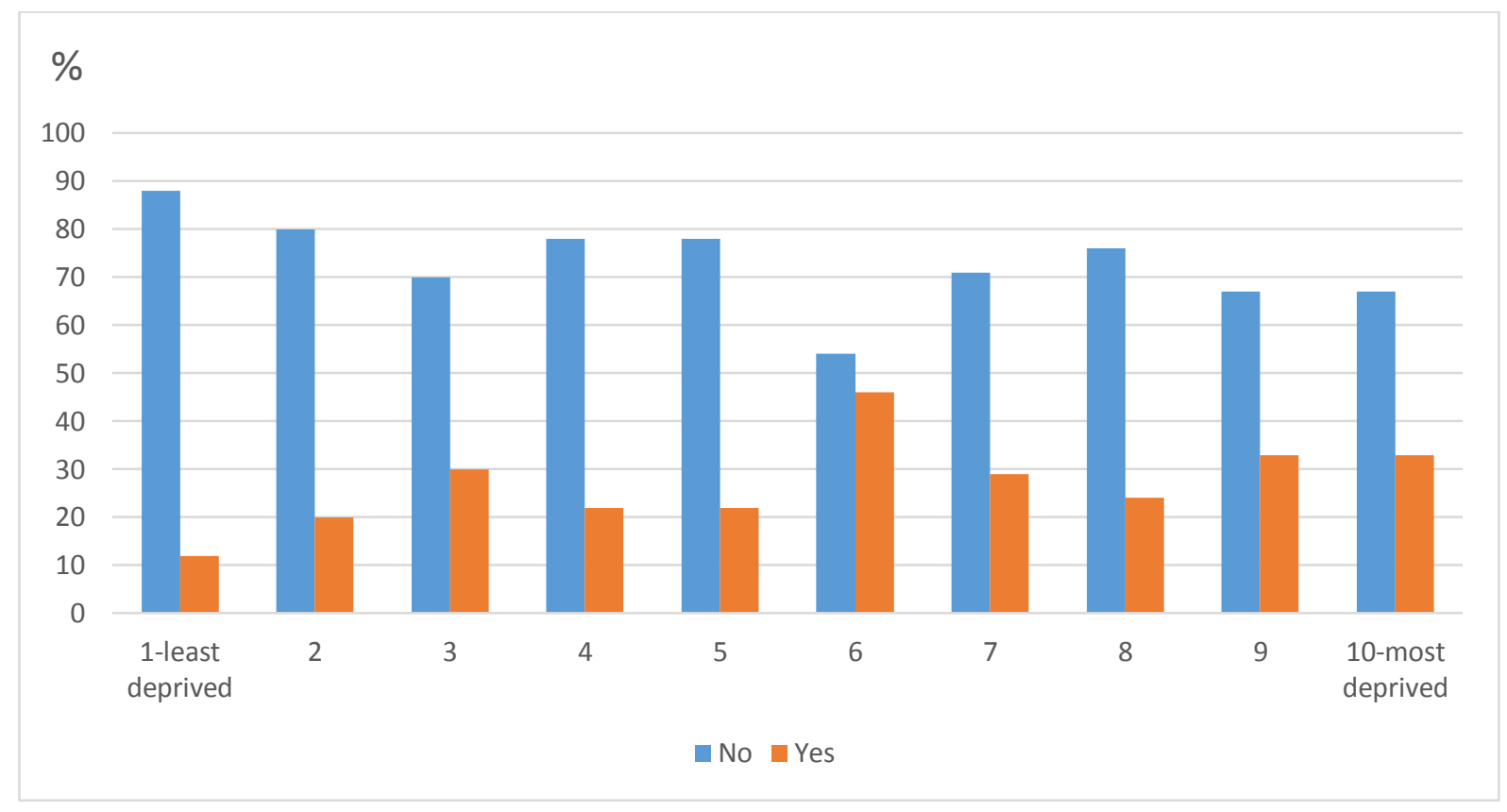

Figure 7: Health Literacy Familiarity and Deprivation Score

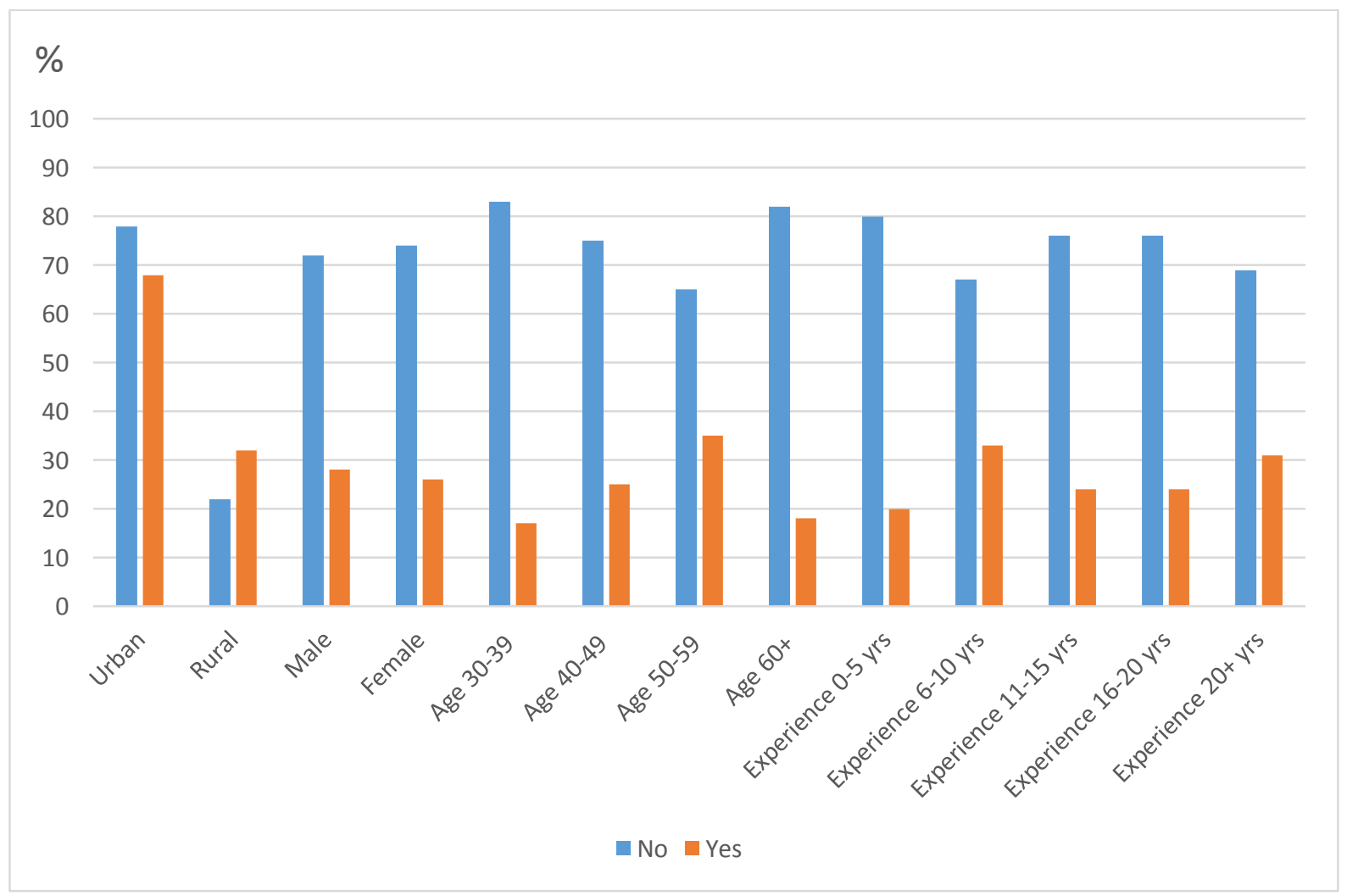

Figure 8: Health Literacy Familiarity and Other Demographics 


\section{Communicating health information in GP practices}

The second part of the survey examined how the participants rated the importance of specific communication strategies within their practice. Analysis of the results highlighted a number of differences between those who identified themselves as familiar with health literacy resources and those who didn't, and also identified differences within demographic groups.

As outlined earlier, the best known health literacy resource that has been extensively discussed in the literature is the "Health Literacy Universal Precautions Toolkit" (DeWalt et al., 2010).

The toolkit is aimed at improving health literacy practice in primary care, and contains a quick start guide, a six-step path to improvement, 20 tools which can be used by healthcare providers, and appendices containing various resources (e.g. sample forms and worksheets). These tools range from practice assessment guidelines, modules to improve spoken and written communication, support improved self-management, and improve support systems. One of the best regarded tools included in the toolkit is "teach-back", where the patient confirms understanding of an instruction by reflecting it back to the clinician in their own words (or demonstrating a required action).

Although the "Health Literacy Universal Precautions Toolkit" has primarily been rolled out in the United States, individual tools have been discussed in the international literature, including publications aimed at New Zealand GPs (Gray, Hilder, \& Stubbe, 2012; Wilson, 2008).

\section{Familiarity with health literacy resources}

All of the participants who identified themselves as familiar with resources that have been specifically created to address health literacy agreed that it was extremely important to verbally present key points about actions the patient needs to do. Although they did give this technique some importance, $12 \%$ of participants who didn't identify as familiar with health literacy resources felt it was difficult to apply. This was the only communication tool or resource that showed a statistically significant difference between participants who were familiar versus unfamiliar with the concept of health literacy.

\section{Urban vs rural}

Participants from both urban and rural areas all agreed that it was important to ask the patient what they already knew about their condition or treatment so that they can scaffold the new information onto the patient's current knowledge. Participants from rural areas were however significantly more likely to agree strongly with this strategy. Urban participants were more likely to believe that scaffolding was difficult to apply, and it would be interesting to explore this further. 
Participants from both urban and rural areas were less likely to agree that it was important to confirm that the patient understands what they have been told verbally by having the patient report a summary of what they have said in their own words. Almost half of rural participants agreed that this was extremely important, as compared to only a third from urban practices. Most participants also agreed that verbal teach-back was difficult to apply, although there were no significant differences between the two groups.

Just about all participants from both urban and rural areas believed that it was important when a patient doesn't speak good English, that an appropriate person (professionally trained or family member) verbally translate the instructions. However, the study found that urban participants were more likely to find this difficult to apply. It would be useful to explore this further, as professional translators are more likely to be accessible in urban areas. It is possible that in rural areas without public transport, new immigrants or elderly people are more likely to be driven to an appointment by a family member who would then be available to translate.

Just under half of all participants from both urban and rural areas agreed that it was extremely important to give patients instructions to visit a specific website to obtain information. A much higher percentage of rural rather than urban participants agreed but felt it was difficult to apply. Rural households are less likely to have access to broadband Internet, and this was especially true two years ago when rural broadband initiatives were only just being rolled out, so this result is not unexpected. (Figure 9)

\section{Deprivation score}

A low percentage of participants across all socioeconomic areas strongly agreed that it was important to have the patient review written instructions and explain them to them. This increased to almost $40 \%$ of participants from the least deprived areas with almost all from the most deprived areas agreeing that it was somewhat important but difficult to apply. This result is probably linked to the socioeconomic gap in print literacy.

Very few participants across all socioeconomic areas agreed that showing patients in-office DVDs with instructions and information was important. Participants from the least deprived areas were most likely to agree strongly with this concept, but participants from the most deprived areas were more likely to agree but also consider the strategy difficult to apply. A lack of appropriate DVD resources in languages other than English may help to explain this difference, as there is a higher proportion of non-English speakers more deprived areas. 


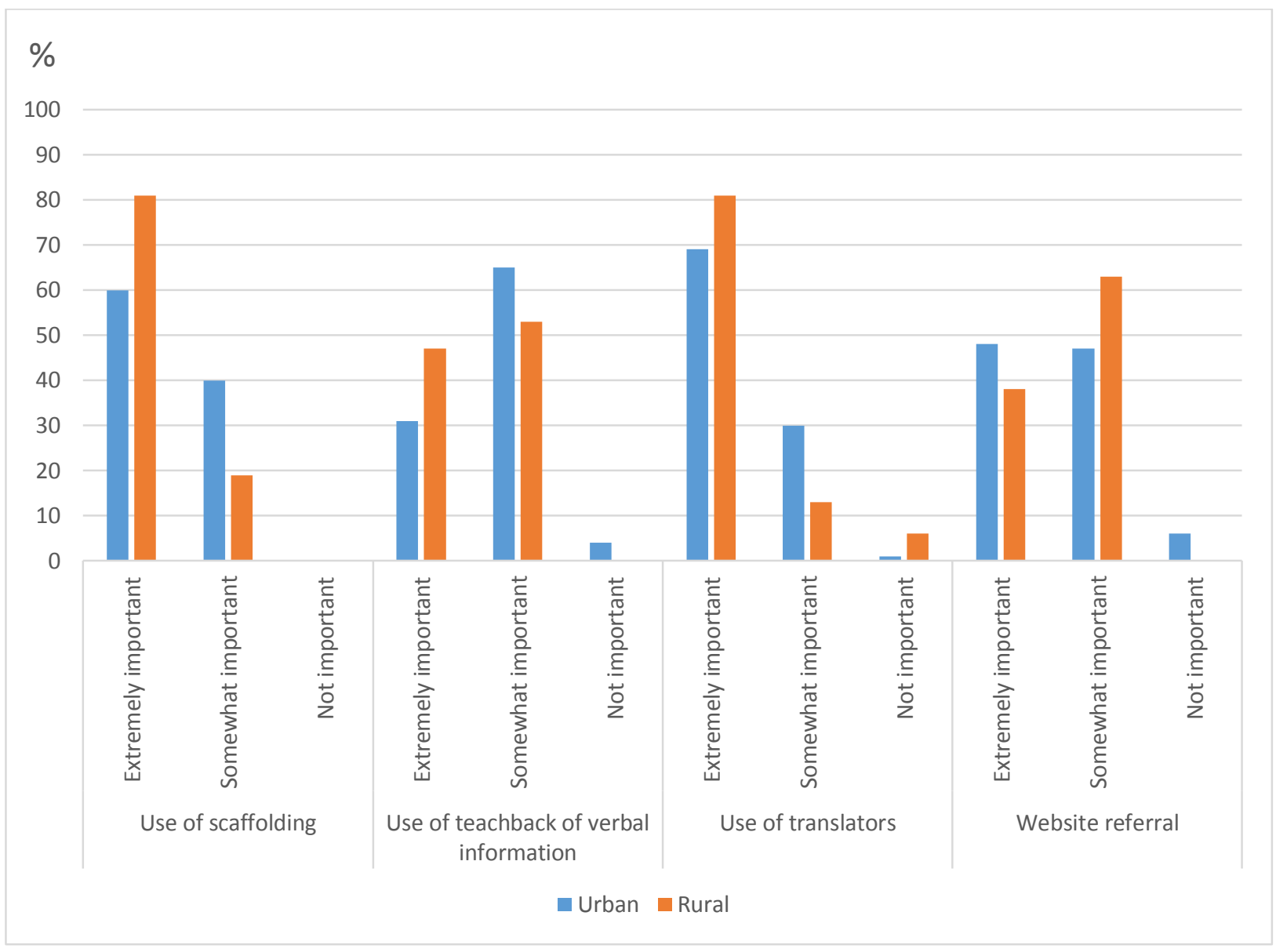

Figure 9: Urban vs Rural and Importance of Communication Strategies

Most participants, regardless of Deprivation Index score, agreed that it is important to use someone (professional or family) to verbally translate their instructions. The majority of participants from the least deprived areas agreed that this was extremely important, as compared to just over half in agreement in the most deprived areas. More deprived areas tend to have a highly multicultural population, so the reduction in importance of this strategy within this group is counter-intuitive and should be the focus of future research.

Participants from the least deprived areas were more likely to place importance on giving their patients instructions to visit a specific website to obtain information, with only a small percentage of those from the most deprived areas agreeing that this was important. Patients from more deprived areas are less likely to have access to technology within the home than those from higher socioeconomic areas, and this is reflected in this finding. (Figure 10) 


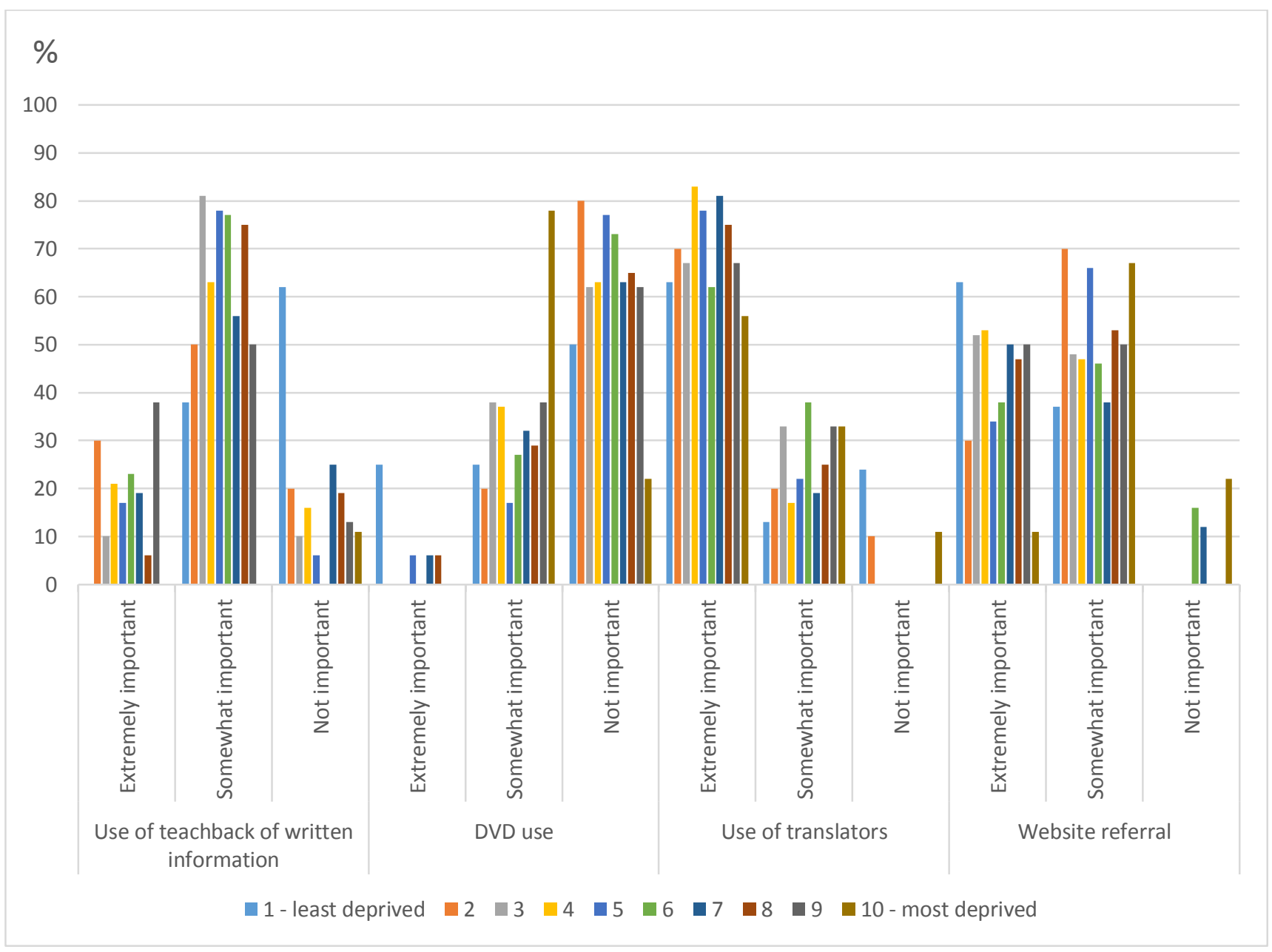

Figure 10: Deprivation Score and Importance of Communication Strategies

Age

Most participants agreed that it was important to ask a patient what they already know about their condition or treatment so that they could scaffold the new information to the patient's current knowledge, although the youngest participants put the most importance on this strategy.

Agreement with scaffolding as a strategy dropped significantly in participants over the age of 60, with over half believing it difficult to apply. The only participant to believe this not important at all was also in this age category.

Almost every participant agreed that it was extremely important to verbally present key points about actions the patient needs to do, although experience appears to be a factor here with a third of participants in the youngest age group believing it difficult to apply.

Three quarters of participants over 50 agreed that it is extremely important to get a nurse to conduct patient education using verbal instructions, compared to only a quarter of those under 40 . 
The role of the practice nurse is evolving, with many taking on more clinical responsibility within practices, and the reduction of importance among younger participants may reflect this (Merrick, Duffield, Baldwin, Fry, \& Stasa, 2012; Phillips et al., 2007).

The importance put on giving patients instructions to visit a specific website to obtain information declined with age, with those over 60 significantly less likely to place importance on this than those in the in the 30-39 age bracket. One would expect lower levels of digital literacy in older participants, and also possibly a higher level of suspicion regarding the potential quality of Internetbased information than younger digital natives. (Figure 11)

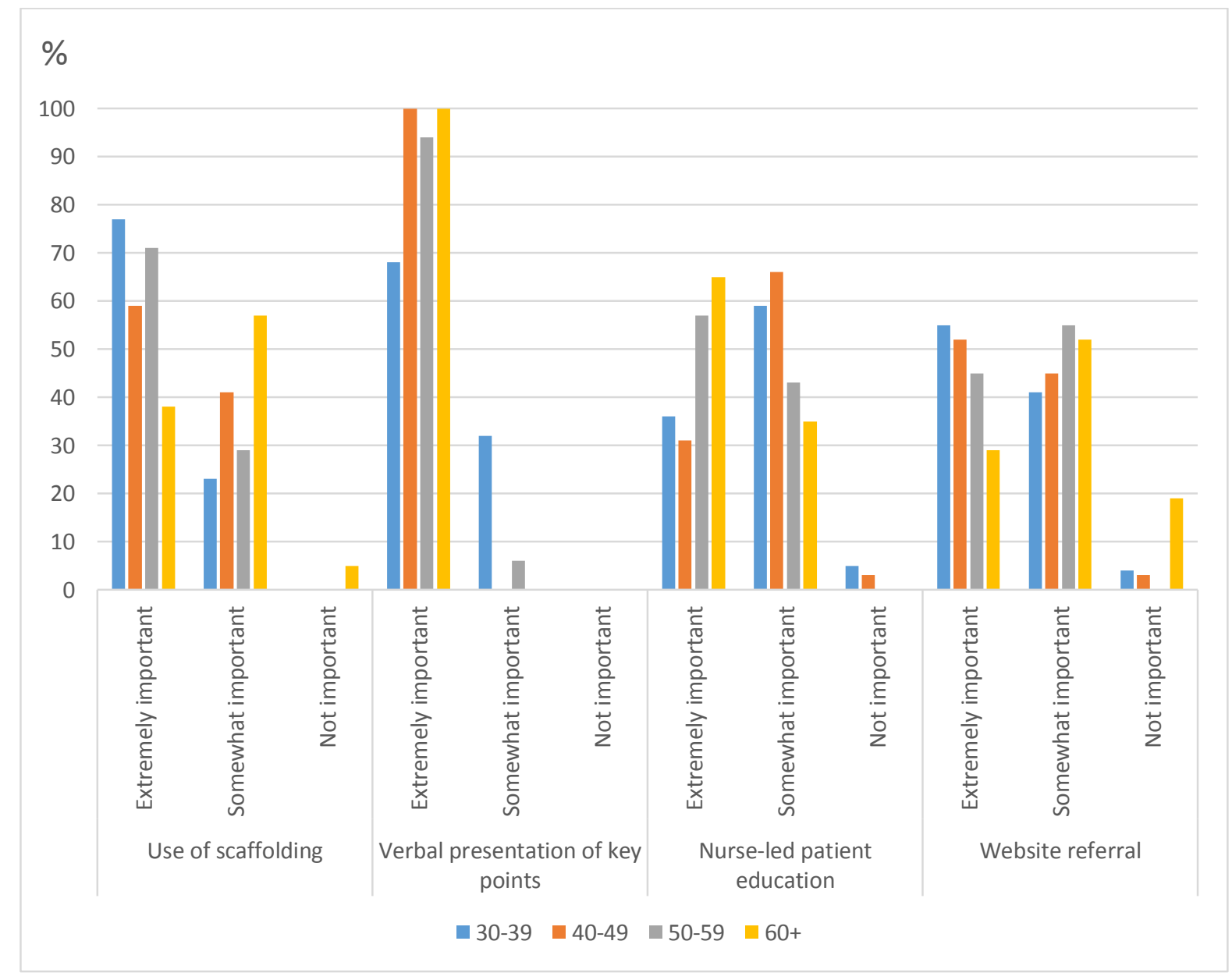

Figure 11: Age and Importance of Communication Strategies

\section{Gender}

There were some significant differences between male and female participants in their attitudes towards health literacy concepts. Females placed more support on providing patients with written materials written for a reading level of 12 years or lower than males, whereas males thought it more important to use written materials that contain pictures illustrating important points than female 
participants. Males were also more likely to believe it extremely important to get a nurse to conduct patient education using their verbal instructions than females.

Although most participants (with very little difference in gender) agreed that it was at least somewhat important to get the patient to review written instructions and explain them back to them. However, most felt this was difficult to apply in reality. This strategy was the only one that participants, especially females, were likely to judge as unimportant. (Figure 12)

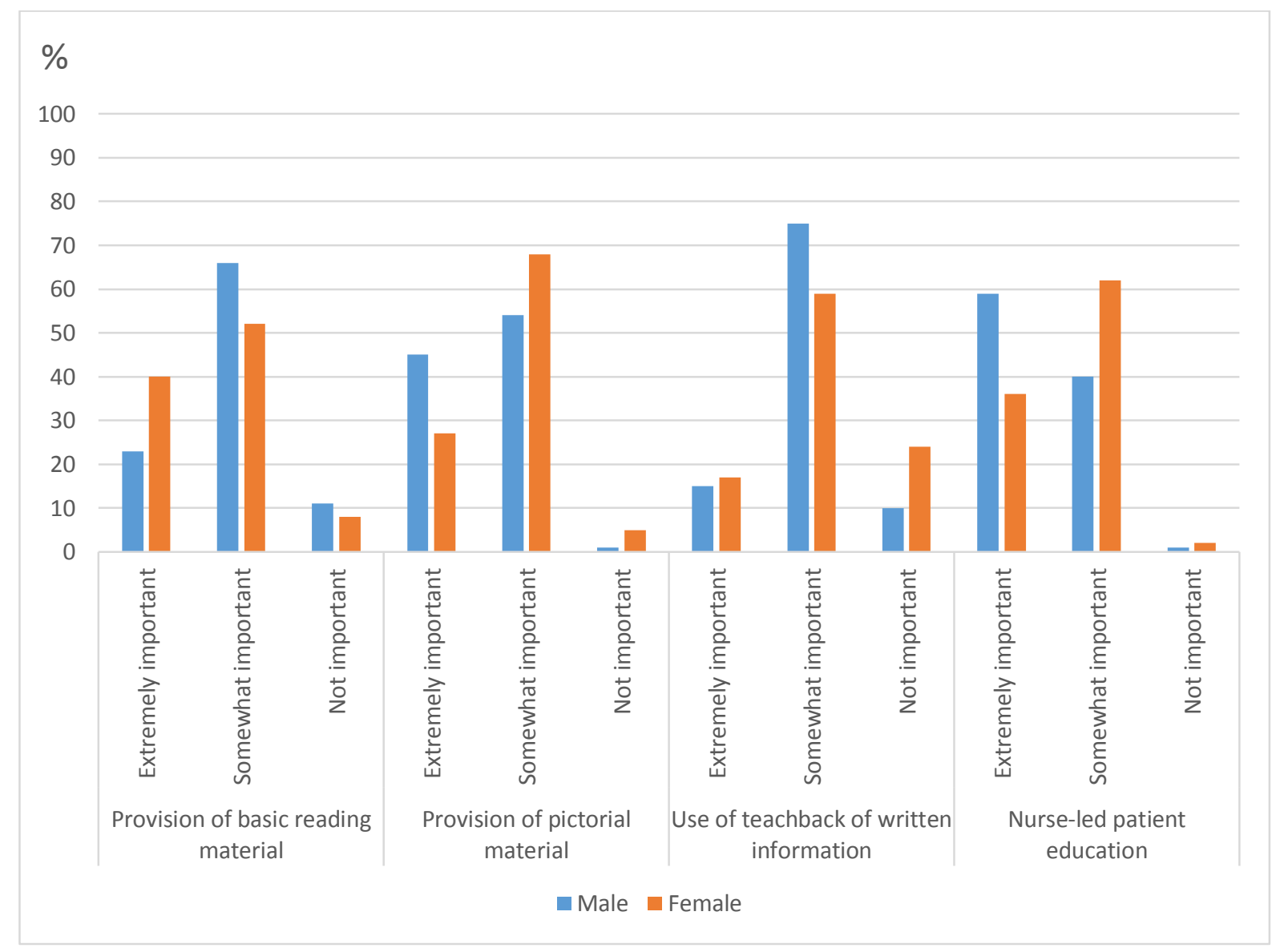

Figure 12: Gender and Importance of Communication Strategies

\section{Experience}

Participants with the least and most experience were the two groups more likely to agree strongly that it was extremely important to get a nurse to conduct patient education using their verbal instructions, especially those in the latter category. This doesn't correlate with the age-related results which found less emphasis on nurse-led education within the younger group of participants, so would be interesting to explore further. A high number of participants with 6-20 years of experience agreed that although somewhat important, this strategy was difficult to apply in reality. (Figure 13) 


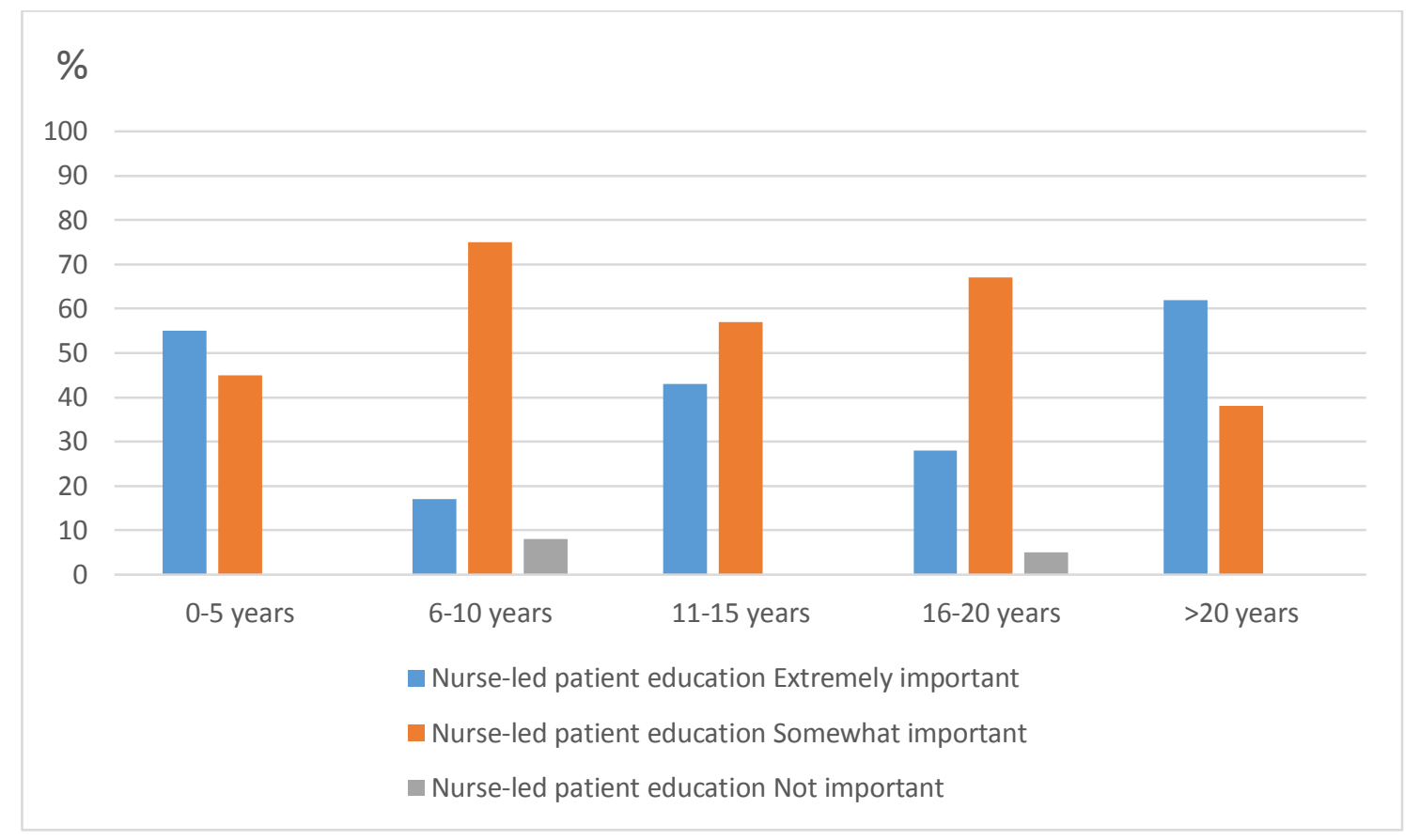

Figure 13: Experience and Importance of Communication Strategies

Length of patient consultation

Another interesting result was the lack of importance placed on getting a nurse to conduct patient education by participants who only spend 10 minutes on average with patients. Participants who on average spent more than 20 minutes with patients were significantly more likely to agree that this strategy was extremely important. It is possible that participants with an extremely large patient load also have less time to spend with patients and generally have more staff resource constraints. (Figure 14)

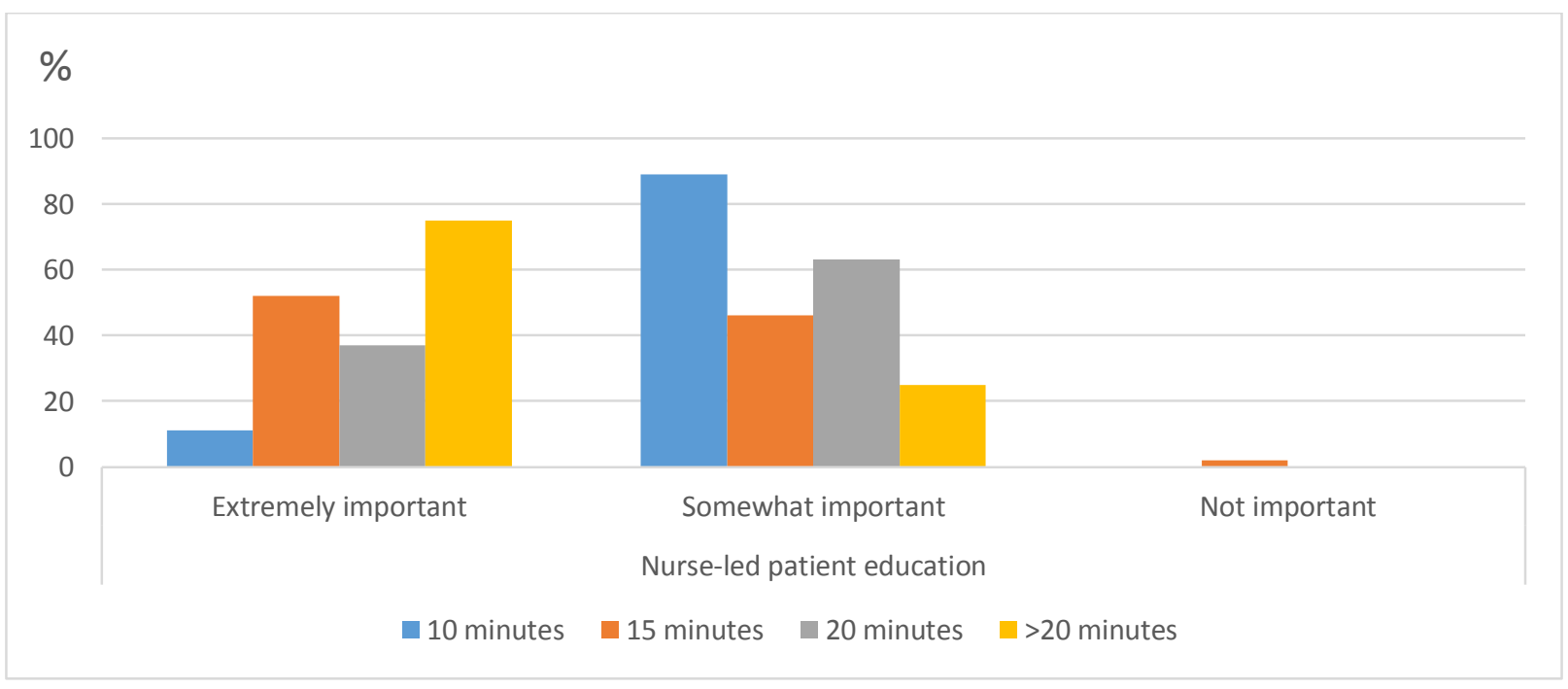

Figure 14: Length of Patient Consultation and Importance of Communication Strategies 


\section{Other strategies}

As well as quantitative data, participants were given the opportunity to suggest any other strategies for communicating information to patients who may have difficulty understanding their health status and treatment plans in an open-ended format.

Answers to these questions can be grouped in the following ways, with some comments falling into more than one group:

- Tailoring communication to the individual;

- Use of specific teaching methods;

- Some form of planned follow-up;

- Use of the Internet to support patients;

- Patient literacy as a topic.

Tailoring communication to the individual included adapting printed health education resources when there wasn't something suitable available, tailoring vocabulary (including the use of common slang terms) and using repetition, and adapting communication styles with more use of oral communication and modelling if there was any doubt about patient literacy.

The use of specific teaching strategies included: giving the patient leaflets; writing their own instructions or drawing pictures; using Google Images to assist in explanations; reviewing specialist reports with patients; considering any cognitive difficulties in individuals and explaining concepts accordingly (this included involving family or caregivers); scaffolding information from previous health experiences; asking patients to research online (including Google) and to come back with a list of questions; using health awareness DVDs in waiting rooms, and; setting up a patient health diary for future review.

Planned follow-up included patient referral to practice nurses, Pharmacists, community health professionals and community support groups, as well as the use of patient diaries and wellness plans to be reviewed later.

Use of the Internet included recommending patients use Google or general Internet searching to research their topic, referring patients to a specific website or online tool, the use of online translation tools, and several warnings about the online health information environment.

Comments about patient literacy were linked to specific strategies used, especially with regard to the use of pictures and oral communication strategies. 
Other comments didn't discuss specific strategies, but were instead more general comments about health literacy and/or patients. Topics discussed were:

- Particular constraints around the use of strategies;

- The importance of the doctor-patient relationship;

- Patient engagement or motivation as an important factor;

- Health literacy as a topic;

- The New Zealand healthcare system;

- The quality (or lack of) of New Zealand health education material;

- Unwillingness to share ideas due to commercial sensitivity.

The major constraint around the use of health literacy strategies was time (especially funded time), followed closely by lack of staff and/or appropriate health education resources. Difficulty in applying strategies due to patient literacy level or cognitive ability was also a constraint, as was the complexity of patient issues.

The importance of listening to patients, and building up trust was seen as crucial, especially with the rise of Internet-influenced patient "knowledge". A lack of patient-trust negates any education efforts by the GP.

There were several comments about patient motivation being critical, and that even well-informed patients needed to be motivated in order to make a difference to their health status.

Comments about health literacy were positive, with participants agreeing that it was good in principle, if difficult to apply due to the constraints outlined above.

Two participants pointed out that the New Zealand healthcare system was not set up to include funded time for patient education, and one declined to share ideas as they could be commercially sensitive.

Participants were also asked whether they used specific methods or tests to evaluate whether their patients struggle with literacy or have other barriers to understanding health information. Very few participants indicated that they did, and only one named a specific test, while two asked their patients about their literacy level.

\section{Familiarity with health literacy resources}

Data was then gathered to measure the specific patient communication concerns that participants may have. 
More than half of the participants who identified themselves as not being aware of resources that have been specifically created to address health literacy did however agree that they knew where to obtain the resources to help patients understand their health status and treatment plans, and most agreed that they would make use of these resources if they knew where to access them. Only a small number of participants who were aware of specific health literacy resources did not know where to obtain these resources, but this group were less likely to agree that they would actually make use of them.

Almost half of participants with knowledge about specific health literacy resources agreed that clinicians received sufficient training to provide effective care for patients who might struggle to understand their health status and treatment plans. Those who were not familiar with these resources were significantly less likely to agree with this, which correlates to their self-reported lack of health literacy knowledge. (Figure 15)

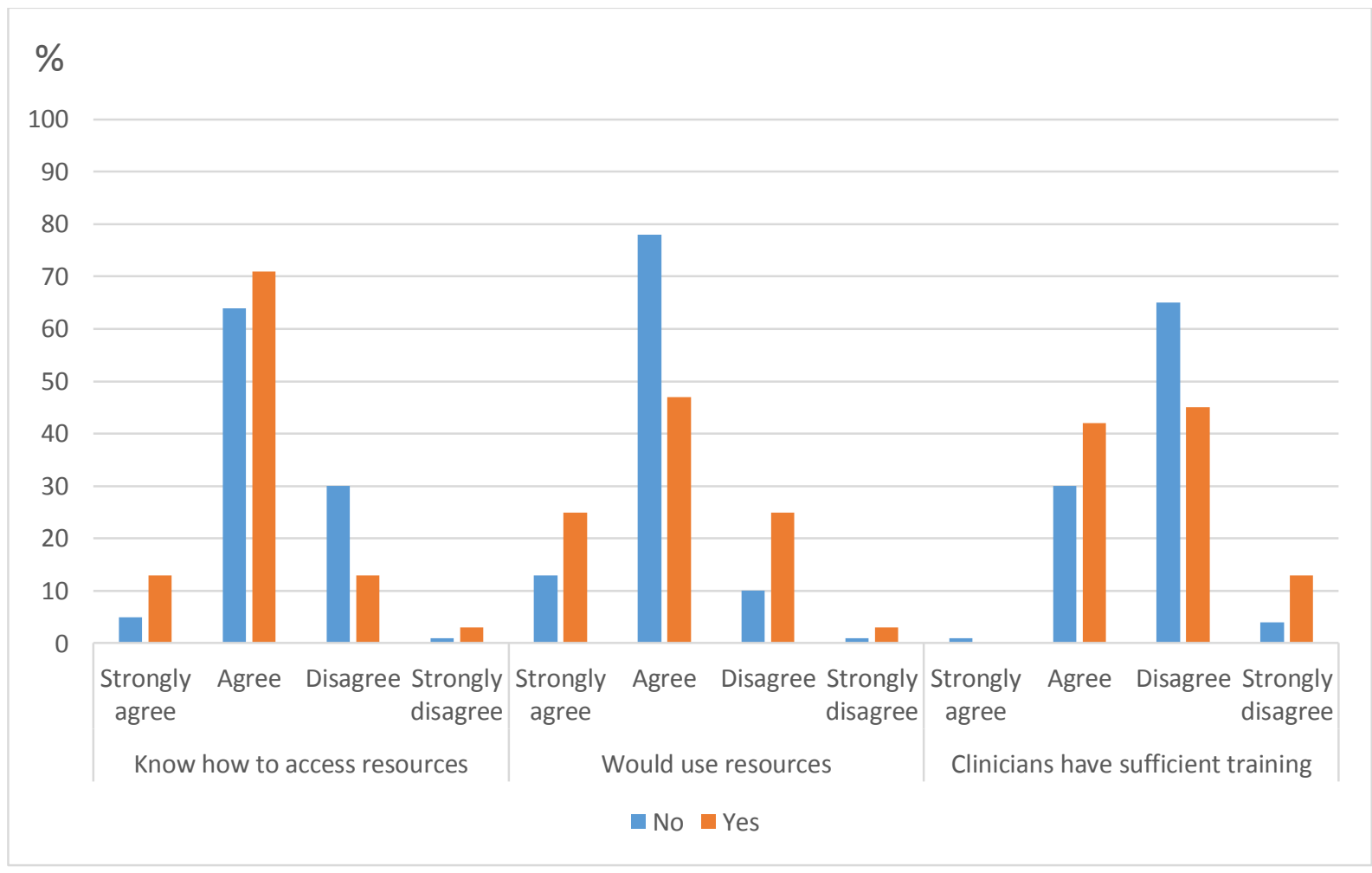

Figure 15: Resource Familiarity and Concern about Patient Communication

\section{Geographic location of practice}

There was some variety in response to the question about familiarity with the resources that can help patients who might struggle to understand their health status and treatment plans, but the three main most populated regions of New Zealand (Auckland, Wellington and Canterbury), all had 
very similar scores, with none extremely confident that they knew about them. Participants from Southland were very confident that they knew about these resources, whereas those from Northland practices all disagreed with this statement.

\section{Urban vs rural}

Rural participants believed more strongly than those from urban practices that a better informed patient is not always the most cooperative patient.

\section{Deprivation score}

There was concern across all socioeconomic areas that their patients may not understand their health status and treatment plans, especially from participants from the most deprived areas, where over half agreed with this statement. The level of concern was lower in the least deprived areas, although one quarter still agreed with the statement. (Figure 16)

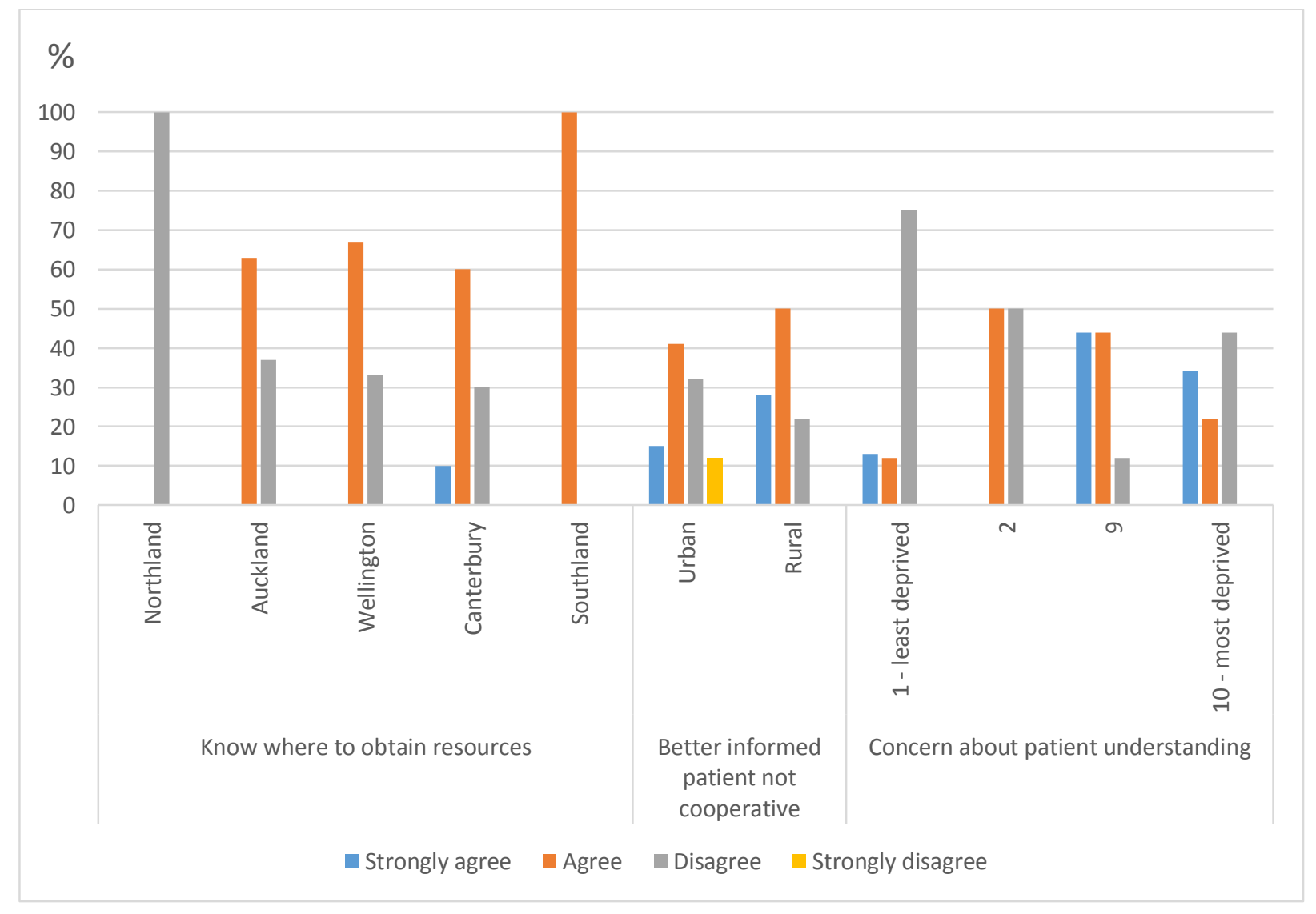

Figure 16: Geographic/Demographic Differences and Concern about Patient Communication 


\section{Gender}

Male participants were more likely to be concerned that their patients would not understand their health status and treatment plans, believe that most patients struggle to communicate effectively in their practice, speak English as a second language, and also consider that that their appointment times allow them the flexibility to spend more time explaining information to patients when needed. In contrast, almost all female participants were confident that they knew where to obtain resources to help patients understand their health status and treatment plans (i.e. compared with just over half of the male participants). The lack of flexibility indicated by female participants could be due to a higher level of family commitments. (Figure 17)

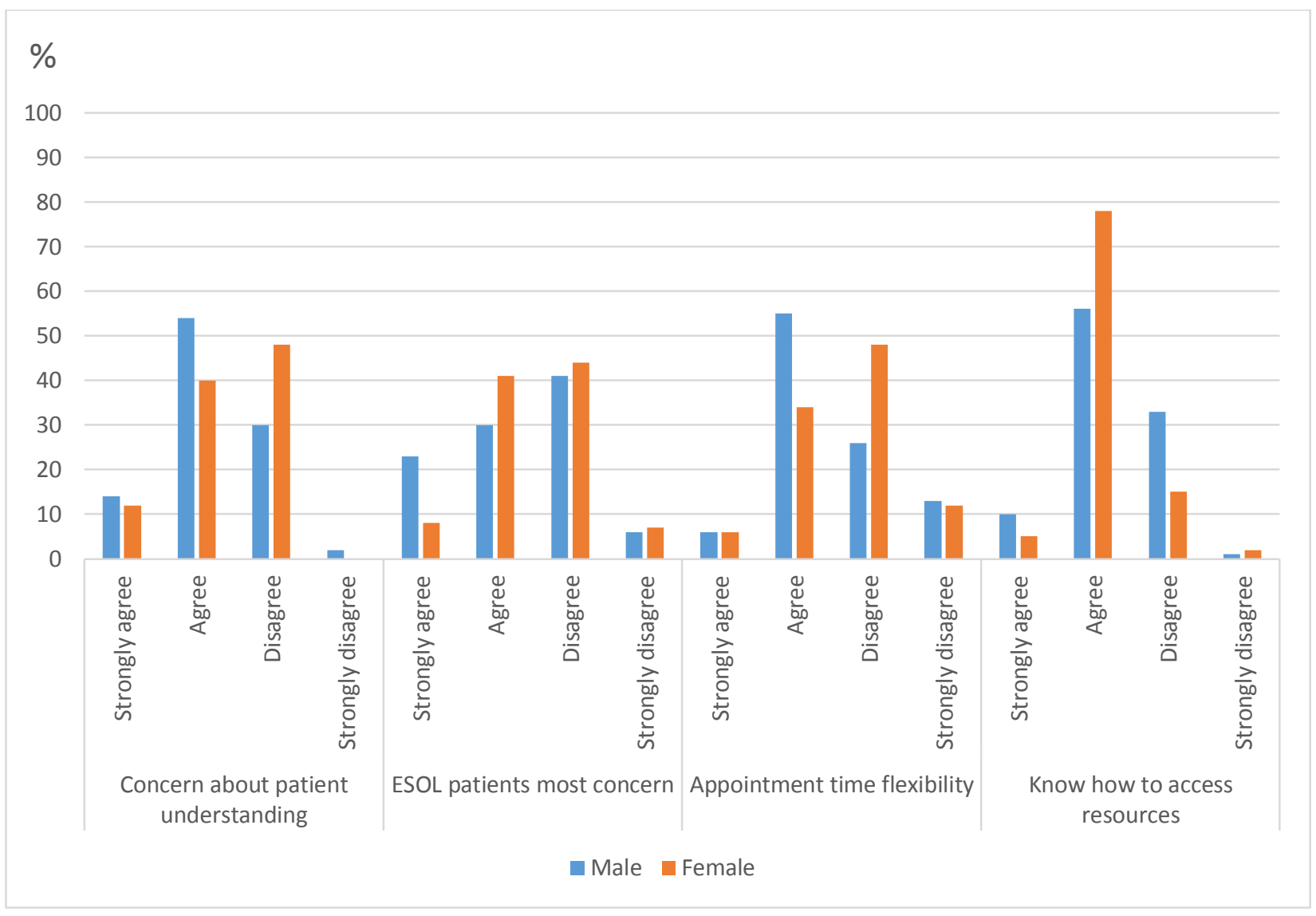

Figure 17: Gender and Concern about Patient Communication

There were also some interesting differences between age, experience and length of patient consultation time. (Figure 18)

Age

There was a strong correlation between flexibility in appointment times and age, with flexibility increasing considerably with each decade. 
Only half of the participants agreed or strongly agreed that their appointment times allowed them the flexibility to spend more time explaining information to patients when needed, with most of these being in the older age brackets.

\section{Experience}

Only half of all participants, regardless of experience, agreed that their appointment times allowed them the flexibility to spend more time explaining information to patients when needed. Only one third of participants with less than five years of experience agreed, compared with almost three quarters of those with more than 20 years of experience as a GP.

\section{Length of patient consultation}

Length of consultation also impacted concern about patient communication, with a sharp increase in agreement that most patients who they struggle to communicate effectively with in their practice speak English as a second language in participants with longer appointment times.

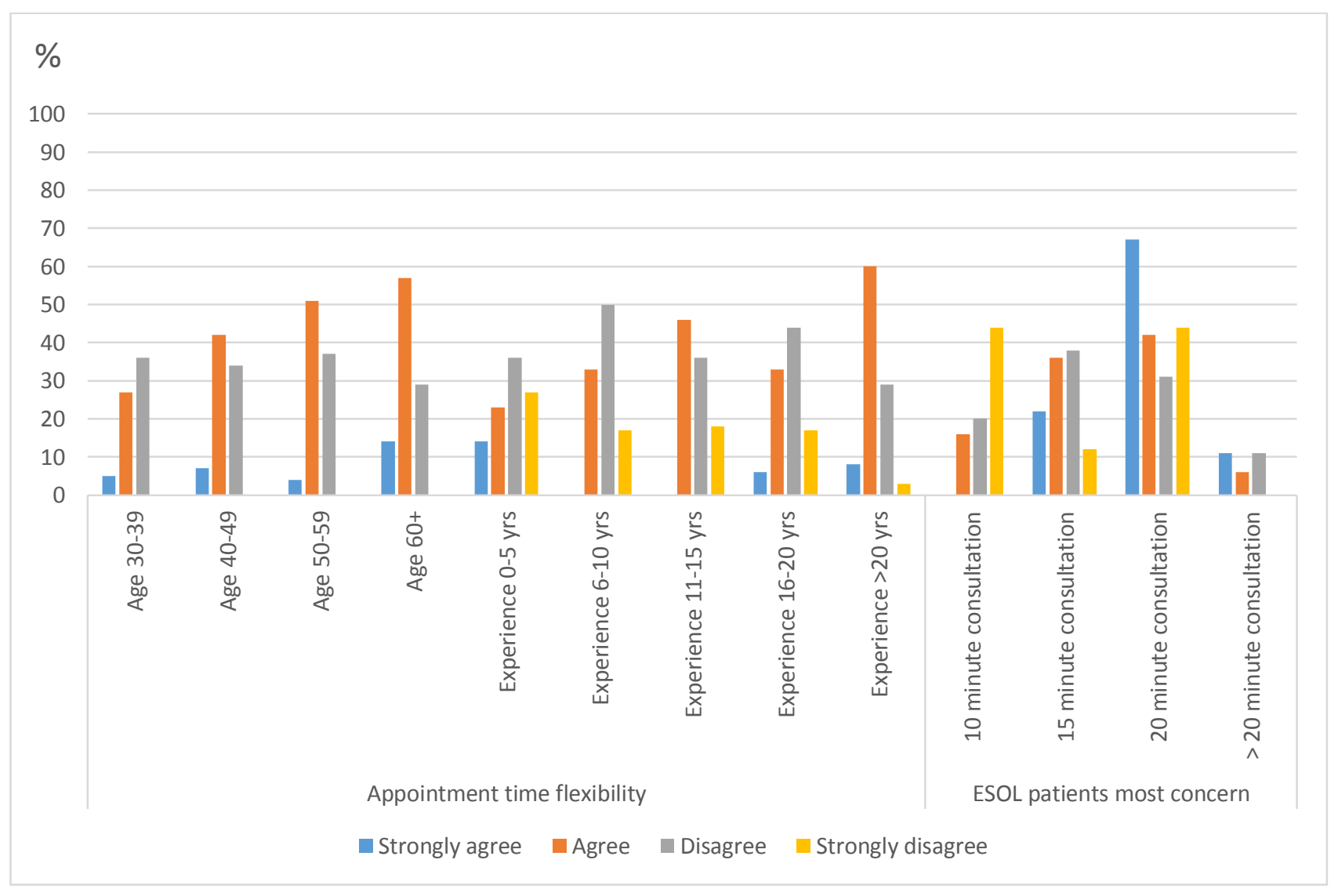

Figure 18: Other Factors and Concern about Patient Communication 


\section{Health Literacy Knowledge}

Quantitative statistics related to health literacy resource knowledge have already been outlined in the overview, but participants were also asked to specify any resources they are familiar with that have been specifically created to address health literacy.

Resources identified fell into the following categories:

- Patient education material including:

○ Printed pamphlets or resources;

○ Websites;

- Health literacy strategies;

- General comments about health literacy.

Most of the 15 participants who commented about print resources identified printed pamphlets or resources as a general resource, although three specified materials in other languages and three materials with pictures. Six of the participants identified Google or the general Internet, while 11 identified specific patient-education websites, often provided by a professional general practice organisation. One participant expressed concern about the quality of health information without specifying its origins, and two warned that the skill of the educator was the vital factor in successful learning outcomes.

Health literacy strategies were only mentioned in a few comments, including the use of literacy assessment tools, the use of translation services and the inclusion of family in consultations when a patient is neurologically compromised. Two participants identified adult literacy programmes, and one identified DVD materials as a tool to support patients with low print literacy.

Four participants stated that they were unfamiliar or only had a very vague awareness around health literacy strategies, although one thought the concept sounded interesting.

Participants were also asked whether they used any of these resources in their practice, and were asked to describe these resources, how useful they find these resources in helping patients understand their health status and treatment plans, and how they found out about them.

Most participants who answered this question identified themselves as being familiar with health literacy resources, although several were not sure. Most of the resources identified were patient education materials, including printed or handwritten instructions or information (including diagrams or pictures), online information and printed medical notes. Only six mentioned explaining information or tests to patients, and also only six mentioned that they referred patients to either nurse or allied health professional led patient education or support groups. Those that did say that 
they used health literacy resources said that they found them very useful, although 28 were not sure how useful they were as they didn't gather any data to evaluate patient learning. Printed information was identified as the most useful, followed by information that had been specifically tailored for the patient or circumstance. Websites, the use of pictures or diagrams, reinforcement or repetition of instructions and the use of verbal instructions were also seen to be useful teaching strategies.

Resource constraints were identified as the main reason that participants didn't find health literacy resources useful, and those who were not sure did admit that these resources could be of some or limited use.

Most participants discovered health literacy resources via their colleagues or the relevant professional organisations. Professional reading, attendance at Continuing Medical Education (CME) meetings, and medical school or postgraduate education were the formal methods identified. Other methods of discovery were unsolicited mail (unspecified or drug company advertising), use of the Internet to deliberately search for resources and also random discovery when looking for something else. Six cited experience as the source of their health literacy knowledge.

\section{Attitudes towards health literacy}

In order to gauge New Zealand GP's attitudes towards the concept of health literacy, participants were asked whether they strongly agreed, agreed, disagreed or strongly disagreed with a number of relevant statements. Once again, there were some interesting differences between demographic groups.

\section{Familiarity with Health Literacy Resources}

Participants who were not familiar with resources that had been specifically created to address health literacy were a lot less likely to strongly agree that improving the health literacy of New Zealanders is a vital step to improving the quality of health care and health outcomes than those who were familiar with them. This group of participants had a higher level of disagreement that low health literacy is only an issue for clinicians practising in areas where there is a high percentage of ethnic minorities, but were more likely to agree that low health literacy is a problem because people are not able to understand the value of preventive health measures than those familiar with the resources.

Participants who were familiar with health literacy resources were significantly less likely than the other group to agree that clinicians don't explain health information in a way that meets the unique learning needs of the patient, which would be interesting to explore further. (Figure 19) 


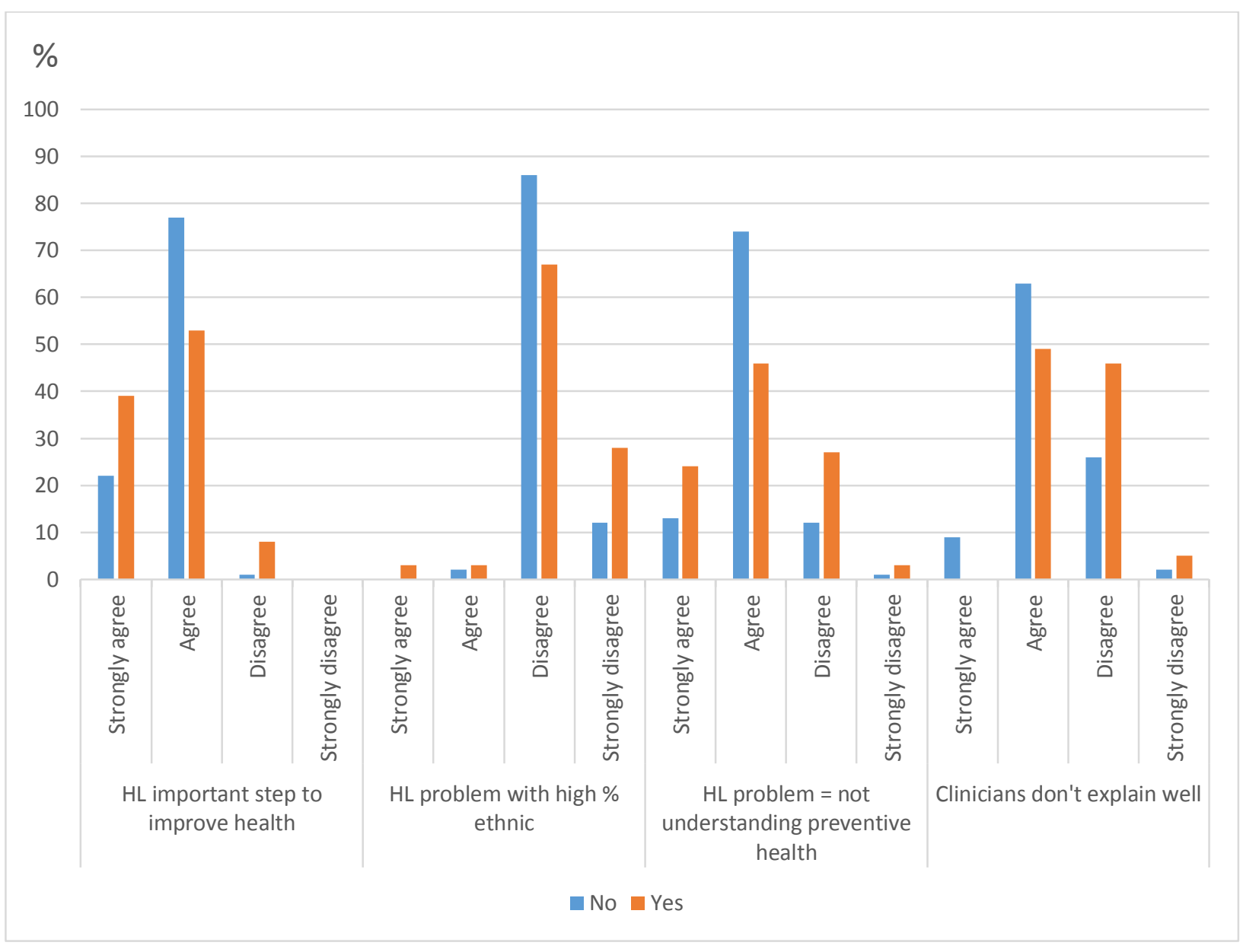

Figure 19: Health Literacy Familiarity and Attitude to Health Literacy Concepts

\section{Geographic location}

Most participants disagreed that health literacy blames the victim for a deeper sociocultural problem, especially those from Northland, Otago, Auckland and Canterbury. Participants from Hawkes Bay and Waikato were the only groups who agreed with this statement. Most of the participants from Hawkes Bay also strongly agreed that teaching health literacy to help consumers negotiate the health care system fails to address the larger problems underlying the New Zealand health care system, a statement all other group disagreed with. (Figure 20)

\section{Urban vs rural}

There were no significant differences in responses between participants from urban vs rural practices. 


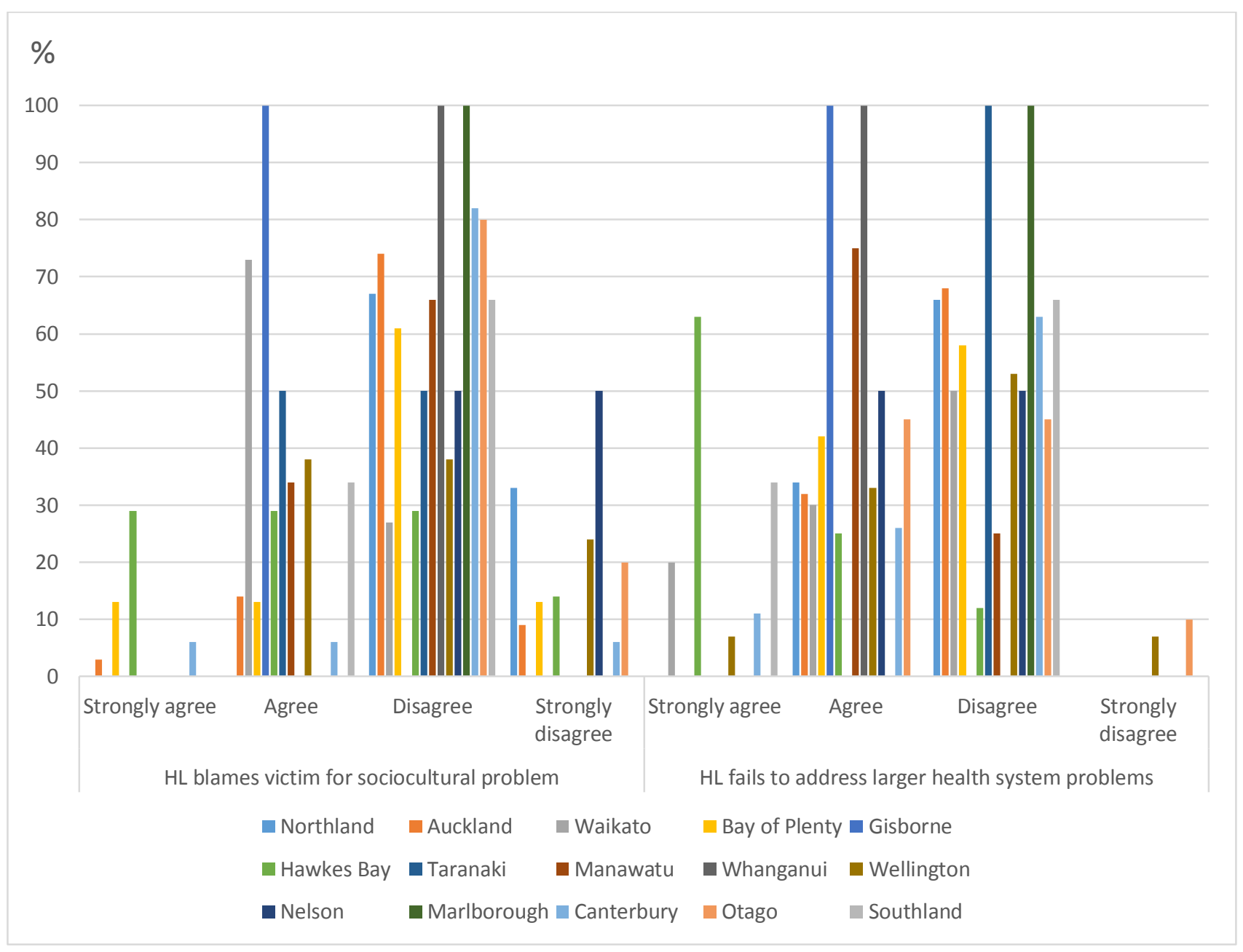

Figure 20: Geography and Attitude to Health Literacy Concepts

\section{Deprivation score}

Participants from the least deprived socioeconomic areas were slightly more likely to agree that well-educated people have adequate health literacy than those from the most deprived group and were more likely to disagree that low health literacy is only an issue where people have complex treatment regimens. Although most participants agreed that health literacy educational results will not be immediate but will take a generation or two to effect cultural changes, there was a significant decrease in agreement as deprivation increased.

There was also a difference in attitude towards the statement that teaching health literacy to help consumers negotiate the health care system fails to address the larger problems underlying the New Zealand health system, with the groups from the most deprived areas more likely to agree than those from less deprived areas. (Figure 21) 


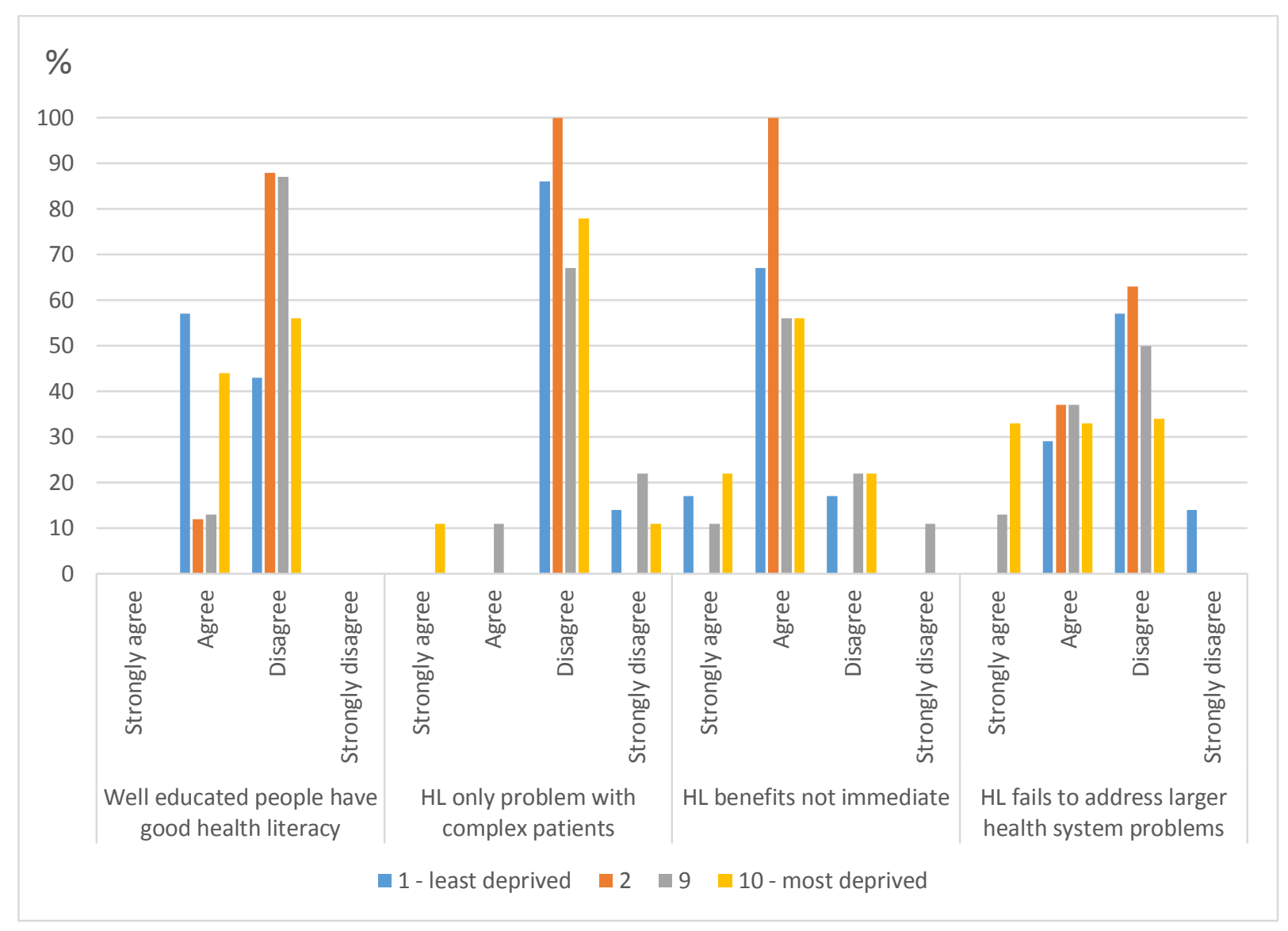

Figure 21: Deprivation Score and Attitude to Health Literacy Concepts

\section{Gender}

There was little difference between male and female participants in response to the statement that well-educated people have adequate health literacy, although females were slightly more likely to agree.

Age

Although participants of any age generally agreed that low health literacy is a problem because people are not able to understand the value of preventive health measures, those over 60 were a little less likely to agree with this statement. The younger age groups were also more likely to agree that health literacy interventions should focus on better matching the reading level of the patient with the readability of the materials he or she is expected to understand. Most of the participants who disagreed with this concept were over the age of 50.

Most participants agreed that health care costs would be reduced as a result of improving health literacy, especially the youngest cohort, with level of agreement with this statement again dropping overall with age. (Figure 22) 


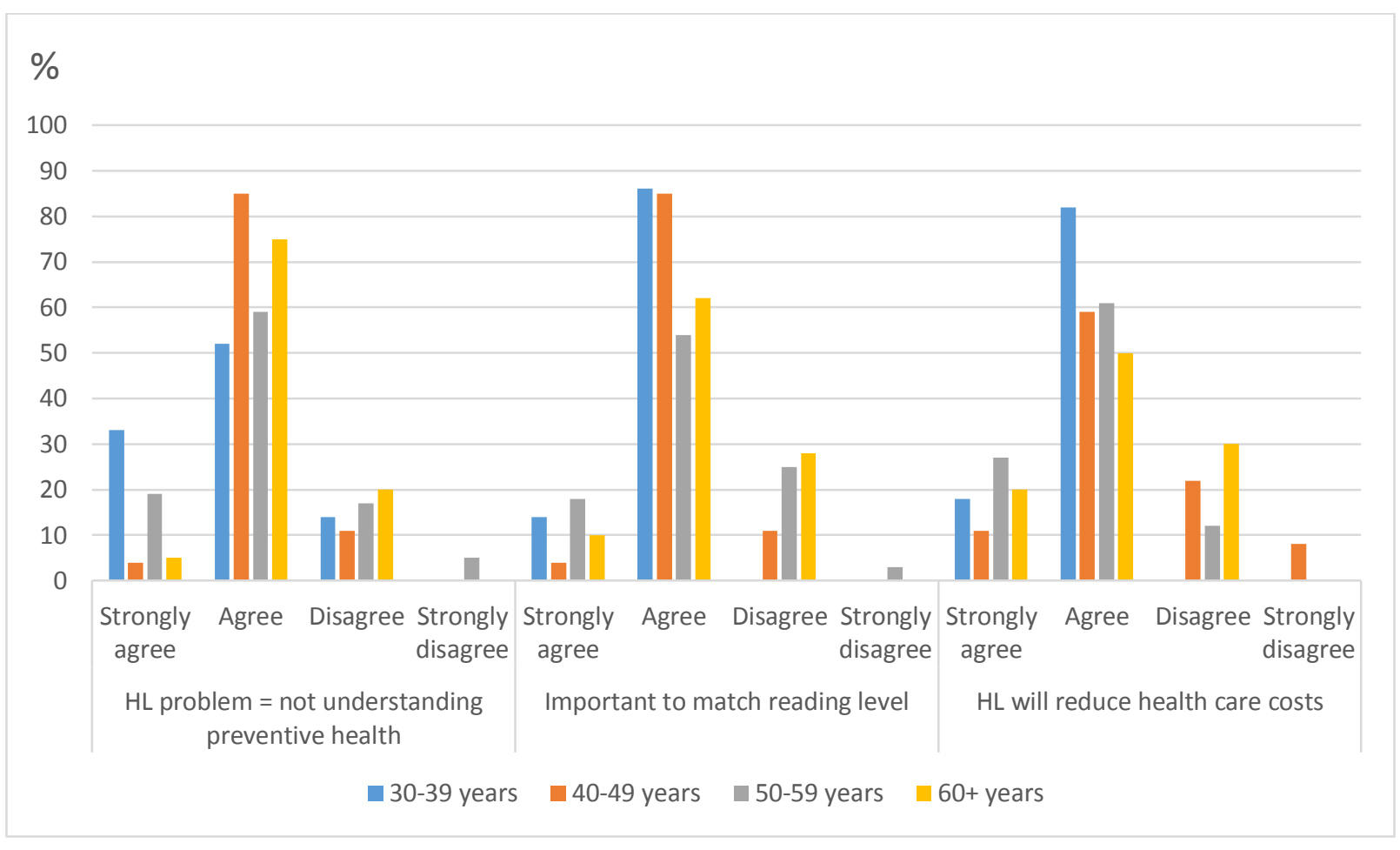

Figure 22: Age and Attitude to Health Literacy Concepts

\section{Experience}

Participants with all levels of agreed that health care costs will be reduced as a result of improving health literacy, although those with less experience were more likely to agree with this statement than those with more than 15 years of experience. Most participants also agreed that health literacy educational results will not be immediate, but will need a generation or more to effect cultural changes, but in this case those with less than five years of experience were less likely to agree.

Almost all participants regardless of experience agreed that health literacy initiatives should focus on increasing the use of plain language in all consumer instructions and communication about health. Participants with the least experience were the most positive about this statement, and those with 6-10 years of experience, the least positive.

Participants with 11-20 years of experience were the groups least likely to agree that health literacy should be conceptually conceived as improving a consumer's basic medical knowledge, although those with more than 20 years of experience were more likely to strongly agree. Cynicism in participants with moderate experience seems to be a trend, and this would be interesting to explore further. (Figure 23) 


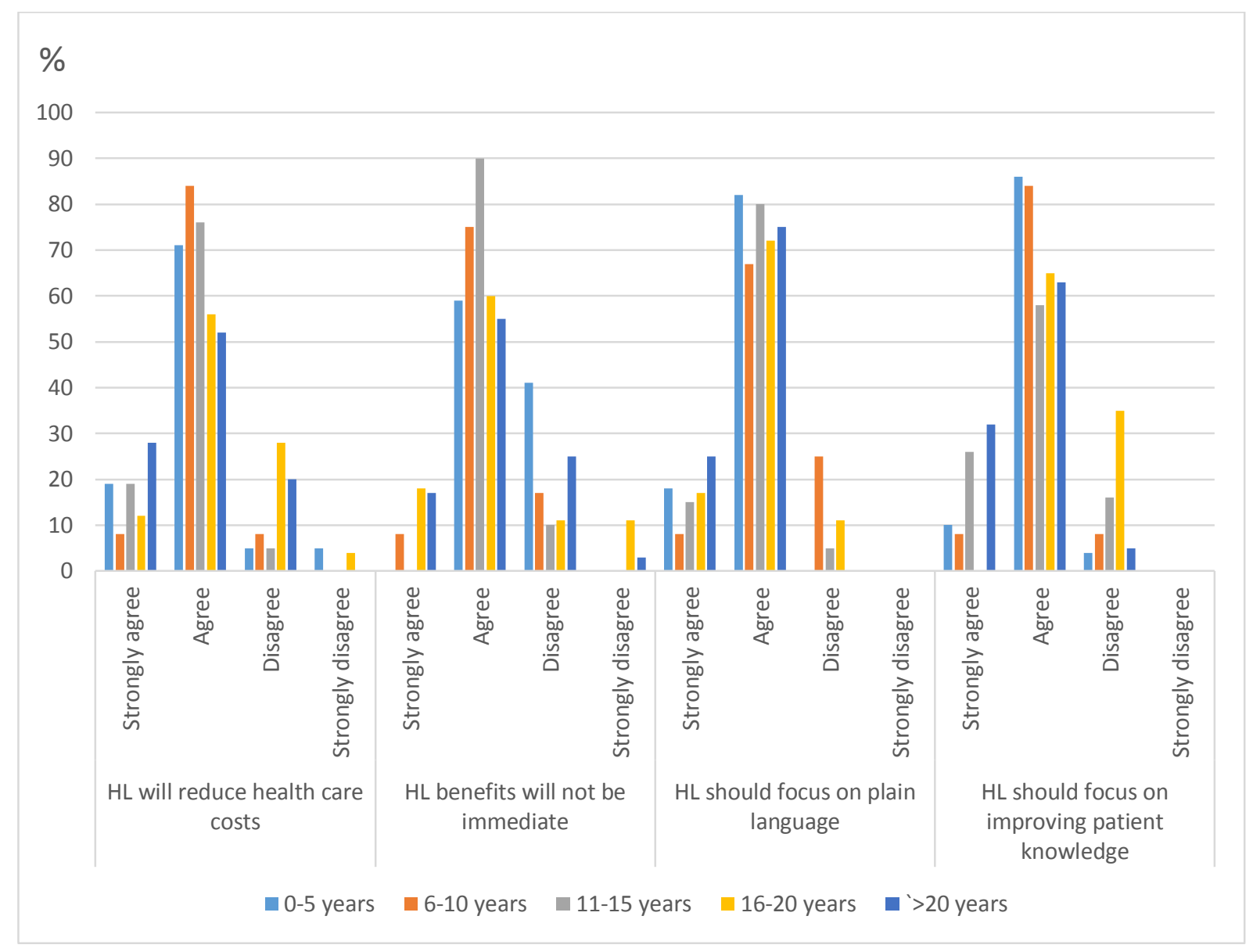

Figure 23: Experience and Attitude to Health Literacy Concepts

Length of patient consultation

Participants from the busiest practices were less likely to agree that low health literacy is a problem in New Zealand, with less than half of those who only spend 10 minutes on average with each patient agreeing with this statement. This rose sharply to agreement in almost all participants who had longer average consultation times. Participants with more than 20 years of experience were also most likely to disagree with the statement that well-educated people have adequate health literacy, with the least experienced most likely to agree with this. Those with five or less years of experience were the most likely to disagree that health literacy blames the victim for a deeper sociocultural problem. (Figure 24) 


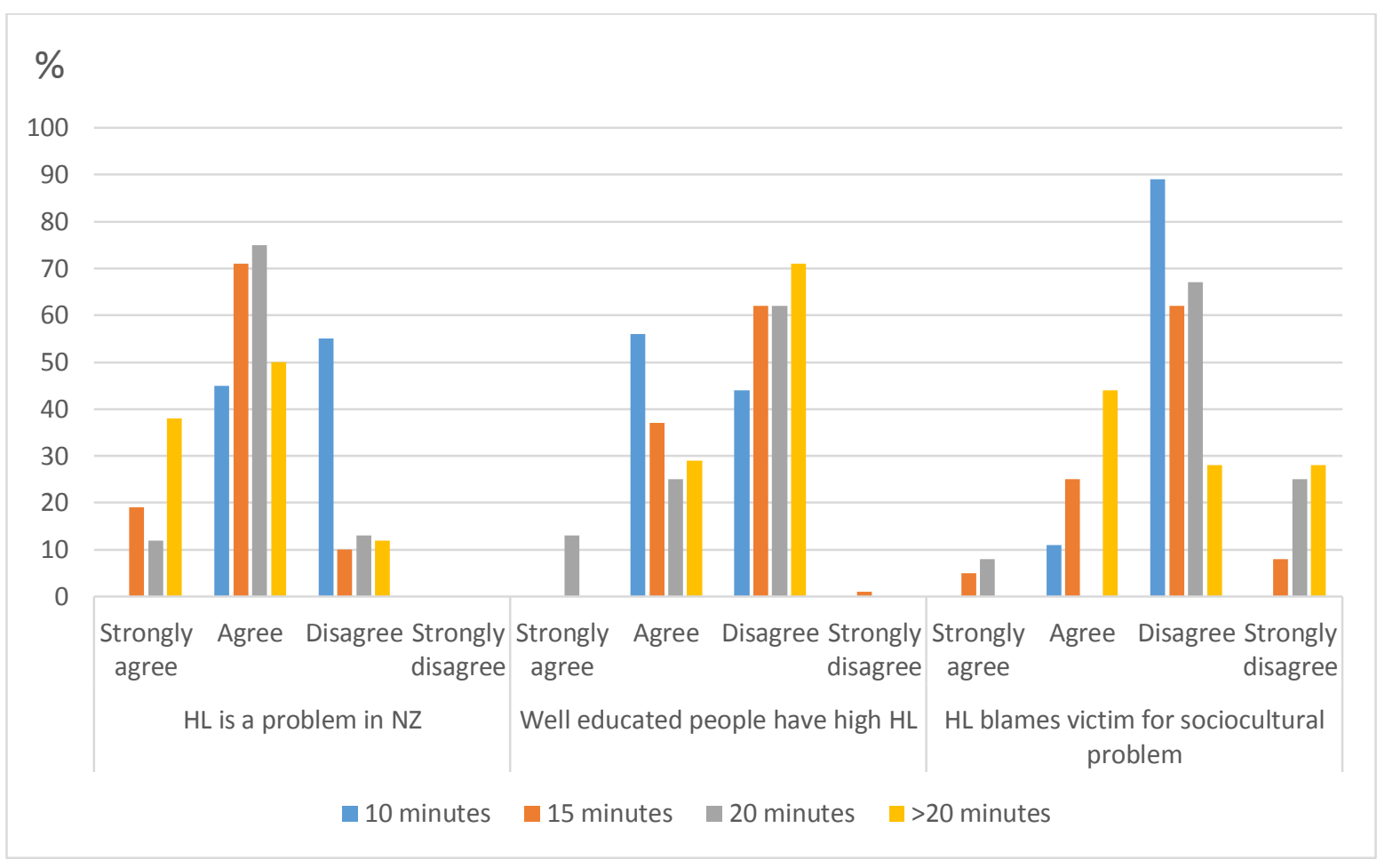

Figure 24: Patient Consultation Length and Attitude to Health Literacy Concepts

General comments

Finally, participants were invited to add any other comments. Much of this comment related to previous questions or the survey design itself.

Comments could be divided into the following groups:

- Health information quality;

- Health literacy as a concept;

- Practitioner health literacy knowledge vs practice reality;

- Demonstrating either a limited or good understanding of health literacy as a concept;

- General research advice and survey feedback.

Participants commented about the mixed quality and often conflicting and confusing nature of health information, both in print, on the Internet, and in advertising (both print and television advertising). One participant claimed there was no appropriate material available at the 12 -orunder reading level, and another would use health education material if it was better. Two participants mentioned that the volume of information, especially on the Internet, led to more confusion, especially if it wasn't relevant to New Zealand, or conflicted with other information they had been given. 
Comments about health literacy as a concept were generally positive, but this was usually attached to further comment about constraints. Some comments about health literacy encompassed patients and their knowledge and behaviour, with several declaring frustration about knowledge everybody should already know about lifestyle and health behaviour. These comments ranged from claiming poverty is a choice, to emphasising that cooperation and engagement are the most important aspect of health literacy. These responses also included the comments that a high level of education doesn't mean high health literacy. Others however commented that a lack of literacy was a barrier to health literacy, while a couple declared that a lack of health literacy was not a problem in their practice as their patients tended to be highly educated. One participant commented that high health literacy increased healthcare costs, as this group of patients had higher expectations around appropriate tests and treatments. Although literacy testing is uncommon among participants, there was a significant level of interest in this concept.

Although participants were often in support of using health literacy resources and tools, there were many comments about the difference between knowledge of these resources and the realities within GP practices. Once again, an emphasis on the importance of building a relationship between patients and health providers was commented on, and the difficulties of doing this with time and funding constraints. This was seen as a healthcare system failure, rather than an issue with the practice management itself. Four participants did comment that although health literacy was a directive within their PHO, this was neither promoted nor audited in any way. A couple of participants felt that health literacy was part of the practice nurse's role, although one felt that they also didn't have sufficient training to be able to utilise the resources effectively.

There were a range of comments that demonstrated either a good level of knowledge or a lack of knowledge around what is meant by health literacy. Nine participants made comments that indicated that they were familiar with the complexity and definition of health literacy. These included comments about the broadness of the concept, that some people were health literate in some aspects but not others depending on their personal situation and is not related to their educational status. Comments about healthcare system limitations also included mention of lack of funding to reduce inequalities and empowering people. There was some frustration evident in these comments because they recognised that programmes to address these problems, especially at a community level, are proven to work. There is therefore a belief among this group of participants that health literacy efforts are doomed to either fail or be minimal in their impact. Comments that indicated a lack of familiarity with the concept of health literacy tended to view health literacy as 
patient literacy in relation to printed health education materials. This group often displayed good health literacy practices, including a recognition of the importance of good communication skills and patient engagement, but didn't recognise these as part of health literacy. Five commented that they didn't need to test literacy as they just "knew" whether their patients were literate or not. The remainder of the comments concerned the research itself, and the quality of the survey. Comments about the research were mostly supportive, although some expressing doubt about its impact. Most of the survey comments were about the need to include a "neither agree nor disagree" or "don't know" option, and the difficulty some participants had in answering some of the questions without this option.

\section{Discussion}

The findings reported in this study revealed that generally GPs were unfamiliar with the tools and resources available to support them in health literacy. If they did have an awareness, their concept of health literacy was limited and focused on the general literacy level of their patients. Health literacy tools named tended to be in the form of print and online health education materials. Reassuringly, many GPs did use health literacy tools, but were not aware that they were in fact using them. These included the use of health care plans, a focus on good communication with their patients, and using plain language. Several GPs expressed concern that there shouldn't just be a focus on literacy, but that communication was also vital.

Health literacy as a concept did seem to be supported, although there was significant cynicism about its effectiveness, mainly due to health system constraints.

\section{Relationship among health literacy knowledge, practice and demographic factors}

GPs who did claim an awareness of health literacy tools were generally from the northern parts of the North Island. At the time this survey was carried out, Auckland-based adult literacy consulting group Workbase Ltd had been actively educating GPs and pharmacists in health literacy, mainly in Northland, Auckland and Waikato, which may explain this apparent geographical trend. Although the majority of participants from these northern regions of New Zealand did claim familiarity of health literacy, none agreed strongly with the specific statement "I am familiar with the resources that can help patients who might struggle to understand their health status and treatment plans". From the main centres, Wellington participants claimed the least knowledge about health literacy tools and resources to support their practice, but most agreed with the statement outlined above. This indicates that Wellington participants may be using these tools, but don't understand the concept of health literacy as fully as those who have been specifically targeted for training to date. 
Participants who identified their practices as rural also identified as having a higher awareness of health literacy resources, and this was demonstrated by the extreme importance most put on the practice of scaffolding new information onto the patient's existing knowledge, the use of "teachback" or getting the patient to review instructions and other important information back in their own words, and the use of translation services. Participants from rural areas put less importance on referral to websites, but this may reflect the slow or non-existent connections found in many rural areas in New Zealand. Rural participants were also more likely to agree that better informed patients could be less likely to be cooperative than those from urban practices.

Participants with practices located in areas with a higher Deprivation Index score were more likely to claim knowledge of health literacy resources than those from less deprived areas. This was demonstrated by a slightly higher use of "teach-back" when giving the patient written resources, a much higher interest in the use of non-written materials, for example DVDs, a much higher concern about their patients' understanding, and a strong belief that health literacy fails to address larger health care system problems. These beliefs and use of strategies reflects the documented health inequalities found within lower socioeconomic groups.

Age also had a strong correlation with health literacy knowledge and practice, with a definite upwards trend between the ages of 30 and 59. The knowledge level declined in those over the age of 60. Those in older age groups were more likely to place importance on the presentation of key points to their patients verbally, were much more likely to use a practice nurse to deliver patient education, had a significantly higher likelihood of flexibility within their consultation time, less likely to take reading level into account and to believe that health care cost will reduce as a result of raising health literacy. Participants in the oldest age category are possibly more likely to have both trained and practiced within an environment of "Doctor as God" and patients were less likely to have researched their conditions and treatment plans. Many of this group also were not in full-time practice, so possibly had more time to devote to patients on a one-on-one level. Literature supports younger clinicians as being more focused on clinical aspects of practice due to their relative inexperience, although this result doesn't reflect the rise of health literacy teaching within medical schools.

There was little difference in the rate of knowledge between male and female participants, although there was some difference in the use of or belief in some of the strategies. Female participants were more likely to put extreme importance on the provision of basic reading materials, although put less importance on the provision of pictorial material. They were more likely to know where to obtain resources to support their patient's understanding, and more likely to believe that health literacy is a 
problem due to a lack of preventive healthcare understanding. Male participants were significantly more likely to put extreme importance on patient education by practice nurses, were more likely to be concerned about their patients' level of understanding and were far more likely to be able to have flexibility in their appointment times. The difference in time flexibility may be a reflection of the balance between work and family, with female participants perhaps more likely to have primary responsibility for children and/or other dependents.

The amount of experience participants had as a GP was also reflected in the results, with those with more than 20 years practice experience more likely to claim knowledge of health literacy tools than those with less than five years practice experience. Those with less experience were significantly less likely to have appointment time flexibility, more likely to agree that higher health literacy will reduce healthcare costs and less likely to agree that it will take time for health literacy efforts to make a difference. It would be interesting to explore this trend in more detail in future studies.

The average length of the consultation time reported contributed to the most significant differences in knowledge about and practice of health literacy. Participants who reported longer average consultation times were more likely to believe patient education delivered by the practice nurse is extremely important. Furthermore, they are significantly more likely to strongly agree that patients who speak English as a second language have more communication problems and that low health literacy is a problem in New Zealand. None of the participants who only spend an average of ten minutes per patient strongly agreed in the importance of this concept, although almost half do agree that it has some merit. Participants who report longer appointment times are also more likely to agree that health literacy blames the victim for a wider sociocultural issue with very few who spend only ten minutes agreeing with this statement. Consultation time constraints are usually driven by external factors like funding, or a shortage of GPs, so it is likely that participants with shorter reported consultation times have no time to think beyond essential clinical care.

Commentary in the open-ended questions mainly fell into two topic areas: identification of health literacy resources as patient education resources, or that health literacy is a good idea, but there are limitations to how much it can address health inequalities due to the way the New Zealand health system is set up.

Resources designed to support health literacy were very much interpreted as resources to support patient in understanding their condition or treatment, rather than resources to support GPs to communicate effectively with their patients or to increase health, engagement and empowerment within communities. Health literacy literature and definitions very clearly utilise the wider interpretation of the topic, so these results suggest that GPs currently in practice in New Zealand are 
not engaging with this literature. Reassuringly, several of the participants did highlight good communication as a vital part of effective patient care (and had good examples of ways they achieved this), but emphasised it as more important than health literacy, not as part of it.

This perceived concept of health literacy being limited to patient education material may also partly explain the cynicism towards the effectiveness of health literacy and also the constraints outlined in the comments. Health literacy resources for GPs have been designed with time effectiveness and ease of use at the forefront, and very few require a high level of extra funding. GPs in New Zealand are operating under tight time-frames and with limited staffing resources, and do not appear to always view Government health policy initiatives in a positive light.

\section{Limitations of Study}

This research only gathered general survey data at one point in time and did not involve any more in-depth follow-up or changes over time. The length of the survey form itself probably resulted in a lower return rate, and some questions could have been better phrased to make them clearer to participants. Although it was considered at the time the survey was designed, it was decided not to list specific health literacy resources that have been created for clinicians, but in retrospect this would have returned very useful data. These research results need to be seen only as an initial investigation into the extent of knowledge primary healthcare practitioners in New Zealand possess in the topic area of health literacy, their attitudes towards the topic, and the extent that they implement any internationally developed health literacy tools.

This research is limited to gathering the views and health literacy practices of General Practitioners only, and does not include that of practice nurses or managers, administration staff, allied health staff, pharmacists or other staff involved in effective communication with patients. The views of the patients are also not being gathered.

\section{Conclusions and future research recommendations}

Primary healthcare practitioners in New Zealand are not particularly familiar with the concept of health literacy and do not tend to believe that health literacy efforts will be effective due to time, resource and health system constraints. Very few intentionally implement any internationally developed health literacy strategies (although many do without recognising them as such), and do not appear to have engaged with international health literacy efforts.

Any health literacy resources created or rolled out in New Zealand to support GPs in their communication will need to be presented in such a way that they are not perceived as an extra externally-driven chore. 
It would be useful to conduct a follow-up study to identify whether the trends observed in this study have changed in the two years since the survey was distributed. Further exploration into the use of specific health literacy strategies by New Zealand primary healthcare practitioners would also be interesting, especially the methods they use to communicate with at-risk population groups. It may be discovered that they are using more of the defined strategies than they realise.

\section{Links between study and librarianship}

Although this research is primarily about communication within primary healthcare, the central concepts of effective communication and teaching \& learning are cross-disciplinary. These are:

- Importance of creating appropriate written (print or electronic) information/teaching materials learners can relate to and understand.

- Ensuring the "whole-environment" is conducive to effective system navigation and learning.

- Adult teaching and learning theory/pedagogy/andragogy.

- Importance of chunking information/teaching materials to support effective learning.

- Scaffolding methods.

- Effective methods of ensuring learners have understood the concepts being taught.

This is in addition to gaining familiarity with the research process, and with this knowledge be better able to understand the challenges students are facing within an academic environment. 


\section{References}

Abel, T. (2008). Measuring health literacy: moving towards a health - promotion perspective. International Journal of Public Health, 53(4), 169-170.

Baker, M. G., Barnard, L. T., Kvalsvig, A., Verrall, A., Zhang, J., Keall, M., ... Howden-Chapman, P. (2012). Increasing incidence of serious infectious diseases and inequalities in New Zealand: a national epidemiological study. The Lancet, 379(9821), 1112-1119.

Baur, C. (2010). New directions in research on public health and health literacy. Journal of Health Communication, 15, 42-50. doi: 10.1080/10810730.2010.499989

Baur, C. (2011). Calling the nation to act: Implementing the national action plan to improve health literacy. Nursing Outlook, 59(2), 63-69.

Berkman, N. D., Sheridan, S. L., Donahue, K. E., Halpern, D. J., \& Crotty, K. (2011). Low health literacy and health outcomes: an updated systematic review. Annals of Internal Medicine, 155(2), 97-U89.

Breslow, L. (1985). Patient Education in Historical Perspective. Bulletin of the New York Academy of Medicine, 61(2), 115-122.

Brooking, K. (2009). Patient's health literacy and its relationship to the changes required to the New Zealand health system to better manage patients with long term conditions. (Masters), University of Waikato, Hamilton.

Cannon, R. (2008). The Social Determinants of Health: SACOSS Information Paper: South Australian Council of Social Service.

Coleman, C. A., Hudson, S., \& Maine, L. L. (2013). Health literacy practices and educational competencies for health professionals: a consensus study. Journal of Health Communication, 18, 82-102. doi: 10.1080/10810730.2013.829538

Conaty-Buck, S. B. (2009). Unblocking barriers: Clearing the channel to improve communication between practitioners and patients with low health literacy. (Dissertation/Thesis), University of Virginia.

DeWalt, D. A., Broucksou, K. A., Hawk, V., Brach, C., Hink, A., Rudd, R., \& Callahan, L. (2011). Developing and testing the health literacy universal precautions toolkit. Nursing Outlook, 59(2), 85-94.

DeWalt, D. A., Callahan, L. F., Hawk, V. H., Broucksou, K. A., Hink, A., Rudd, R., \& Brach, C. (2010). Health Literacy Universal Precautions Toolkit. Rockville, MD: Agency for Healthcare Research and Quality. 
Eagle, L., Hawkins, J., Styles, E., \& Reid, J. (2006). Breaking through the invisible barrier of low functional literacy: implications for health communication. Studies in Communication Sciences: Special Issue on Health Literacy, 5(2), 29-55.

Eckman, M. H., Wise, R., Leonard, A. C., Dixon, E., Burrows, C., Khan, F., \& Warm, E. (2012). Impact of health literacy on outcomes and effectiveness of an educational intervention in patients with chronic diseases. Patient education and counseling, 87(2), 143-151.

Eichler, K., Wieser, S., \& Brügger, U. (2009). The costs of limited health literacy: a systematic review. International Journal of Public Health, 54(5), 313-324. doi: 10.1007/s00038-009-0058-2

Frosch, D. L., May, S. G., Rendle, K. A. S., Tietbohl, C., \& Elwyn, G. (2012). Authoritarian Physicians And Patients' Fear Of Being Labeled 'Difficult' Among Key Obstacles To Shared Decision Making. Health Affairs, 31(5), 1030-1038. doi: 10.1377/hlthaff.2011.0576

Gann, R. (1991). Consumer health information: The growth of an information specialism. Journal of Documentation, 47(3), 284-308.

Gann, R. (1992). Consumer health information. Health libraries review, 9(1), 34-36.

Goodyear-Smith, F., \& Buetow, S. (2001). Power issues in the doctor-patient relationship. Health Care Analysis, 9(4), 449-462. doi: 10.1023/A:1013812802937

Gray, B., Hilder, J., \& Stubbe, M. (2012). How to use interpreters in general practice: the development of a New Zealand toolkit. Journal of Primary Health Care, 4(1), 52-61.

Green, L. W., \& Kreuter, M. W. (2005). Health program planning: an educational and ecological approach: McGraw-Hill New York.

Harris, J., \& Hutt, M. (1996). Providing Consumer Health Information: The second report of the focus group on consumer health information. Wellington: New Zealand Health Information Service.

Hasnain-Wynia, R., \& Wolf, M. S. (2010). Promoting health care equity: is health literacy a missing link? Health Services Research, 45(4), 897-903. doi: 10.1111/j.1475-6773.2010.01134.x

Health Navigator. (2011). Waipuna Statement 2011. from

http://www.healthnavigator.org.nz/centre-for-clinical-excellence/health-literacy/waipunastatement/

Hernandez, L. M. (2013). Health Literacy: Improving Health, Health Systems, and Health Policy Around the World - Workshop Summary. Washington, D.C.: Institute of Medicine of the National Academies.

Hogan Smith, K., \& Mayer, S. (2009). The "Big Three" Consumer Health Sites and Web Technology Trends: MedlinePlus ${ }^{\circledR}$, Healthfinder $^{\circledR}$, and CAPHIS. Journal of Consumer Health on the Internet, 13(3), 213-222. 
Jin, J., Sklar, G. E., Min Sen Oh, V., \& Chuen Li, S. (2008). Factors affecting therapeutic compliance: A review from the patientas perspective. Therapeutics and Clinical Risk Management, 4(1), 269-286.

Logan, R. A. (2007). Clinical, classroom, or personal education: attitudes about health literacy. Journal of the Medical Library Association, 95(2), 127.

Mårtensson, L., \& Hensing, G. (2012). Health literacy - a heterogeneous phenomenon: a literature review. Scandinavian Journal of Caring Sciences, 26(1), 151-160. doi: 10.1111/j.14716712.2011.00900.x

Mayer, G. G., \& Villaire, M. (2007). Health literacy in primary care: A clinician's guide: Springer Publishing Company.

Medical Council of New Zealand. (2010). New Zealand Medical Workforce in 2010 Wellington.

Medical Council of New Zealand. (2013). The New Zealand Medical Workforce in 2012 from https://www.mcnz.org.nz/news-and-publications/media-releases/the-new-zealand-medicalworkforce-in-2012/

Merrick, E., Duffield, C., Baldwin, R., Fry, M., \& Stasa, H. (2012). Expanding the role of practice nurses in Australia. Contemporary Nurse: A Journal for the Australian Nursing Profession, 41(1), 133140.

Ministry of Health. (2013). New Zealand Health System. from http://www.health.govt.nz/newzealand-health-system

Nielsen-Bohlman, L., Panzer, A. M., \& Kindig, D. A. (2004). Health literacy: a prescription to end confusion: National Academies Press.

Nutbeam, D. (2008). The evolving concept of health literacy. Social Science \& Medicine, 67(12), 20722078.

Nutbeam, D., \& Kickbusch, I. (2000). Advancing health literacy: a global challenge for the 21st century. Health Promotion International, 15(3), 183-184.

OECD. (2013). Skilled for life? Key findings from the survey of adult skills.

Oliver, G., \& Bidwell, P. (2001). Hospitals and consumer health information in New Zealand: the role of the library. Health Information \& Libraries Journal, 18(2), 83-90.

Onieal, M.-E. (2010). Health literacy, health care reform. Clinician Reviews, 20(4), 1, 17.

Ontario Medical Association. (2010). Patient-Centred Care: Policy Paper.

Osborne, H. (2012). Health Literacy from A to Z: Jones \& Bartlett Publishers.

Parker, R. M., \& Kindig, D. A. (2006). Beyond the Institute of Medicine Health Literacy Report: Are the Recommendations Being Taken Seriously? Journal of General Internal Medicine, 21(8), 891-892. 
Parker, R. M., Ratzan, S. C., \& Lurie, N. (2003). Health Literacy: A Policy Challenge For Advancing High-Quality Health Care. Health Affairs, 22(4), 147-153.

Phillips, C., Dwan, K., Pearce, C., Hall, S., Porritt, J., Yates, R., \& Sibbald, B. (2007). Time to talk, time to see: changing microeconomies of professional practice among nurses and doctors in Australian general practice. Contemporary Nurse: A Journal for the Australian Nursing Profession, 26(1), 136-144. doi: 10.5172/conu.2007.26.1.136

Pleasant, A., \& Kuruvilla, S. (2008). A tale of two health literacies: public health and clinical approaches to health literacy. Health Promotion International, 23(2), 152-159. doi: 10.1093/heapro/dan001

Priston, M., Searle, P., \& New Zealand Ministry of Health. (2010). Kōrero mārama: health literacy and Māori : results from the 2006 Adult Literacy and Life Skills Survey: Ministry of Health.

Public Health Association of BC. (2012). An Inter-sectoral Approach for Improving Health Literacy for Canadians. from http://www.phabc.org/userfiles/file/IntersectoralApproachforHealthLiteracy-FINAL.pdf

Rees, A. M., \& Young, B. A. (1981). Consumer health information source book. New York: R. R. Bowker.

Ridpath, J. R., Larson, E. B., \& Greene, S. M. (2012). Can integrating health literacy into the patientcentered medical home help us weather the perfect storm? JGIM: Journal of General Internal Medicine, 27(5), 588-594. doi: 10.1007/s11606-011-1964-6

Robertson, I. (2008). An Introduction to Activity Theory. University Class Lecture. Melbourne, Australia: RMIT University.

Roper, W. L. (1993). Health Communication Takes on New Dimensions at CDC. Public Health Reports, 108(2), 179-183.

Rudd, R. E., Rosenfeld, L., \& Simonds, V. W. (2012). Health literacy: a new area of research with links to communication. Atlantic Journal of Communication, 20(1), 16-30.

Ryall, T. (2008). Better, Sooner, More Convenient: Health Discussion Paper by Hon Tony Ryall MP. Wellington: National Party.

Salmond, C., Crampton, P., \& Atkinson, J. (2007). NZDep2006 Index of Deprivation. from http://www.otago.ac.nz/wellington/otago020348.pdf

Schillinger, D., Bindman, A., Wang, F., Stewart, A., \& Piette, J. (2004). Functional health literacy and the quality of physician-patient communication among diabetes patients. Patient education and counseling, 52(3), 315-323. 
Schnitzer, A. E., Rosenzweig, M., \& Harris, B. (2011). Health Literacy: A Survey of the Issues and Solutions. Journal of Consumer Health on the Internet, 15(2), 164-179. doi: $10.1080 / 15398285.2011 .573347$

Schoen, C., Osborn, R., Doty, M. M., Bishop, M., Peugh, J., \& Murukutla, N. (2007). Toward higherperformance health systems: adults' health care experiences in seven countries, 2007. Health Affairs, 26(6), w717-W734.

Shannon, C. E. (1948a). A Mathematical Theory of Communication. Bell System Technical Journal, 27(4), 623-656.

Shannon, C. E. (1948b). A Mathematical Theory of Communication. Bell System Technical Journal, $27(3), 379-423$.

Sherbino, J., Upadhye, S., \& Worster, A. (2009). Self-reported priorities and resources of academic emergency physicians for the maintenance of clinical competence: a pilot study. CJEM, 11(3), 230-234.

Sheridan, N. F., Kenealy, T. W., Connolly, M. J., Mahony, F., Barber, P. A., Boyd, M. A., . . Moffitt, A. (2011). Health equity in the New Zealand health care system: a national survey. International Journal for Equity in Health, 10,14p.

Shipman, J. P., Kurtz-Rossi, S., \& Funk, C. J. (2009). The health information literacy research project. Journal of the Medical Library Association : JMLA, 97(4), 293-301.

Shohet, L., \& Renaud, L. (2006). Critical analysis on best practices in health literacy. Canadian Journal of Public Health, 97, S10-13.

Simonds, S. K. (1974). Health Education As Social Policy. Health education monographs, 2, 1-10.

Smith, S., \& Duman, M. (2009). The state of consumer health information: an overview. Health information and libraries journal, 26(4), 260-278.

Sørensen, K., Van den Broucke, S., Fullam, J., Doyle, G., Pelikan, J., Slonska, Z., \& Brand, H. (2012). Health literacy and public health: A systematic review and integration of definitions and models. BMC Public Health, 12, 80. doi: http://dx.doi.org/10.1186/1471-2458-12-80

Statistics New Zealand. (2014). New Zealand: An Urban/Rural Profile. from http://www.stats.govt.nz/browse_for_stats/people_and_communities/Geographicareas/urban-rural-profile.aspx

Stewart, M. N. (2012). Practical patient literacy: The medagogy model: McGraw-Hill Medical.

The Joint Commission. (2007). "What did the Doctor say?": Improving health literacy to protect patient safety Health Care at the Crossroads. Illinois: The Joint Commissionhttp://www.jointcommission.org/assets/1/18/improving_health_literacy.pdf. 
Thorn, W. (2009). International Adult Literacy and Basic Skills Surveys in the OECD Region OECD Working Paper (Vol. No. 26): OECD.

Truog, R. D. (2012). Patients and doctors--evolution of a relationship. New England Journal of Medicine, 366(7), 581-585. doi: 10.1056/NEJMp1110848

UK Department of Health. (2009). The Information Standard: a Department of Health Certification Scheme for Health and Social Care Information in England. from http://www.theinformationstandard.org/

United States Department of Health \& Human Services. (2000). Healthy people 2010: Government Printing Office.

US Department of Health and Human Services, O. o. D. P. a. H. P. (2010). National Action Plan to Improve Health Literacy.

Vancheri, C. (2011). Innovations in Health Literacy: Workshop Summary: National Academies Press.

Vernon, J., Trujillo, A., Rosenbaum, S., \& DeBuono, B. (2009). Low Health Literacy: Implications for National Health Policy. 2007 University of Connecticut, Connecticut.

WAVE Advisory Board. (2001). From strategy to reality: The WAVE project. Wellington: Ministry of Health.

Wilson, H. (2008). Becoming patient centred: a review. New Zealand Family Physician, 35(3), 164170.

World Health Organization. (1998). Health promotion glossary. Geneva: World Health Organization. World Health Organization. (2005). The Bangkok Charter for Health Promotion in a Globalized World Geneva: WHO.

Younis, J., Salerno, G., Chaudhary, A., Trickett, J. P., Bearn, P. E., Scott, H. J., \& Galbraith, K. A. (2013). Reduction in Hospital Reattendance due to Improved Preoperative Patient Education Following Hemorrhoidectomy. Journal for healthcare quality, 35(6), 24-29.

Zarcadoolas, C., Pleasant, A., \& Greer, D. S. (2005). Understanding health literacy: an expanded model. Health Promotion International, 20(2), 195-203. doi: 10.1093/heapro/dah609 
Appendices

Appendix I: Survey Cover Letter

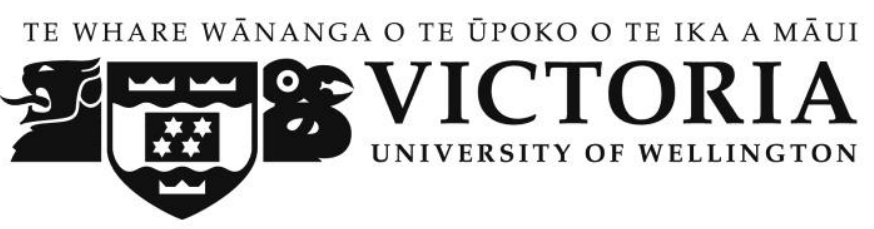

\section{Participant Information Sheet for a Study of Health Literacy Knowledge and Practice}

Researcher: Jane Thomsen: School of Information Management, Victoria University of Wellington

I am a Masters student in Information Management at Victoria University of Wellington. As part of this degree I am undertaking a research project leading to a thesis. The project I am undertaking is the knowledge of, attitudes towards, and implementation of internationally developed health literacy tools by General Practitioners in New Zealand. The University requires that ethics approval be obtained for research involving human participants, and this has been obtained from the School of Information Management Human Ethics Committee.

I am inviting a selection of GPs (selected randomly from a publicly available database) to participate in the study by filling out the attached questionnaire. It is envisaged that the questionnaire will take about a quarter of an hour to complete. The questionnaire may be filled out in paper and mailed back to me in the enclosed postage paid envelope, or alternatively be filled out online at http://bit.ly/Rk8gJq.

Responses collected will form the first of two phases of my research project and will be put into a written report on an anonymous basis. It will not be possible for you to be identified personally. Only grouped responses will be presented in this report. All material collected will be kept confidential. No other person besides me and my supervisor, Professor Rowena Cullen, will see the questionnaires. The thesis will be submitted for marking to the School of Information Management and deposited in the University Library. It is intended that one or more articles will be submitted for publication in scholarly journals, and papers presented at conferences. Questionnaires will be destroyed two years after the end of the project.

International research has demonstrated that low health literacy has a significant impact on health, and as a result many tools and resources have been created and made available to healthcare providers. This research hopes to identify how useful these resources are within a New Zealand 
context, and explore whether there is potential for the creation of resources that would better support the New Zealand primary care community. A summary of findings from this research will be submitted to the New Zealand Doctor newspaper, and participants may elect to email me at thomsejane@myvuw.ac.nz if they would like to request the full report.

You are under no obligation to participate in this research, but by submitting this questionnaire you will be understood to have given your consent.

If you have any questions or would like to receive further information about the project, please contact me at thomsejane@myvuw.ac.nz or my supervisor, Professor Rowena Cullen, Associate Dean (Research), Victoria Business School, Victoria University, PO Box 600, Wellington, phone 04 4636436, rowena.cullen@vuw.ac.nz.

Jane Thomsen

Signed:

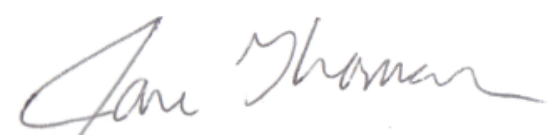


Appendix II: Survey

Thank you for agreeing to participate in this survey. The data you provide will enhance the understanding of the current state of health ilteracy In New Zealand.

Please complete all the questions marked with a star. All other questions are optional.

The questionnaire should take less than 15 minutes to complete. 
Demographic information

*1. In which geographic region is your practice located?

(] Nonthand

(C) Auckiand

(C) Wakaio

(3) Bay of Pienty

(] cisborne

() Hawker's Bay

(] Taranak

(C) Manawatu-Wanganui

C Wellingion

(] Ta6man

Nesan

Marbarough

$\bigcirc$ west casst

$\bigcirc$ cantertury

○otago

$\bigcirc$ southiand

*2. Please select whether you consider your practice to be predominantly urban or rural?

$\bigcirc$ urban

Rü 
*3. Socioeconomic position is regarded as a major determinant of health. Factors such as income, employment status, housing and education can have both direct and indirect impacts on health and have cumulative effects over lifetime. In New Zealand socioeconomic position is measured using the deprivation index.

Which score would best describe the community in which you practice? (You can find more information about the NZ deprivation index at www.health.govt.nz/publication/nzdep2006-index-deprivation)

O1 \{Leastdeprived\}

$\mathrm{O}^{2}$

$\mathrm{O}^{3}$

$\mathrm{O}^{4}$

$\mathrm{O}^{5}$

$\mathrm{O}^{6}$

$\mathrm{O}_{7}$

$\mathrm{O}^{8}$

$\mathrm{O}^{8}$

O 10 Mast deprived)

*4. Is your practice part of a PHO?

$\bigcirc$ res

$\bigcirc^{\mathrm{No}}$

5. If yes, which one?

6. If you are a member of a PHO, is there a directive for health literacy or better health communication with patients?

Ores

ON

Dant know

Comment

*7. What is your gender?

O Ma:e

Framse 

*8. Please indicate which age group you belong to
Y Younger than 30
( 30.38
(
$\mathrm{O}^{50-58}$
Oover 60

*9. How many years have your been in your current type of practice?

$\mathrm{O}^{05}$

$\mathrm{O}^{5-10}$

$\mathrm{O}^{11-15}$

(16-20

Mom than 20

* 10. How many patient visits do you have on an average day? |

*11. What is the average number of minutes you spend with a patient on an average day?

O 10 minutes

O 15 minutes

C 20 minutes

Other $\{p$ ease specty $y$ 
Communicating health information in your practice

This section will explore any methods or tools you may find useful when communicafing informafon to your patients

12. How important do you consider the following strategies to be when communicating information to patients who may have difficulty understanding their health status and treatment plans?

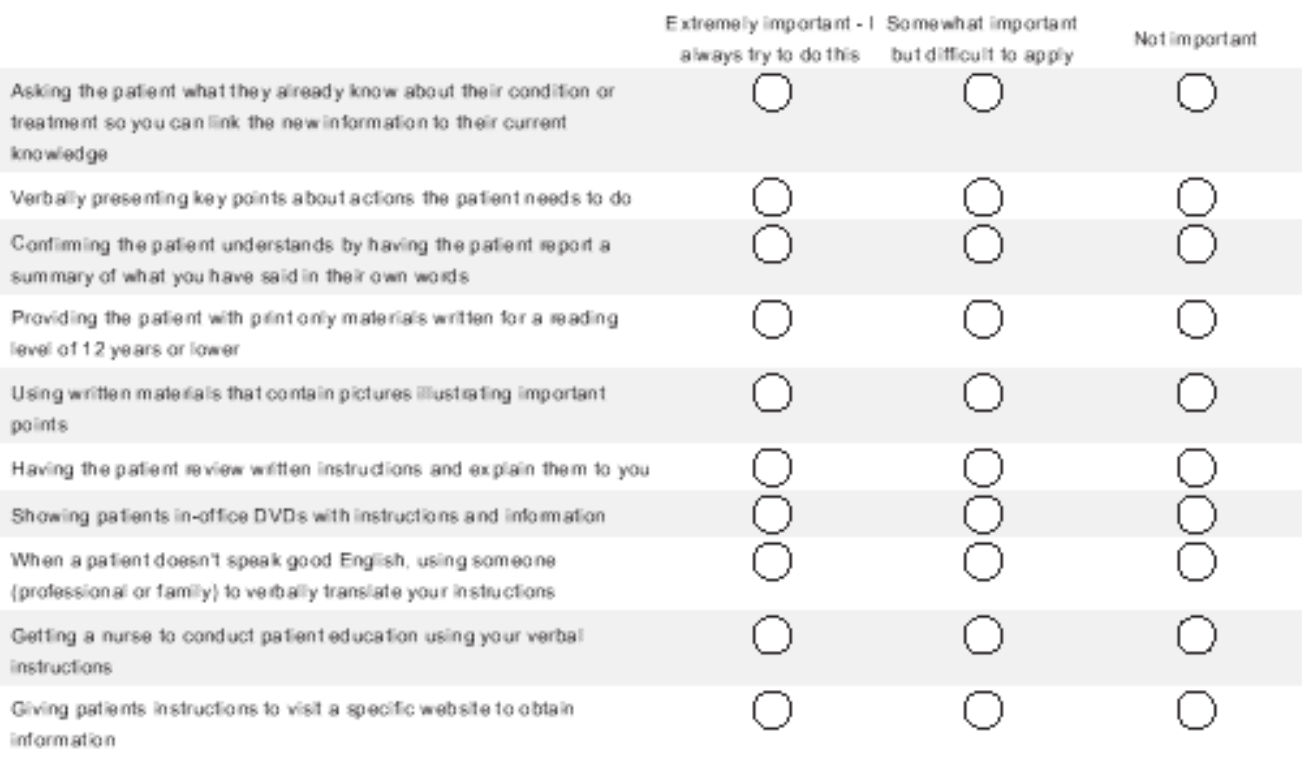

\section{Can you suggest any other strategies?}

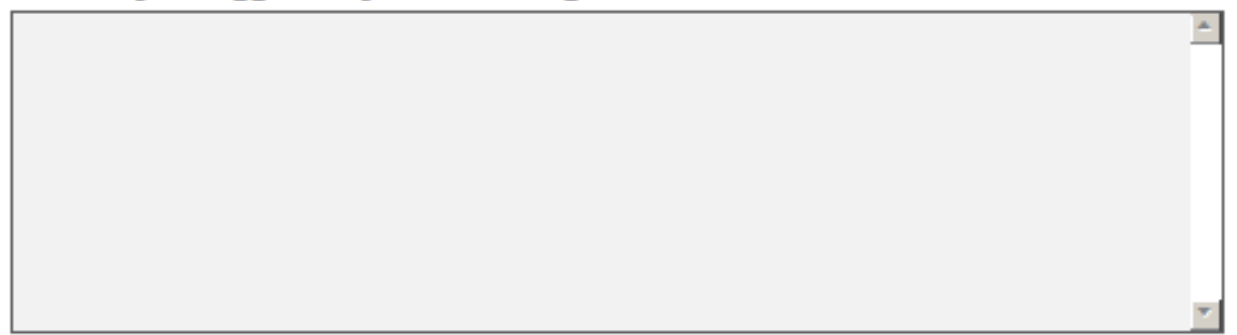

14. How do you evaluate or test whether your patients struggle with literacy or have other barriers to understanding health information?

$\square$ Idortevaruate patents for this

I evaluate patients based on persona knowiedge of their background, appearance, skely education levef et

I use a farmal adut heath 5 feracy lest \{please specify which onels belowi 


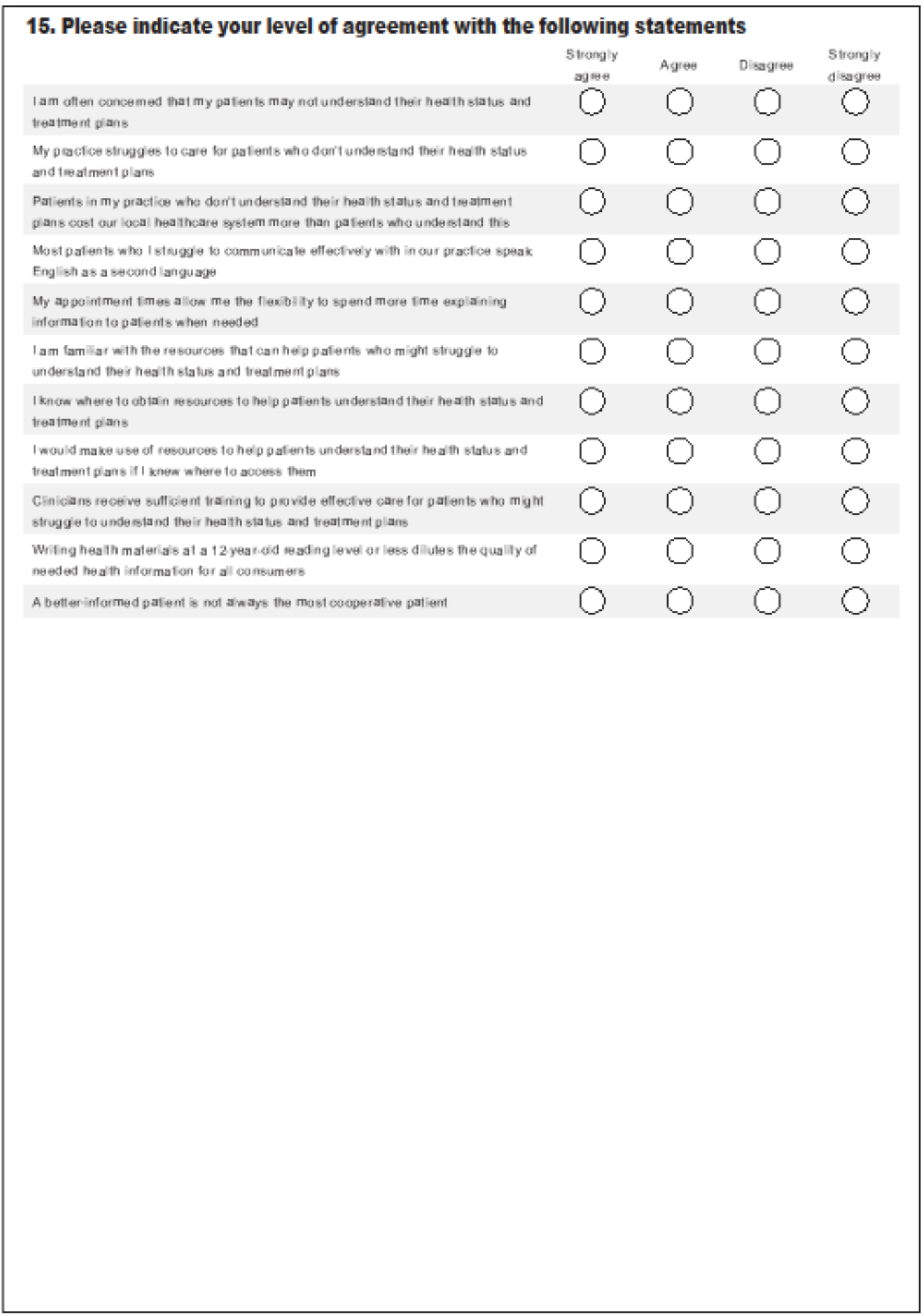

Page 6 


\section{Health Literacy}

The questions in the previous section deal with the canceptof heath lifacy. There are many detintions of heath lefacy, the most recent cambining cetica elements of earier definitions

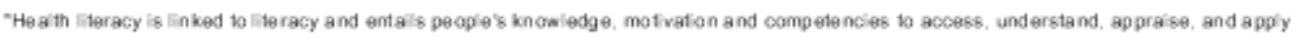
hea th information in order to make judgements and take decisions in everyday lle concerning hea thcas disease prewention and heath promotion to maintain or improve qualty of 150 dueng the life course " $\mid 50$ rensen, 2012\}|

Fonuting patents understand (and from the patenf 8 perspective, ensuring they understand what you have bid them) is an important efement

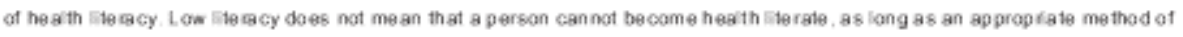
cammunication is used. Research has suggested that even highiy educaled peopes can arso strugge with heath steracy in times of stress cil Tne66, solevel of education is a component, but not the only reason that patents may not understand

Many tods and resources have been developed internationaly (especially in the US) 10 support heath professiona's in effectively cammunicating with patents, and this section examines whe ther the 5 resources are ulised or even relevant in the Ner Zearand pimary care cantext

16. Are you familiar with any resources that have been specifically created to address health literacy?

0 No

( Yes

"I "Yes" prease specty

17. Do you use any of these tools or resources in your practice? (Please describe)

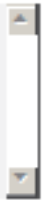

18. Please describe how useful you find these tools in helping patients understand their health status and treatment plans 


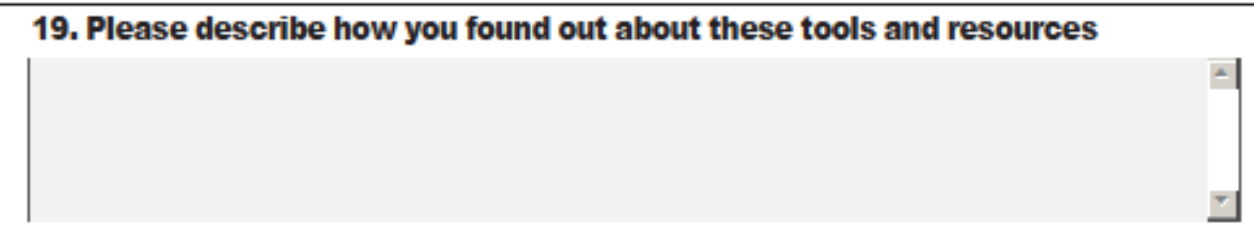

20. Please indicate whether you agree or disagree with the following statements

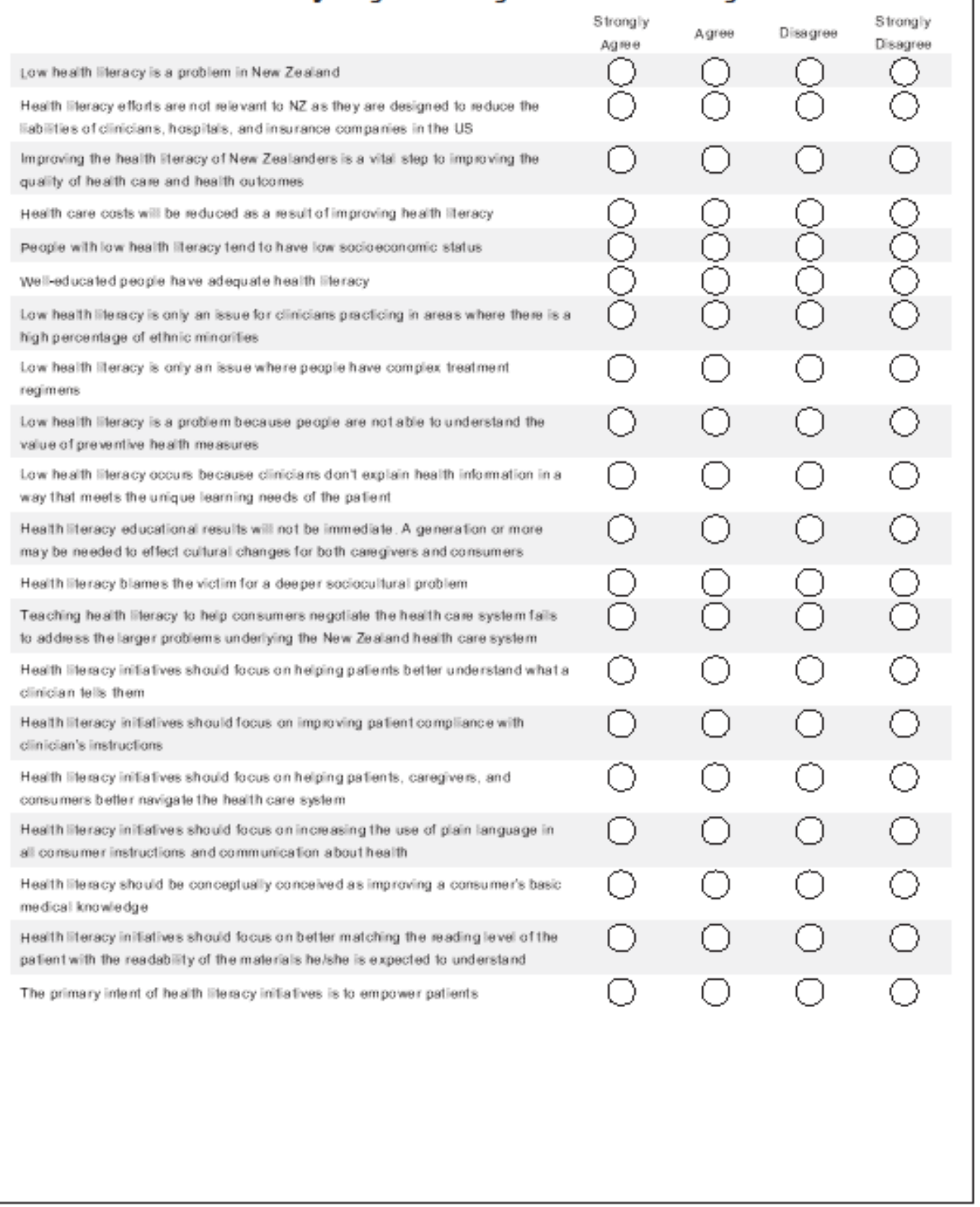




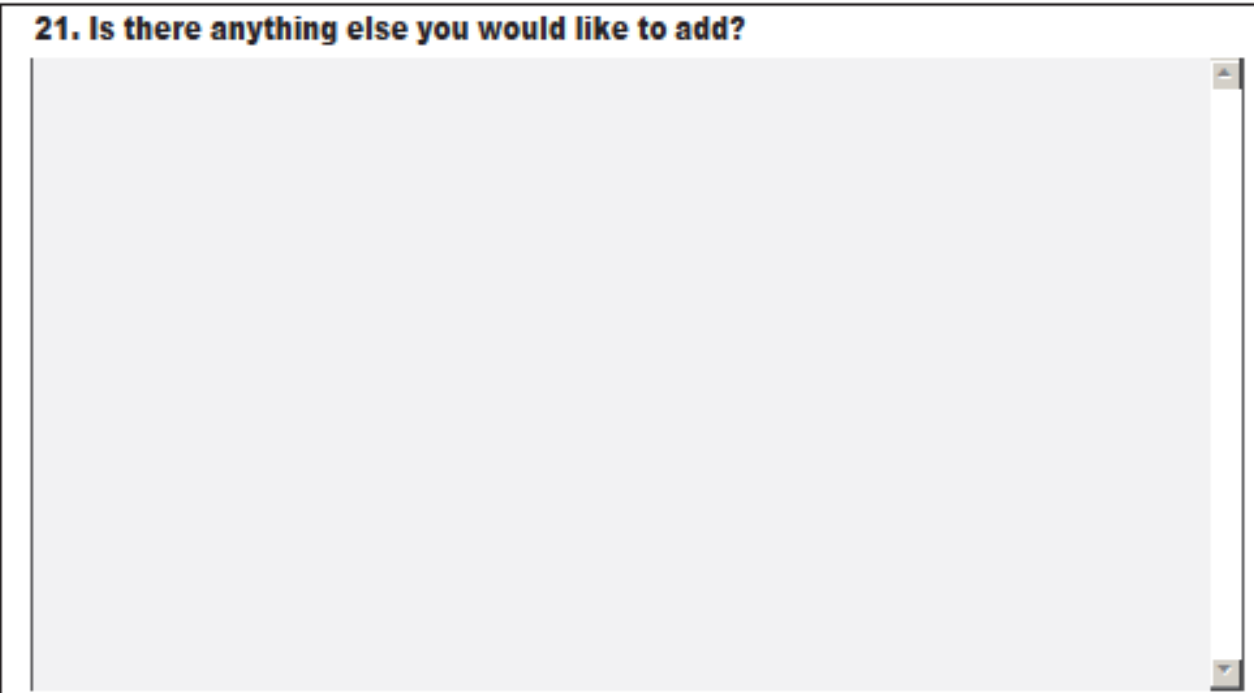

Thank you wery much for participating in this survey. The informaton you have shared will provide valuable data for this study

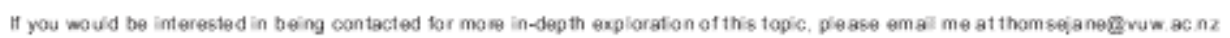

